\title{
UHPC INFILLED CIRCULAR STEEL TUBE COLUMN DESIGN
}

\author{
by \\ Youssef Hilal \\ B.Eng, Ryerson University, Toronto, Canada 2017
}

\author{
An MRP \\ presented to Ryerson University \\ in partial fulfilment of the \\ requirements for the degree of \\ Master of Engineering \\ in the program of \\ Civil Engineering
}

Toronto, Ontario, Canada, 2019

(C) Youssef Hilal, 2019 


\section{Author's Declaration}

I hereby declare that I am the sole author of this Major Research Project (MRP). This is a true copy of the MRP, including any required final revisions.

I authorize Ryerson University to lend this MRP to other institutions or individuals for the purpose of scholarly research.

I further authorize Ryerson University to reproduce this MRP by photocopying or by other means, in total or in part, at the request of other institutes or individuals for the purpose of scholarly research.

I understand that my MRP will be made electronically available to the public. 


\title{
Abstract \\ UHPC INFILLED CIRCULAR STEEL TUBE COLUMN DESIGN
}

\author{
by \\ Youssef Hilal \\ Master of Engineering \\ Civil Engineering \\ Ryerson University, Toronto, Canada 2019
}

Previous researchers studied the behavior of Ultra-High Performance Concrete (UHPC) columns confined with steel tubes. However, predicting the influence of the confinement effect and the compressive capacity of these columns has yet to be further examined. Currently, the Canadian design code limits for reinforced concrete do not reach the strength nor the strain produced by using UHPC. This project uses the Canadian design methods for a cross-section of UHPC to form a column interaction curve and compared it with six test specimens. The effects of steel tube confinement will also be examined. Additionally, the Eurocode 4 (EC4) method, which includes the strengths of UHPC and confinement of steel tube, was used to formulate another column interaction curve. The results show that the Canadian code severely underestimates the design strength of confined UHPC while the EC4 provides much more accurate results. 


\section{Acknowledgments}

First and foremost, I would like to thank Dr. Hesham Marzouk for guiding me through every step of this project and always offering his guidance and knowledge.

I would also like to thank Dr. Hesham Othman for helping me with both the analytical analysis and the experimental work. His experience and assistance offered a great deal of support throughout the project and it could not have been completed without him.

A special thank you to Nidal Jaalouk, Khaleel Stoney, and the lab research assistants. Their assistance in the structural lab was greatly appreciated and essential to the experimental component of this project.

I would like to thank my colleagues, Navneet Singh and Jamil Madanat. Their help with constructing, casting, and testing the specimens was highly valued.

Lastly, I would like to thank Ryerson University for giving me the opportunity to further add to my academic portfolio. 


\section{Dedication}

I would like to dedicate this project to my family and friends. Their patience, love, and support showed no boundaries in helping me achieve this academic milestone. 


\section{Table of Contents}

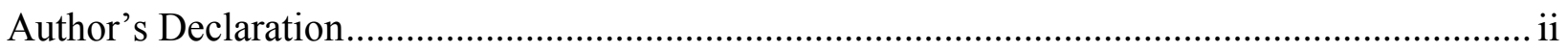

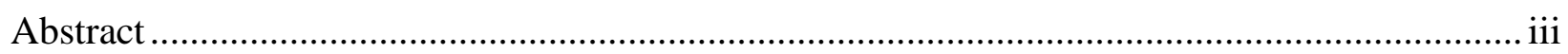

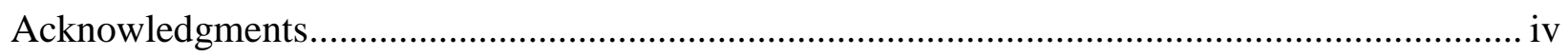

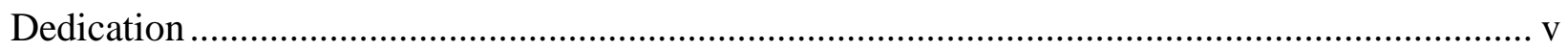

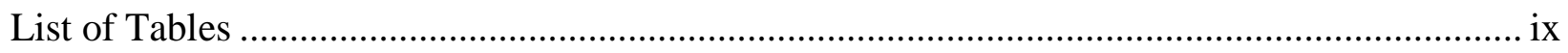

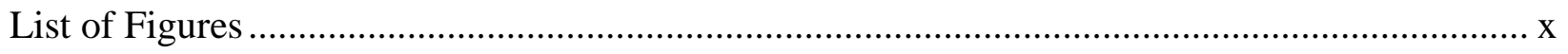

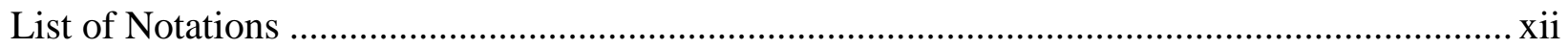

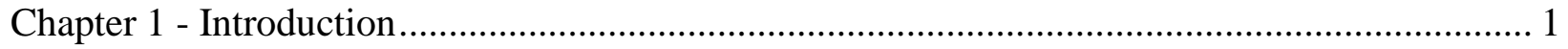

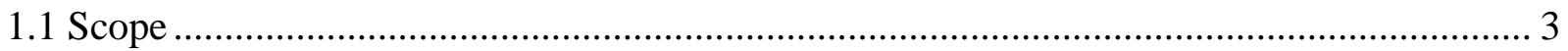

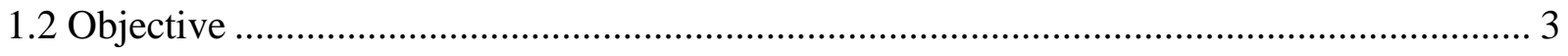

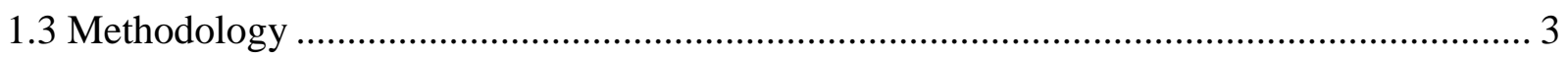

Chapter 2 - Literature Review....................................................................................... 5

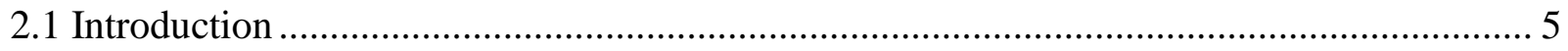

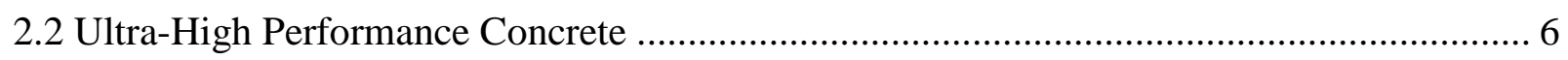

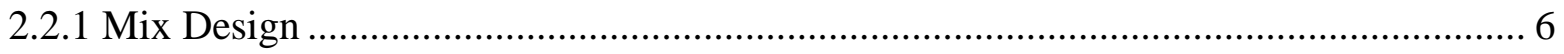

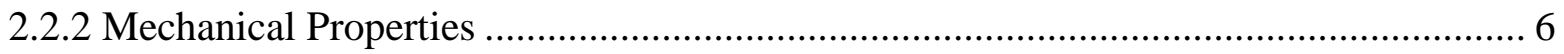

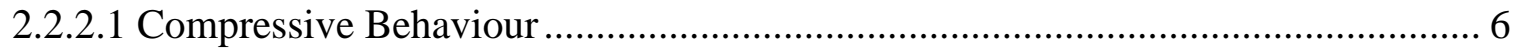

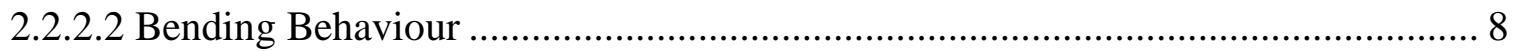

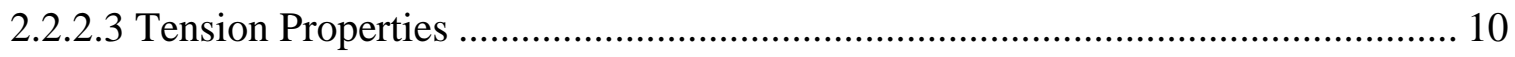

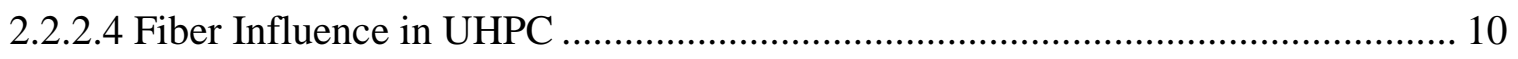

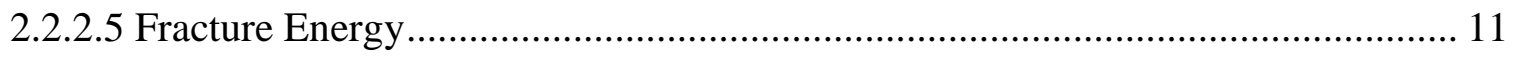

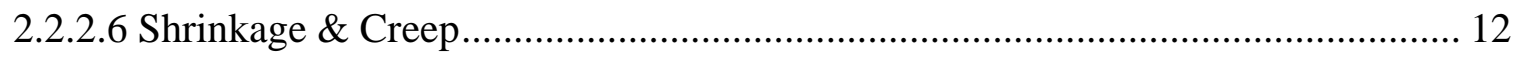

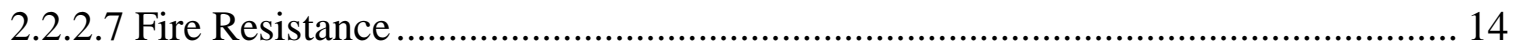

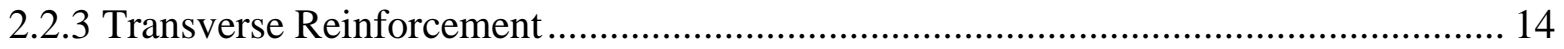




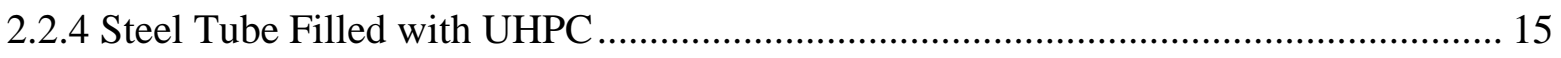

2.2.4.1 Confinement Effect of Steel Tube ...................................................................... 19

2.3 Design of UHPC Composite Columns............................................................................ 20

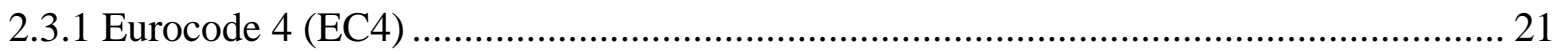

2.3.2 Canadian Design Code (CSA A23.3-14) .................................................................... 21

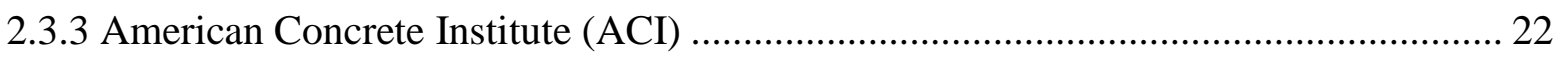

2.4 Application and Benefits of using UHPC Confined with Steel Tubes .............................. 22

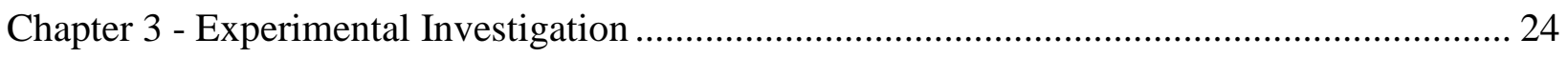

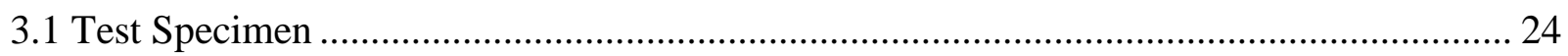

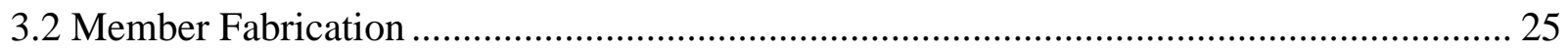

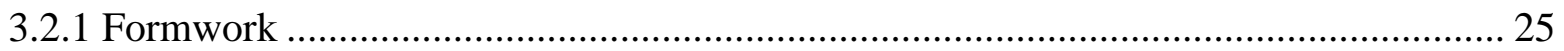

3.2.2 Reinforcement Set-up ........................................................................................ 26

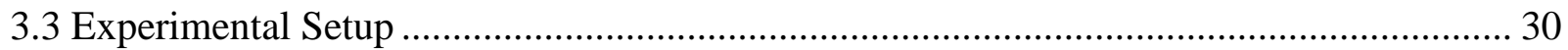

3.3.1 Compressive Machine ............................................................................................... 30

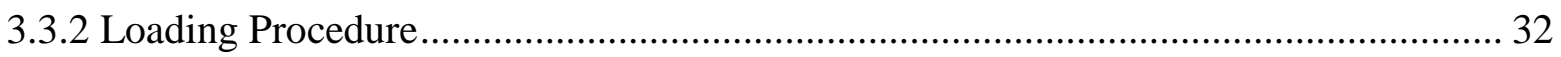

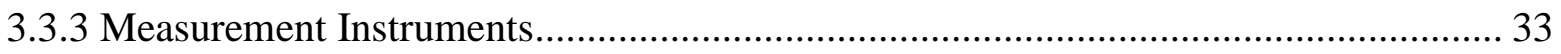

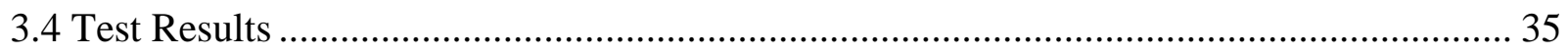

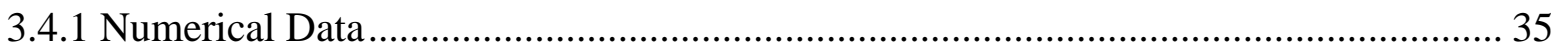

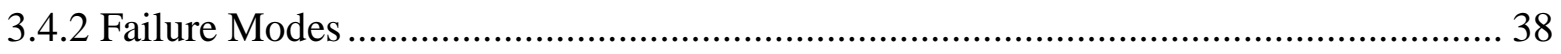

Chapter 4 - Analytical Analysis - Column Interaction Curve ....................................................... 39

4.1 Canadian Code Design ................................................................................................ 39

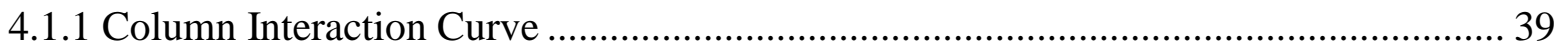

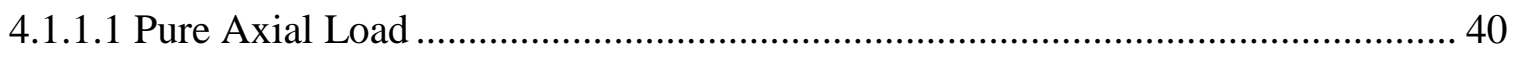

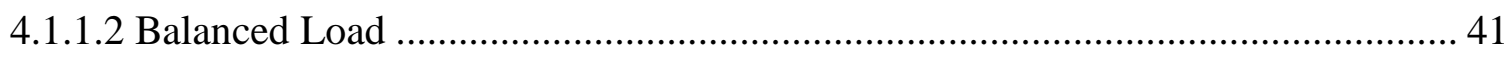

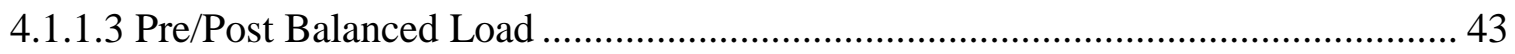




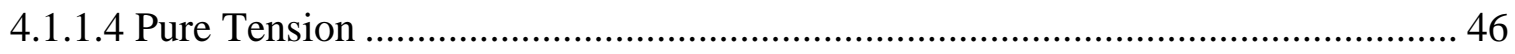

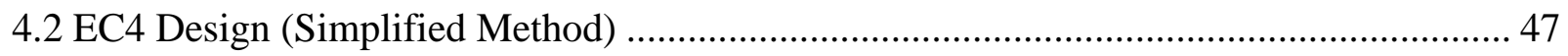

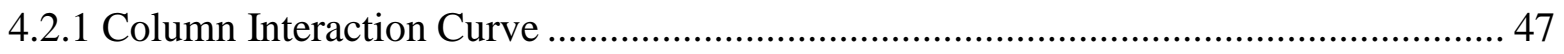

4.2.1.1 Pure Axial Load (Point A) ................................................................................... 48

4.2.1.2 Pure Bending (Point B) ................................................................................... 49

4.2.1.3 Prior to Steel Yield (Point C) .............................................................................. 50

4.2.1.4 Balanced Load (Point D) ............................................................................ 50

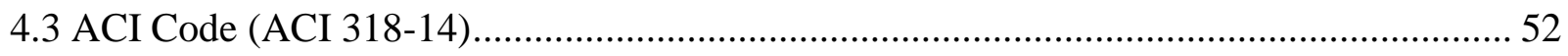

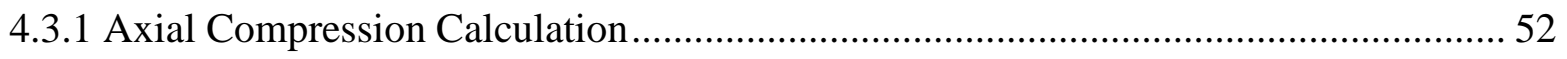

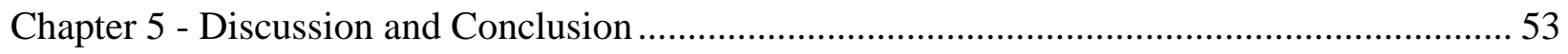

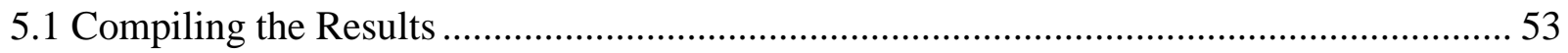

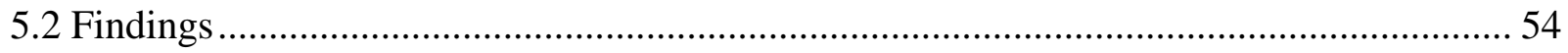

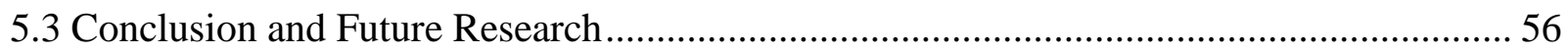

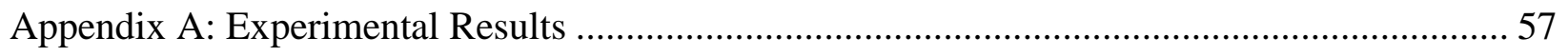

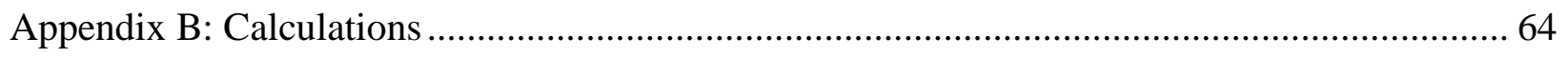

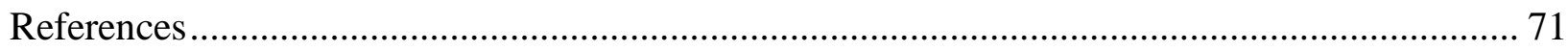




\section{List of Tables}

Table 2-1: Concrete Encased Sections - Advantages and Disadvantages (2)............................ 18

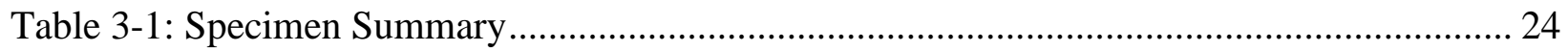

Table 3-2: HSC and UHPC Mix Design Proportions ......................................................... 29

Table 3-3: Load and Displacement Data from Experimental Results ................................... 36

Table 4-1: Canadian Design Code Data Points to be Plotted for Interaction Curve.................... 46

Table 4-2: EC4 Code Method Data to Plot Column Interaction Diagram.................................. 51

Table 5-1: Pure Axial Capacity Comparison for All Specimen Tested .................................... 53 


\section{List of Figures}

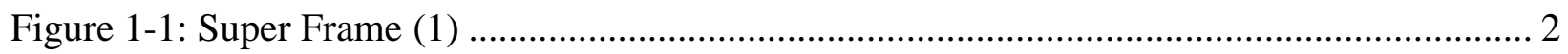

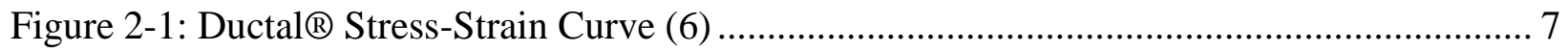

Figure 2-2: Stress-Strain Curve for UHPC with Various Fiber Percentage (7)......................... 8

Figure 2-3: Ductal ${ }^{\circledR}$ Bending Strength vs. Micron Displacement (6) ..................................... 9

Figure 2-4: Load-Strain Curve for Fiber Reinforced UHPC (8) ............................................. 9

Figure 2-5: Shrinkage Strain of NSC, HSC, and UHPC (18) ............................................... 13

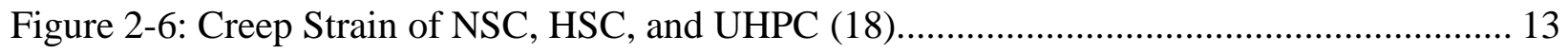

Figure 2-7: CFST Comparison with Varying Concrete and Steel Strengths (23) .................... 16

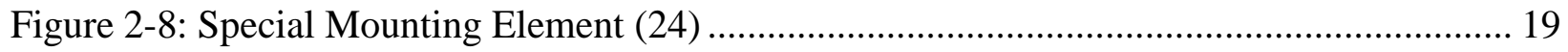

Figure 2-9: Uniform Lateral Pressure in Circular Columns (26)........................................... 20

Figure 3-1: Unconfined (Left) and Confined (Right) Column Formwork .............................. 25

Figure 3-2: Bending the 6-M Rebar for Transverse Reinforcement ......................................... 26

Figure 3-3: Completed Shaped Transverse Reinforcement ..................................................... 26

Figure 3-4: Final Steel Cage Reinforcement for 600 mm (left) and 1000 mm (right) Specimen. 27

Figure 3-5: Close-up of Transverse Reinforcement Connection to Longitudinal Rebar............. 27

Figure 3-6: Cross-Section of Confined (left) and Unconfined (right) Column Sections............. 28

Figure 3-7: HSC (left) and UHPC (right) Samples Cut and Polished ..................................... 29

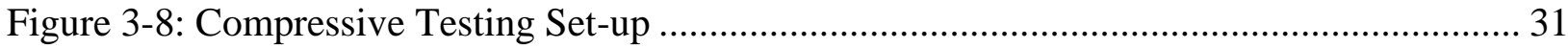

Figure 3-9: Compressive Testing Set-up with Plexiglass Protection...................................... 31

Figure 3-10: Top Portion of Loading Specimen with the Rubber Layer (top) .......................... 32

Figure 3-11: Position Transducer Placement During Compressive Testing ............................. 34

Figure 3-12: Test Set-up Recording the Readings Taken During Testing ............................... 35

Figure 3-13: Load vs. Time for 1000 mm HSC and UHPC Confined Specimen...................... 37

Figure 3-14: Load vs. Time for 600 mm HSC and UHPC Confined Specimen......................... 37

Figure 3-15: Deformation Shapes of All Six Specimen After Testing ................................... 38

Figure 4-1: Column Interaction Diagram for UHPC Confined Cross-Section Using the Canadian

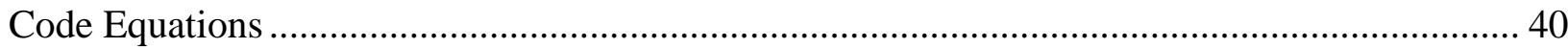

Figure 4-2: Neutral Axis and Compression Depth of Cross-Section Under Balanced Conditions

Figure 4-3:Neutral Axis and Compression Depth of Cross-Section Prior to the Steel Yielding.. 44 
Figure 4-4:Neutral Axis and Compression Depth of Cross-Section Post Steel Yielding ............ 45

Figure 4-5: UHPC Confined Column Interaction Curve Using EC4 Simplified Method ........... 47

Figure 4-6: Four Points Used to Form Column Interaction Diagram - EC4 (2) ....................... 48

Figure 5-1: UHPC Interaction Curve - Canadian Code, EC4, and Experimental Data ............... 53

Figure 5-2: Stress-Strain Curve for Differing Concrete Strengths (22) .................................. 55 


\section{List of Notations}

$\emptyset_{c} \quad$ Resistance factor for concrete

$\emptyset_{s} \quad$ Resistance factor for steel

$\alpha_{1} \quad$ Mathematical parameter of equal compression for stress distribution

$\beta_{1} \quad$ Mathematical parameter of equal compression for stress distribution

$\varepsilon_{\text {cmax }} \quad$ Maximum compression strain in concrete

$\varepsilon_{s 1} \quad$ Steel strain in reinforcement area $A_{s 1}$

$\varepsilon_{s 2} \quad$ Steel strain in reinforcement area $A_{s 2}$

$\varepsilon_{y} \quad$ Yield strain

$\eta \quad$ Reduction factor for concrete strength higher than $90 \mathrm{MPa}$

$\eta_{a o} \quad$ Factor for influence of slenderness and load eccentricity for steel tube

$\eta_{c o} \quad$ Factor for influence of slenderness and load eccentricity for concrete

$A_{a} \quad$ Cross-sectional area of steel tube confinement

$A_{a 1} \quad$ Cross-sectional area of steel tube confinement of area $A_{s 1}$

$A_{a 2} \quad$ Cross-sectional area of steel tube confinement of area $A_{s 2}$

$A_{g} \quad$ Gross area of column cross-section

$A_{s} \quad$ Cross-sectional area of longitudinal reinforcement

$A_{s 1} \quad$ Cross-sectional area of longitudinal reinforcement at a distance $d_{1}$ from the compression face of the column

$A_{s 2} \quad$ Cross-sectional area of longitudinal reinforcement at a distance $d_{2}$ from the compression face of the column

$A_{\text {st }} \quad$ Total area of longitudinal reinforcement

$a \quad$ Depth of the equivalent rectangular stress block 


\begin{tabular}{|c|c|}
\hline$C_{c}$ & Compression stress resultant by concrete \\
\hline$C_{r}$ & Compression stress resultant \\
\hline$C_{\text {sbar }}$ & Compression stress resultant by longitudinal reinforcement \\
\hline$C_{\text {stube }}$ & Compression stress resultant by steel tube confinement \\
\hline$c$ & $\begin{array}{l}\text { Neutral axis depth (distance from extreme compression fiber to the neutral } \\
\text { axis) }\end{array}$ \\
\hline$c_{b}$ & Neutral axis depth based on strain distribution \\
\hline$c_{g}$ & Center of gravity \\
\hline Cover & Clear cover for reinforcement rebar \\
\hline$D_{s}$ & Diameter of equivalent longitudinal reinforcement tube (EC4 notation) \\
\hline$d$ & Cross-section depth \\
\hline$d_{1}$ & Depth to top layer of reinforcement \\
\hline$d_{2}$ & Depth to bottom layer of reinforcement \\
\hline$d_{b}$ & Longitudinal reinforcement bar diameter \\
\hline$d_{t i e}$ & Diameter of tie bars \\
\hline$e$ & Eccentricity \\
\hline$e_{b}$ & Balanced eccentricity \\
\hline$F_{r s}$ & Tension force resultant in the reinforcement and confinement \\
\hline$F_{r s 1}$ & Tension force resultant in the reinforcement and confinement of area $A_{s 1}$ \\
\hline$F_{r s 2}$ & Tension force resultant in the reinforcement and confinement of area $A_{s 2}$ \\
\hline$f_{c}^{\prime}$ & Specified compressive strength for concrete \\
\hline$f_{c d}$ & Design strength of concrete section (EC4 notation) \\
\hline$f_{c d}$ & Design strength of concrete section (EC4 notation) \\
\hline
\end{tabular}




\begin{tabular}{|c|c|}
\hline$f_{s 1}$ & Magnitude of stress in reinforcement area $A_{s 1}$ \\
\hline$f_{s 2}$ & Magnitude of stress in reinforcement area $A_{s 2}$ \\
\hline$f_{s d}$ & Design strength of reinforcement section (EC4 notation) \\
\hline$f_{y}$ & Yield strength for steel \\
\hline$f_{y d}$ & Design strength of steel tube section (EC4 notation) \\
\hline$h_{n}$ & Height of the neutral axis (EC4 notation) \\
\hline$M_{\max , R d}$ & $\begin{array}{l}\text { Design resistance to pure bending of a CFST column at balance } \\
\text { point/maximum bending resistance (EC4 notation) }\end{array}$ \\
\hline$M_{p l, R d}$ & Design resistance to pure bending of a CFST column (EC4 notation) \\
\hline$M_{r}$ & Factored moment resistance \\
\hline$M_{r b}$ & Moment resistance in balanced conditions \\
\hline$N_{D R}$ & $\begin{array}{l}\text { Design resistance to compression of a CFST column at balance load (EC4 } \\
\text { notation) }\end{array}$ \\
\hline$N_{p l, R d}$ & Design resistance to compression of a CFST column (EC4 notation) \\
\hline$N_{p m, R d}$ & $\begin{array}{l}\text { Design resistance to compression of a CFST column prior to steel yielding } \\
\text { (EC4 notation) }\end{array}$ \\
\hline$P_{r b}$ & Axial force in balanced conditions \\
\hline$P_{\text {rmax }}$ & Maximum axial load resistance \\
\hline$P_{\text {ro }}$ & Factored axial load resistance \\
\hline$T_{s 1 b a r}$ & Tension stress resultant by longitudinal reinforcement of area $A_{s 1}$ \\
\hline$T_{\text {s1tube }}$ & Tension stress resultant by steel tube confinement of area $A_{s 1}$ \\
\hline$T_{\text {s2bar }}$ & Tension stress resultant by longitudinal reinforcement of area $A_{s 2}$ \\
\hline$T_{\text {s2tube }}$ & Tension stress resultant by steel tube confinement of area $A_{s 2}$ \\
\hline$T_{s b a}$ & Tension stress resultant by longitudinal reinforcement \\
\hline
\end{tabular}




\begin{tabular}{|c|c|}
\hline$T_{\text {stube }}$ & Tension stress resultant by steel tube confinement \\
\hline$t_{s}$ & Thickness of equivalent longitudinal reinforcement tube (EC4 notation) \\
\hline$t_{\text {tube }}$ & Thickness of steel tube section \\
\hline$W_{p a, n}$ & $\begin{array}{l}\text { Plastic section modulus of structural steel section relative to neutral axis } \\
\text { (EC4 notation) }\end{array}$ \\
\hline$W_{p a}$ & Plastic section modulus of structural steel section (EC4 notation) \\
\hline$W_{p c, n}$ & $\begin{array}{l}\text { Plastic section modulus of concrete section relative to neutral axis (EC4 } \\
\text { notation) }\end{array}$ \\
\hline$W_{p c}$ & Plastic section modulus of concrete section (EC4 notation) \\
\hline$W_{p s, n}$ & $\begin{array}{l}\text { Plastic section modulus of reinforcement section relative to neutral axis } \\
\text { (EC4 notation) }\end{array}$ \\
\hline$W_{p s}$ & Plastic section modulus of reinforcement section (EC4 notation) \\
\hline ACI & American Concrete Institute \\
\hline CFST & Concrete Filled Steel Tube \\
\hline CSA & Canadian Standards Association \\
\hline EC4 & Eurocode 4 \\
\hline HPC & High Performance Concrete \\
\hline HSC & High Strength Concrete \\
\hline $\mathrm{NSC}$ & Normal Strength Concrete \\
\hline UHPC & Ultra-High Performance Concrete \\
\hline
\end{tabular}




\section{Chapter 1 - Introduction}

Concrete is one of the most frequently used building materials in the word. It can take many shapes through various formwork, it is strong in compression, and can be combined with steel to improve tensile resistance. These are characteristics that make it a very versatile material. In the past century, concrete research has taken many leaps forward. One of the more recent improvements on this age-old material is Ultra-High Performance Concrete (UHPC). Prior to UHPC, the strongest concrete used in the field was High Strength Concrete (HSC) reaching an average compressive strength of $90 \mathrm{MPa}$. On the other hand, UHPC can reach compressive strengths of at least $150 \mathrm{MPa}$, making it twice as strong as the average HSC. This could revolutionise the construction industry due to the economic benefits and new engineering applications of UHPC.

The main economic advantage of using ultra-high strength materials such as UHPC is creating efficient designs. Liew et al. (1) present a paper regarding the applications and benefits of Concrete Filled Steel Tube (CFST) columns in high rise buildings. The end goal for using CFST with UHPC is to form a 'super frame' shown in Figure 1-1. The 'super frame' is similar to a typical out-rigger and belt truss system but have mega columns on the outside which are composed of CFST (1). By using UHPC, the spacing between each horizontal stiffness system can be increased and therefore reducing how many of them are used in a high rise building. UHPC can reduce a column's size while maintaining the load capacity, creating large work spaces that are valuable to commercial buildings (1). Using the 'super frame' and ultra-high strength materials uses a smaller amount of structural supports, providing a more efficient and therefore more economical design for future buildings. 


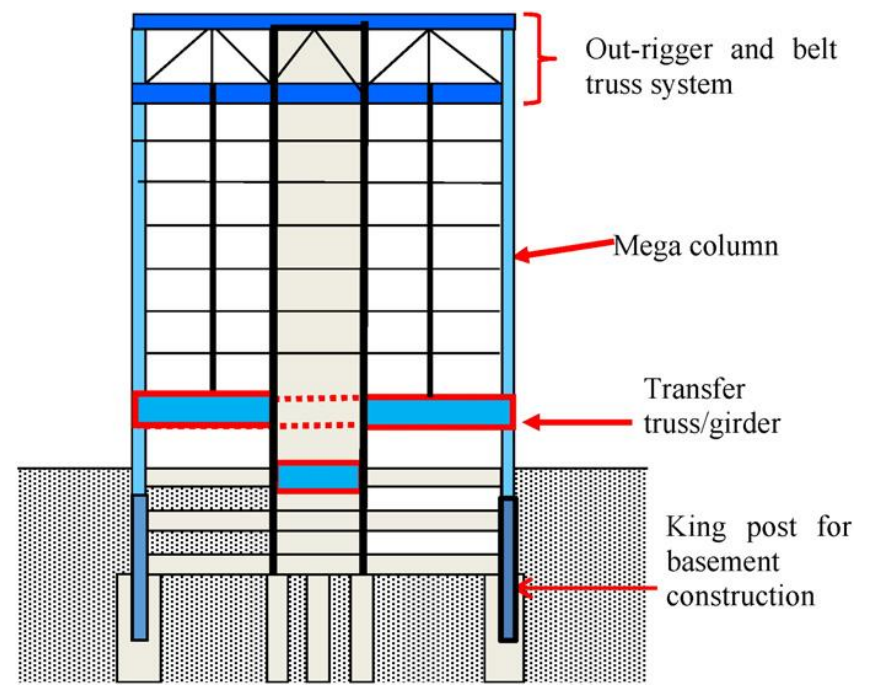

Figure 1-1: Super Frame (1)

While it has many benefits, the long term behaviours and design methods for UHPC still require more research to accurately estimate the capacity of strengths as high as $150 \mathrm{MPa}$. Due to its brittle nature, UHPC tends to perform best when confined with a tube steel section. This confinement effect is another area that needs to be investigated for accurate design predictions. Currently, the Eurocode 4 (EC4) (2) is the most established design code for predicting the strength of UHPC which includes the confinement effect. Both the American Concrete Institute (ACI 31814) (3) and the Canadian Design Code (CSA A23.3-14) (4) have equations for designing reinforced concrete; neither of which produce accurate results but rather underestimate the capacity of an UHPC columns specifically with steel tube confined section.

This project report is focused on determining the capacity and a column interaction curve for a circular UHPC with steel confined circular column using the available codes, while comparing the predicted capacity to the experimentally obtained one. The same specimens have been duplicated with high strength concrete (HSC) as a reference to the UHPC columns. The axial 
strength for each section is predicted using the CSA A23.3-14, ACI 318-14, and EC4 standards to see which code is the most accurate with the lab results.

\subsection{Scope}

The scope of this research is:

> To develop a column interaction curve for a steel confined UHPC circular column using Canadian and EC4 design methods.

\subsection{Objective}

The objective of the study is:

$>$ Compare how UHPC behaves with and without confinement

$>$ Use CSA A23.3-14, ACI 318-14, and EC4 design methods and compare the results with the axial capacity from experimental data

> Develop a column interaction curve using both the Canadian code and the EC4 design methods and comparing it with experimental data

\subsection{Methodology}

To achieve the objectives listed above, a detailed literature review was conducted followed by analytical numerical calculations using the various code methods. A carefully executed experiment of the specimen provided the necessary data to validate the analytical results.

The following is a summary of each of the chapters in this report:

Chapter 1 introduces the topic and reasons for the research, the scope of the work, and the objective to be obtained in the end.

Chapter 2 includes a comprehensive literature review of UHPC confined columns and similar studies. The research is compiled under different subheadings according to their relevancies. Past 
research on UHPC, confinement effects, use of fibers, use of steel confinement, code design methods, and application of UHPC are discussed.

Chapter 3 discusses the experimental setup, procedures, and methods, as well as the results. This will include discussion on the different specimens tested and the results obtained from each test. Chapter 4 contains the analytical design from CSA A23.3-14, ACI 318-14, and the EC4 codes. It will also have the procedure for the development of the column interaction curve for the Canadian code and EC4 methods.

Chapter 5 is the final chapter and will be the comparison and conclusion for chapters 4 and 5 . The conclusion will also contain any areas of improvements and gaps to be filled with future research. 


\section{Chapter 2 - Literature Review}

\subsection{Introduction}

Concrete is used in most infrastructure projects as a building material. As such, it is paramount for concrete to be strong and durable. By continuously making improvements on this material, future structures can be built stronger and more efficiently through reduction in material usage.

The goal of this literature review is to study previous work done using Ultra-High Performance Concrete (UHPC) and the confinement effect gained by using steel tubes. The current concrete used in high rise building is mainly High-Strength Concrete (HSC). HSC typically has a compressive strength up to $90 \mathrm{MPa}$. UHPC has been found to reach strength around $150 \mathrm{MPa}$. This increase in strength is much larger than standard HSC and could change the way tall buildings are designed in future infrastructure. Future buildings can be built taller than ever before with larger column free spans. However, since it is a relatively new product, research must be conducted for engineers to better understand how it works to ensure safe and efficient designs in the future.

One area of research that has been documented and explored is steel confined UHPC. Because of the superior material properties of UHPC, and the steel fibers, its results when confined are shown to be more beneficial than when it is applied to HSC. This literature review examines the global research on UHPC with emphasis on the influence of confinement and the mechanical properties of the material. 


\subsection{Ultra-High Performance Concrete}

\subsubsection{Mix Design}

Achieving compressive strengths higher than $150 \mathrm{MPa}$ in concrete is not an easily achievable feat. Ordinary concrete is composed of aggregate, sand, cement, and water. Theses are relatively simple components and produce a mix design that reflects that. To better optimized the mix and reach strengths levels of over $150 \mathrm{MPa}$ to obtain UHPC, different materials such as cement supplementary materials can to be added.

Wille et al. (5) researched a simple way to get concrete over $150 \mathrm{MPa}$ so it can be classified as UHPC. To improve the compressive strength, moderate cement fineness should be used and the $\mathrm{C}_{3} \mathrm{~A}$ content to be much less than $8 \%$ to lower water demand. A common cement supplementary material that is to increase the strength in concrete is silica fume. Wille et al. (5) found that silica fume added to the mix should have a carbon content less than $0.5 \%$ and an optimum amount of it used is $25 \%$ of the cement by weight. Medium sized glass powder is also used in the mix with about $25 \%$ of the cement by weight. A final key property that Wille et al. (5) used was a water to cement ratio range of $0.16-0.27$, with approximately 0.22 as the most effective.

\subsubsection{Mechanical Properties}

Ductal $^{\circledR}$ concrete was used as the UHPC mix in this investigation due to its superior mechanical properties compared to NSC or HSC. The mechanical properties investigated are: compressive behaviour, bending behaviour, tension properties, fracture energy, shrinkage \& creep, fatigue, fiber influence, and fire resistance.

\subsubsection{Compressive Behaviour}

In terms of compressive performance, Ductal ${ }^{\circledR}$ displays performance 4-8 times higher than conventional concrete (6). NSC and HSC can have strengths varying from 20-90 MPa, while 
UHPC exhibits strengths higher than $150 \mathrm{MPa}$. With this increase in stress, the strain value of concrete will also increase. Figure 2-1 shows the stress-strain curve of Ductal ${ }^{\circledR}$ compared to ordinary concrete (6). Ductal ${ }^{\circledR}$ can reach compressive strengths as high as $200 \mathrm{MPa}$ with a resulting strain value of approximately $0.45 \%$ compared to $0.3 \%$ for ordinary concrete.

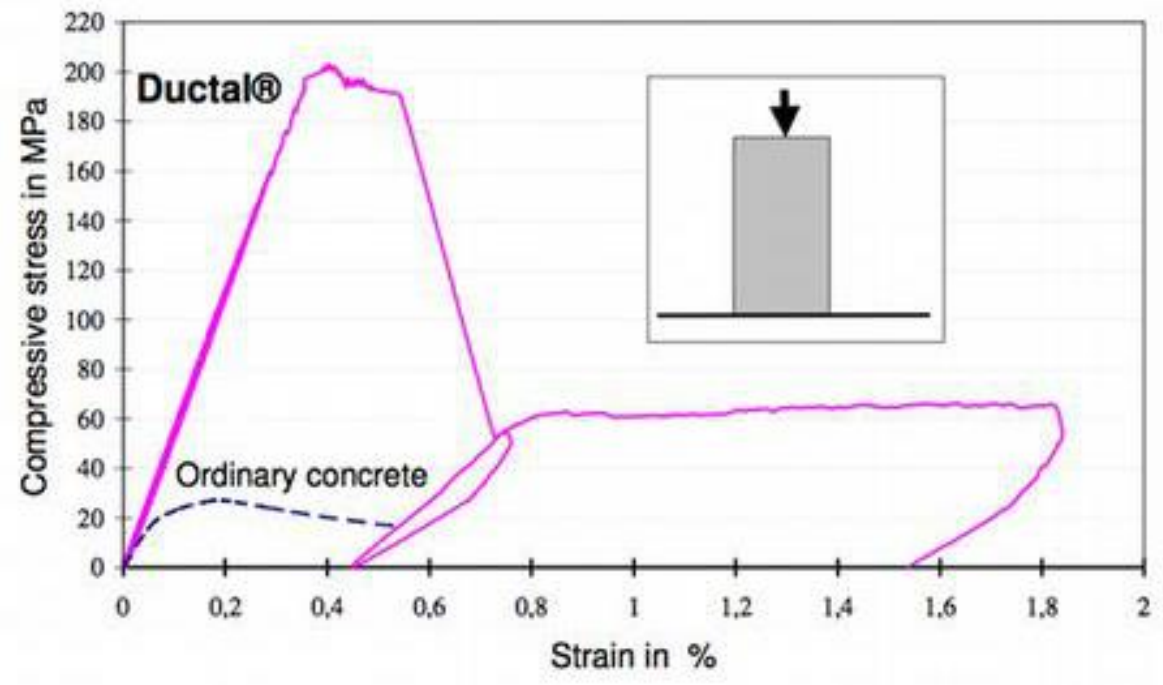

Figure 2-1: Ductal ${ }^{\circledR}$ Stress-Strain Curve (6)

Zahra Yazdizadeh, (7) a Master of Applied Science graduate at Ryerson University, produced the stress-strain curve in Figure 2-2. The resulting strain for stresses of UHPC strengths of $150-170 \mathrm{MPa}$ is around $0.45 \%$. This value of strain can be used to obtain more accurate results when calculating the load capacity of a concrete section. 


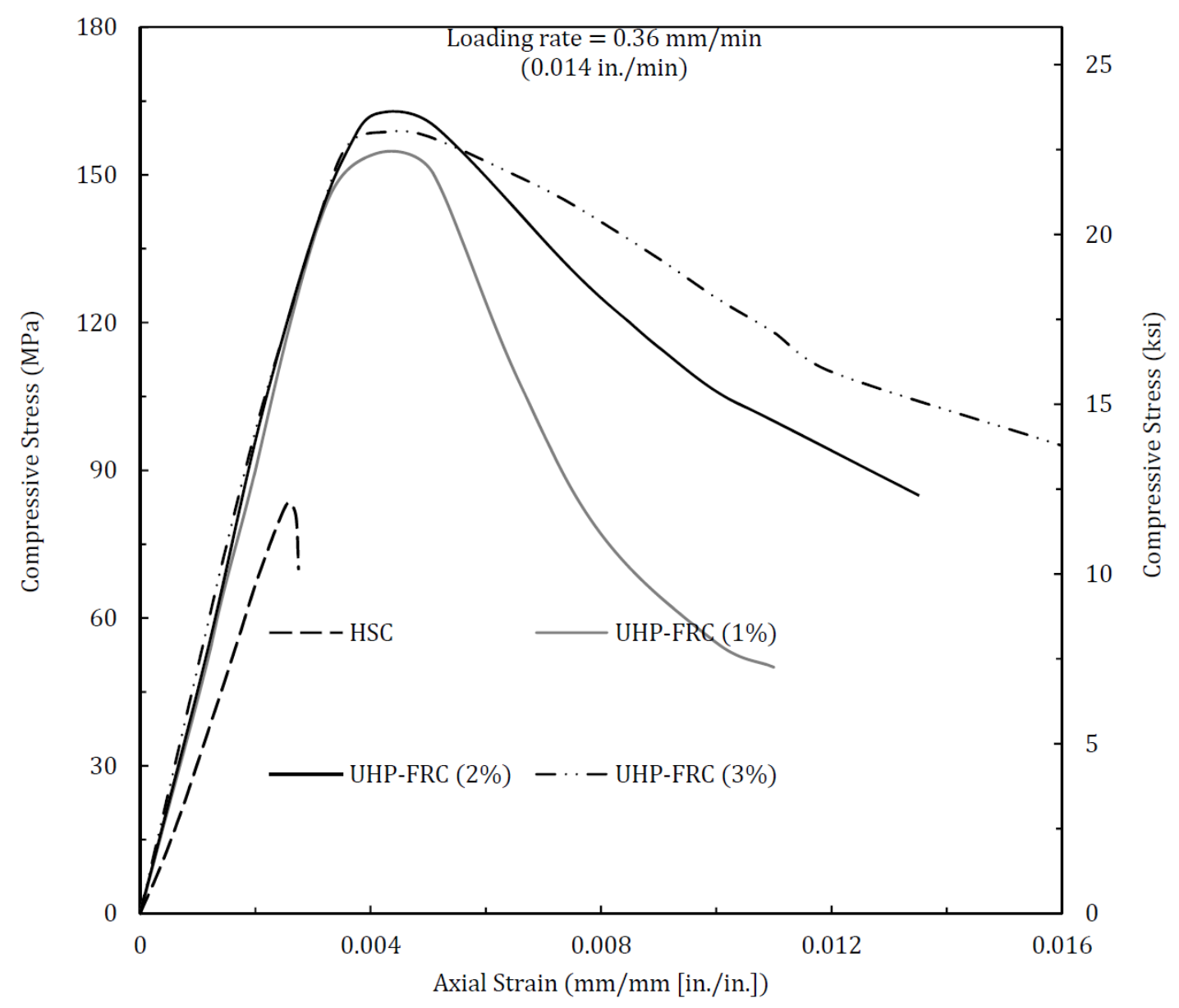

Figure 2-2: Stress-Strain Curve for UHPC with Various Fiber Percentage (7)

\subsubsection{Bending Behaviour}

Ductal $^{\circledR}$ UHPC contains steel fibers in the mix design, improving the concrete's ductile behaviour under bending moment load (6). Once the elastic limit is exceeded under flexural loading, micro-cracks occur that are held tightly by the fibers (6). Figure 2-3 (6) shows how UHPC reinforced with steel fibers can produce much stronger bending moment strength. 


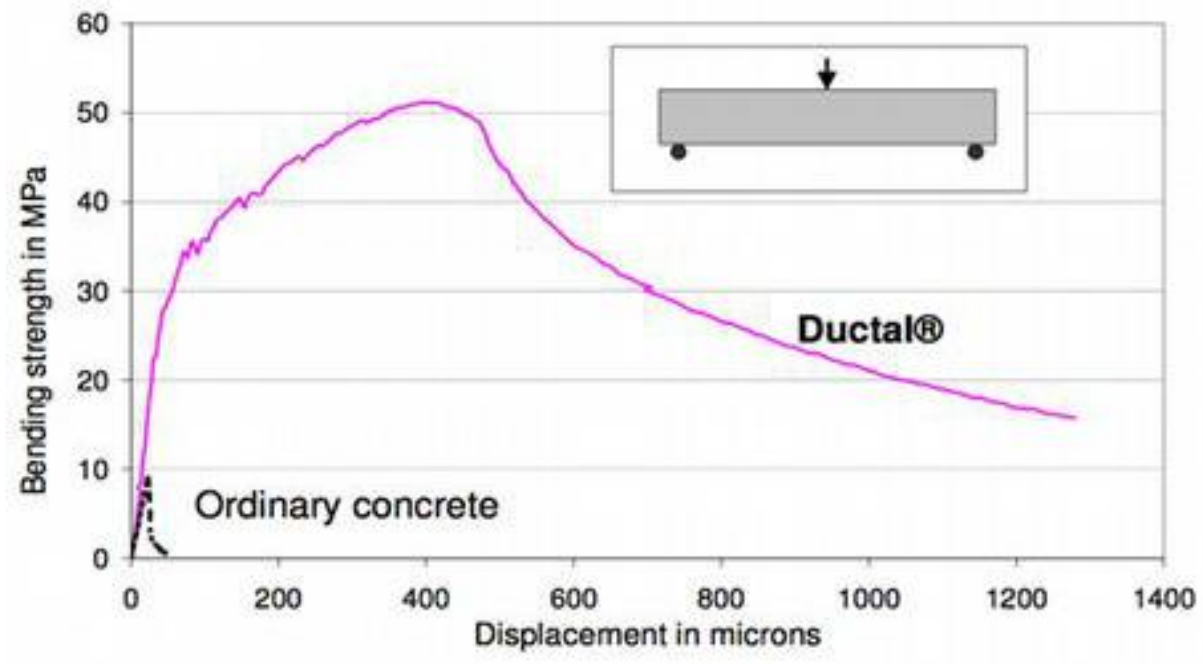

Figure 2-3: Ductal ${ }^{\circledR}$ Bending Strength vs. Micron Displacement (6)

Wahba et al. (8) tested UHPC fiber reinforced beams and found that cracks are sealed and held tightly due to the presence of fibers. Surface cracks would appear at approximately $80-90 \%$ of the ultimate load. Internal cracks formed at a load well before ultimate and later propagating to the surface. The load-strain curve in Figure 2-4 produced by Wahba et al. (8) shows that the fiber addition to the UHPC mix increases the strain of the beam by increasing ductility.

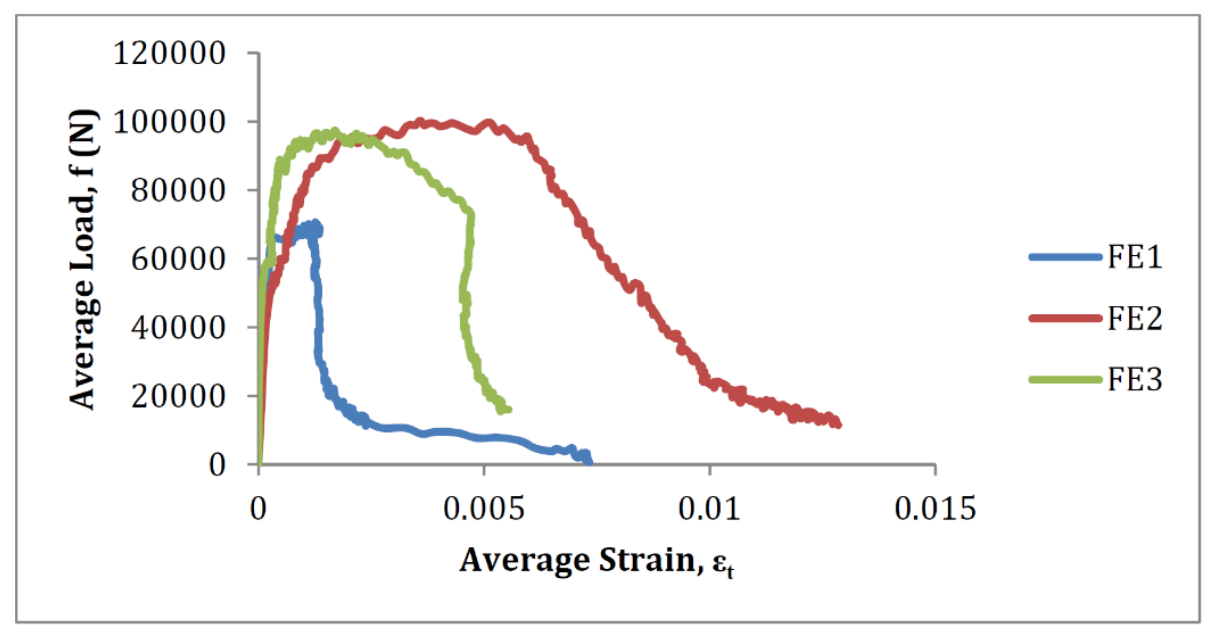

Figure 2-4: Load-Strain Curve for Fiber Reinforced UHPC (8) 


\subsubsection{Tension Properties}

The U.S. Department of Transportation published a report of the material properties of UHPC in 2006 based on a series of experimental research that they have conducted. Concrete is very strong in compression but lacks strength in tension. The research conducted on UHPC found that the tensile strength is approximately $5 \%$ of the compressive strength (9).

\subsubsection{Fiber Influence in UHPC}

In 2017, the Institution of Structural Engineering at the University of Kassel, Germany compared the effect UHPC infilled steel tubes with and without fibers (10). They found that increasing the amount of steel fibers in the mix does not increase the strength of confined UHPC tubes. However, it does increase ductility and minimize localized deformation of steel tube, since the fibers provide extra resistance to shear failure of the concrete core.

Although the fibers do not contribute much directly to the axial strength of the concrete, they help increase the bending moment resistance. This added steel percentage in the cross-section of the columns provides more tension resistance in axial loading cases. In Canadian design practices, the concrete tensile resistance contribution is typically ignored because, relatively speaking, it is almost insignificant. This is also a more conservative design approach, but it does ensure a larger factor of safety. UHPC has a larger tensile stress resistance than HSC, which is worth considering in design. Including the tensile resistance of the fibers in the capacity calculations would lead to a slightly more efficient design. Because it is common practice in design to neglect the tensile capacity of concrete, the fibers will not be included as part of the calculations for this investigation. 
In Australia, researchers at the University of Technology (11) tested the axial-flexural interaction of fiber-reinforced polymers (FRP), for both confined and unconfined. They found that the FRP confined columns reached a higher moment capacity, lateral displacement at failure, and axial displacement at max load.

The fiber reinforcements in UHPC help reduce compression failure due to how brittle the material tends to be in nature (10). HSC inhibits inverse proportionality in terms of strength and frailty; stronger materials are typically more brittle. To improve the strength of concrete, especially its early strength during casting, the cement particles are made finer by grinding (12). But while this increases the strength, it also increases how brittle the material can be. Fibers help strengthen the concrete in the form of failure, as found trough experimental evidence.

UHPC undergoes three macrostructural mechanical failure modes: compressive, tensile cracking, and tensile fiber pullout (9). Despite the added failure mode due to the fibers, they have added benefits to the performance

Researchers have found that the post peak load behaviour of UHPC filled tubular columns can be very brittle. To combat this, a minimum $1 \%$ volume of steel fibers or 0.3 steel contribution ratios should be used in the design (13). This helps in improving the ductility of the section and in turn compensate for some of its brittle properties. Fibers can also improve the performance of a section by improving the confinement effect. This means that they can be used to partially replace transverse reinforcement, reducing steel congestion and improving workability (14).

\subsubsection{Fracture Energy}

Calculated from the stress-displacement curve, the fracture energy of concrete is the energy required to form a surface crack using the tensile stress (15). H. Marzouk and Z. W. Chen (15) published about the fracture energy of NSC and HSC. It has been found that HSC had an 
approximate value of 5 times the area under the ascending curve of the stress-strain diagram compared to 10 times the area for NSC (15). The reported fracture energy for HSC and NSC are $160 \mathrm{~N} / \mathrm{m}$ and $110 \mathrm{~N} / \mathrm{m}$ respectively, whereas UHPC tested values were over 14,000 N/m (16). The fracture energy of UHPC is a hundred times the strength of HSC due to the addition of the steel fibers (16). With such a high fracture energy compared to NSC and HSC, fiber reinforced UHPC is ideal for impact-resistant loads such as explosions (17).

\subsubsection{Shrinkage \& Creep}

Creep tests for Ductal ${ }^{\circledR}$ were carried out in France and the U.S. (6) resulting in a creep coefficient or 0.8 compare to that of ordinary concrete which is around 3-4. Heat treatment would reduce this ever further is heat treatment is applied to the concrete (6). Ductal ${ }^{\circledR}$ has a low water to cement ratio, limiting any drying shrinkage without subsequent residual shrinkage (6).

Yazdizadeh et al. (18) tested and measured shrinkage and creep of NSC, HSC, and UHPC. It was found that as the strength of the concrete increases, the shrinkage and creep strains are decreased. Figure 2-5 and Figure 2-6 show the results of shrinkage and creep strains respectively for three different concrete strengths. UHPC performs better than its lower strength counterparts in resisting creep and shrinkage as time goes on. This is a very important property for a material to have because it increases the durability of it, therefore lengthening its service life. 


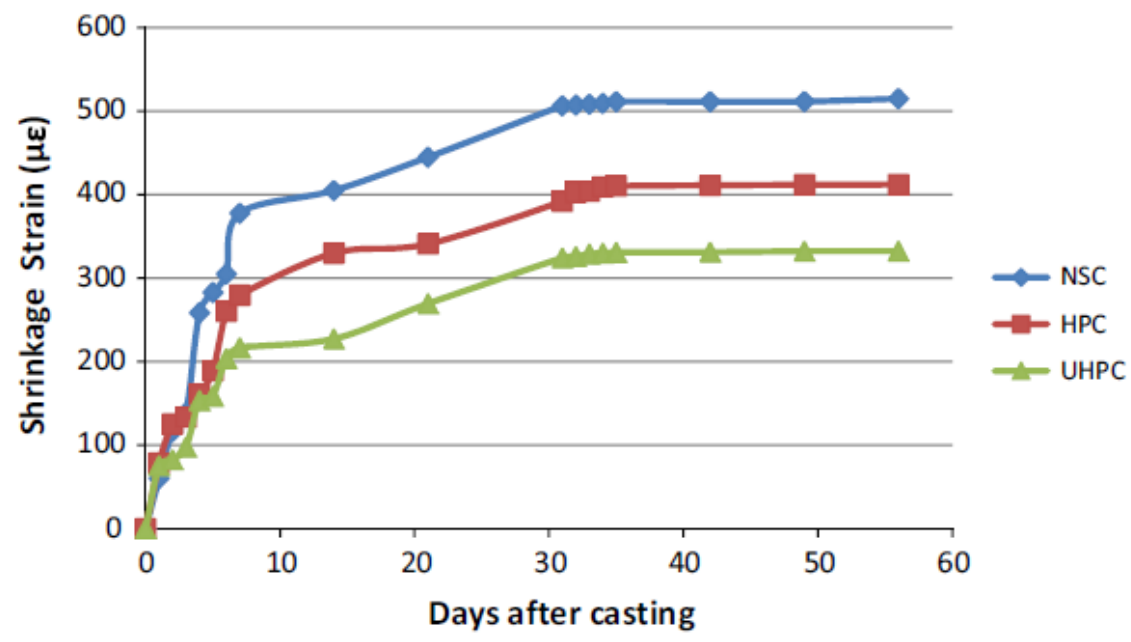

Figure 2-5: Shrinkage Strain of NSC, HSC, and UHPC (18)

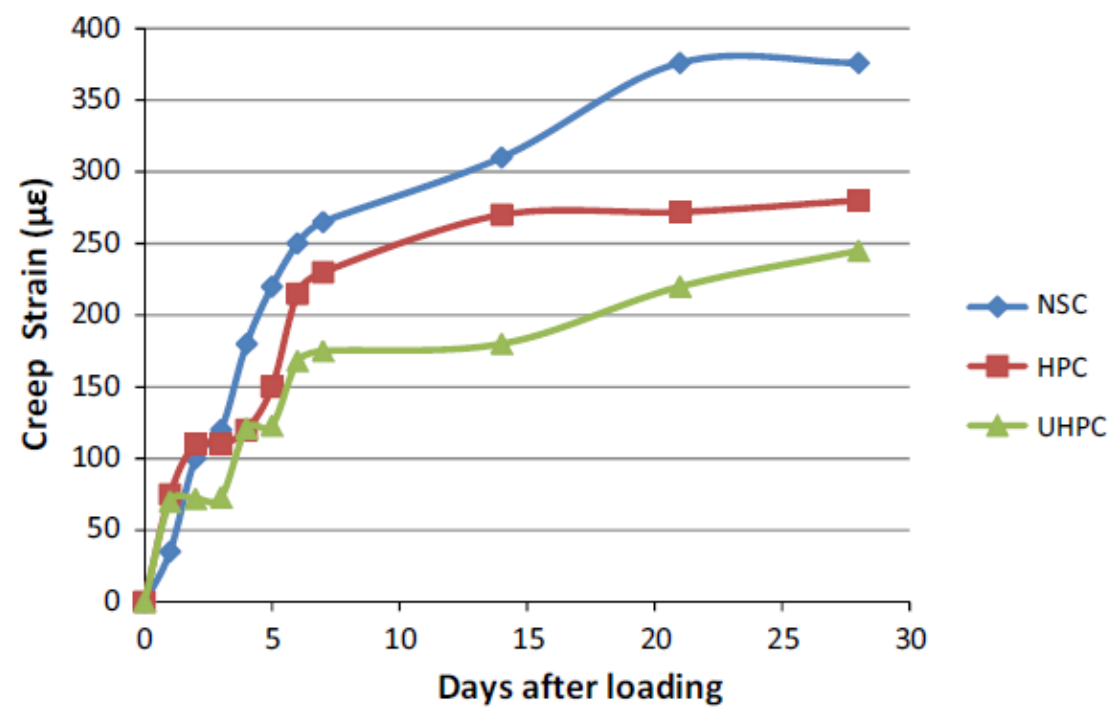

Figure 2-6: Creep Strain of NSC, HSC, and UHPC (18) 


\subsubsection{Fire Resistance}

Based on decades of usage, concrete materials typically perform better than steel when exposed to fire. The fiber elements in UHPC make it more susceptible to failure than Normal Strength Concrete (NSC). Vojvodic et al. (19) considered this during the experiment conducted at the Graz University of Technology, Austria. The tested UHPC-NSC composite column had a UHPC core and an NSC jacket that encompassed the high-performance core. The NSC concrete layer did not include any steel fibers and was therefore more resistance to fire than UHPC. It also acted as a load bearing component as it can still take some compressive forces. The authors did however experience early spalling in the NSC cover, concluding that a reduction factor may be considered when designing these UHPC-NSC composite columns.

Under high temperatures, the steel fibers heat up and undergo explosive spalling. Researchers have found that polypropylene fibers can be used instead of steel ones to reduce explosive spalling that occurs in UHPC under high temperatures (20).

\subsubsection{Transverse Reinforcement}

In practice, columns have both longitudinal and transverse reinforcement. The Institute of Structural Concrete at Graz University of Technology, Austria conducted research on UHPC and UHPC-NSC composite columns under concentric loading. One of the variables that were changed in the research was the spacing between transverse reinforcement. It was found that increasing the amount of transverse reinforcement had insignificant impact on the UHPC (19).

Transverse reinforcement can be used to improve the confinement effect of the concrete, which has its own added benefits. Adding high strength transverse reinforcement reduces later 
expansion under axial compression and result in more confining pressure, which improves the confinement efficiency (21).

Researchers in 2016 comprehensively concluded that increasing the amount of transverse reinforcement improves concrete strength, post-peak deformability, and toughness (22). Improving the post-peak performance is important because then the column will not fail immediately after the reinforcement yields but rather it holds up for a longer duration and has a slower rate of deformation. Using well-detailed and designed transverse reinforcement also reduces steel congestion, improving construction cost and time (22).

\subsubsection{Steel Tube Filled with UHPC}

The UHPC tends to be very brittle but the confinement proved to result in improvement in strength, ductility, and improve loading capacity (10). This composite cross-section works very well with UHPC duet to the brittle nature of the material. The added ductility to the column also improves how well it can handle any bending moment resistance, therefore using a smaller composite section rather than a larger concrete column. 
CFST under large compressive load can prevent, or at the very minimum delay, the local buckling of the column (1). When designing reinforced concrete, common practice dictates to design the section so that the steel yields first and ensure a gradual failure rather than sudden. One factor to consider when using a composite section is matching strength of concrete and steel should be used (1). Using steel and concrete with matching Ultra High strengths guarantees that the concrete core will not be crushed before the steel shell yields. This manner allows the column to undergo a gradual, visible failure.

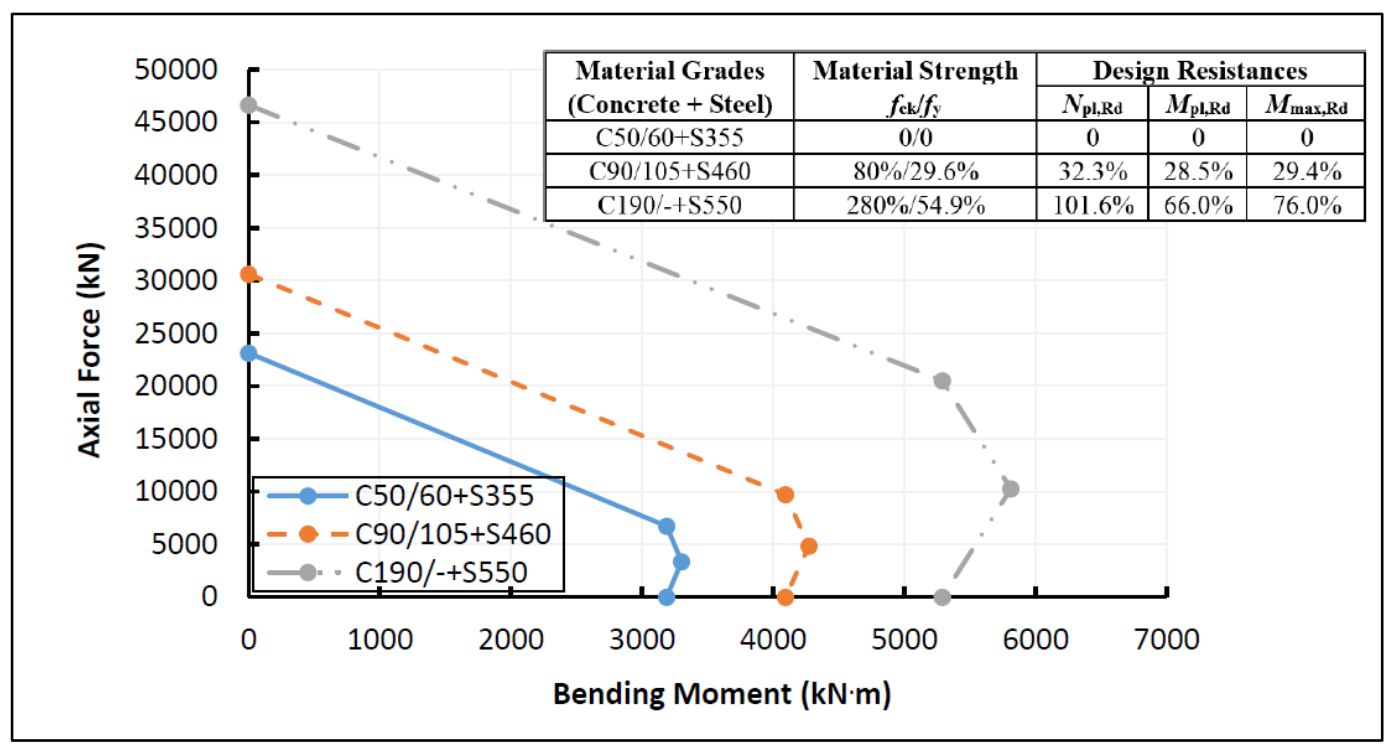

Figure 2-7: CFST Comparison with Varying Concrete and Steel Strengths (23)

It was found that then steel strength up to $550 \mathrm{MPa}$ can be used with concrete strength up to $190 \mathrm{MPa}$ (23). This research was based on pairing different strength concrete with different strength steel tubes. Figure 2-7 shows and interaction diagram (drawn based on the simplified Eurocode 4 method). The UHPC core used with the steel shell pairing produces a gradual increase in ultimate strength. As expected, the material strength and the column's ability to withstand axial and bending force are proportional. One significant note is the larger jump from C90/S460 to 
C190/S550. Using a matching set of high performance materials is shown to yield the best results, and the confinement at this level of strength produces the most efficient load resistance.

An outer steel jacket can also be very beneficial in rapid construction. Concrete of any strength requires formwork for a minimum amount of time to ensure sufficient curing has occurred, then the desired shape will hold once the form is removed. The steel structure acts as a permanent formwork that does not need to be removed (1). This is a great benefit to the increasing need of rapid construction since it saves time assembling and disassembling formwork. In today's need for rapid infrastructure, fast track construction is becoming more popular with. Saving construction time and reducing the impact on the area where construction is taking place will reduce the direct and indirect costs of the project. Infilled concrete tubes are one way that time and money can be saved during the building phase of any project.

There are multiple ways that steel reinforcement and confinement can be arranged, each with advantages and disadvantages. The simplest is a circular steel tube, but other shapes have proven to be more beneficial in certain areas than others. The Institute for Steel and Composite Structures at the University of Wuppertal, Germany (2) presented a list of various cross-sections and a list of their respective advantages and disadvantages, as shown in Table 2-1. Each crosssection can be used for different design criteria based on the advantages it can provide and what the situation calls for. 
Table 2-1: Concrete Encased Sections - Advantages and Disadvantages (2)

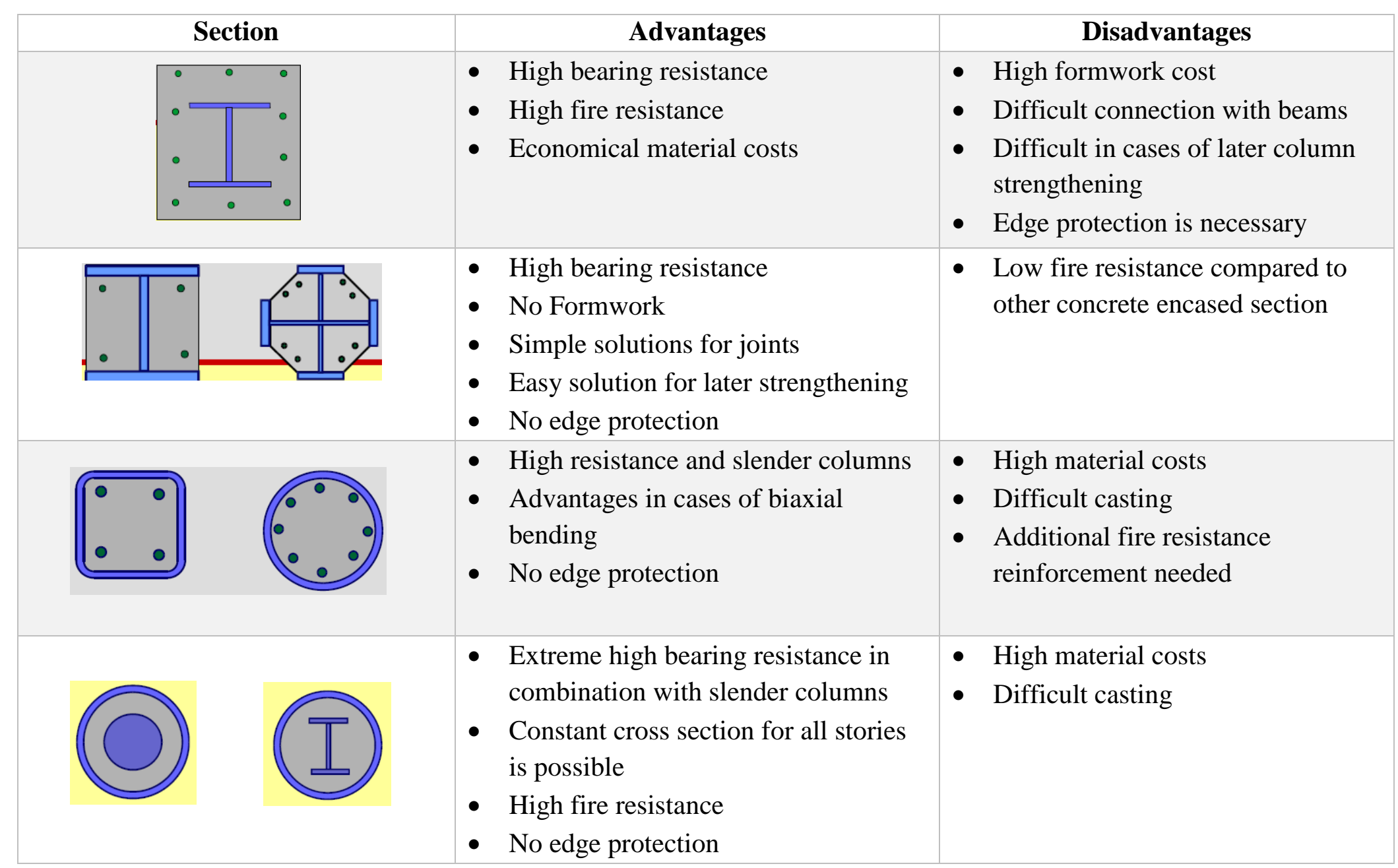


Composite structures are, by definition, not a homogenous structure and therefore require additional attention regarding connections and joints. For example, if the column in a building is made of UHPC the slab connecting to it is typically made up of NCS. To combat this, researchers suggest a special mounting element where the rebars can be arranged inside the joint as shown in Figure 2-8 (24). This concept carries the shear force from the lab to the lower column and reduces the failure at the joint (24).

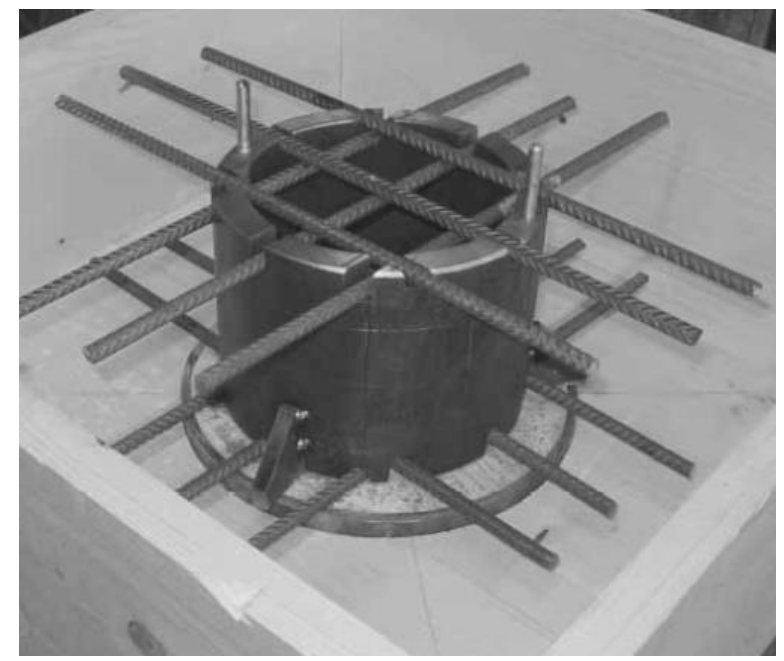

Figure 2-8: Special Mounting Element (24)

\subsubsection{Confinement Effect of Steel Tube}

Part of what makes the addition of fibers, reducing stirrup spacing, and CFST improve the resistance of a designed section is that all these factors provide a confinement effect. Researchers in Kessel, Germany stated that circular cross-sections provide the best results when looking at the confinement effect (24). This is most likely due to a circle being symmetrical on any plane crossing through the center, resulting in equal stress containment from all angles. Figure 2-9 provides a visual illustration of the confinement lateral pressure of circular steel tube confinement. 


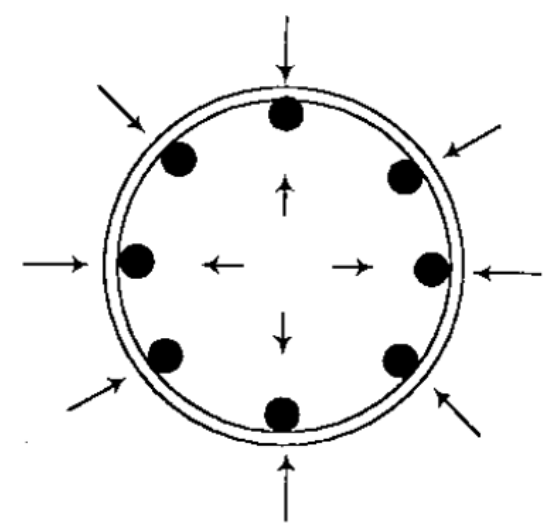

Figure 2-9: Uniform Lateral Pressure in Circular Columns (26)

Currently, there are no existing models that accurately predict how confinement improves the performance of steel confined concrete. What is known is that confinement improves the strength and ductility of the tested columns when using UHPC, but this is underestimated by current estimation models (25). Compared to conventional concrete, UHPC displays improved confinement effectiveness as the confinement pressure is increased (25).

An analytical model was proposed for confined HSC that was verified through experimental data for concrete ranging from 30-130 MPa (26). While this may have been validated for HSC, it would most likely require adjustments for UHPC.

\subsection{Design of UHPC Composite Columns}

Because of its relatively new introduction into the field, UHPC still requires a lot of research and experimental evidence before all its properties and long term behaviours are known. Along with the material itself being new, the idea of using it within a confined steel form is still being introduced in the field and has not yet reached the point of being common practice. So far, the European code, Eurocode 4 (EC4), is the leading design force for UHPC and CFST. 
For NSC and HSC, the typical maximum strain limit is 0.003 and 0.0035 respectively. The properties of UHPC are still being investigated but what is known so far is that the strain value of NSC or HSC does not yield accurate results. In a paper published by the University of Technology, Iraq and the University of Adelaide has found that a strain of 0.004 provides highly conservative predictions of P-M diagram (11). Much like how the strain in HSC is higher than NSC, the maximum concrete value for UHPC should end up being greater than 0.0035 for accurate results.

\subsubsection{Eurocode 4 (EC4)}

In general, the EC4 has underestimated the confinement effect that involves UHPC (13). This means overdesigning because the code does not yet have the capability to accurately estimate how strong this method of construction is.

The current Eurocode 4 lower limit for steel contribution is 0.2 , and after experimentation it is recommended that the limit should be increased to 0.3 (20). This is because UHPC filled steel tubes are very brittle if the steel contribution is too low and raising this limit in the code can improve the performance of the column (20).

Researchers at Istanbul Technical University, Turkey tested the axial capacity of UHPC filled steel tube and compared the results to the EC4 design procedure. It has been found that the EC4 overestimates the axial bearing capacity by about $15 \%$ because it includes the confinement effect of the tube (27). This is a rather aggressive estimation to the capacity of the column and needs a reduction factor.

\subsubsection{Canadian Design Code (CSA A23.3-14)}

Currently, the Canadian code does not include any from of designing for UHPC and CFST. Once more research is conducted in this field using the Canadian Code, new equations or factors can be formed to predict the load resistance capacity and implement it in future design. 


\subsubsection{American Concrete Institute (ACI)}

Very similar to the Canadian design code, the American Concrete Institute (ACI) does not yet have detailed design for UHPC and CFST. The same researchers at Istanbul Technical University, Turkey that compared the results of axial capacity of UHPC composite columns and compared it to EC4 also looked at the ACI code. They found that results are, on average, $20 \%$ lower in design compared to experimental results (27). The ACI design code is currently very conservative when estimating the axial capacity of UHPC filled steel tubes. More research should be conducted to confirm this and through experiments a more accurate design procedure can be developed for the high-performance material.

\subsection{Application and Benefits of using UHPC Confined with Steel Tubes}

When designing tall buildings, lateral loads such as wind or earthquakes are usually the most complicated forces to account for. Designing a structure to accommodate for these loads with large, unsupported spans is difficult to accomplish. The use of UHPC encased in steel can provide a large amount of lateral resistance while using a lower number of columns. This is used to form a 'super frame' to be used in tall buildings.

Since steel structure are usually prefabricated and assembled on site, they are built much faster than concrete ones. Some of these benefits of steel structures are $20 \%$ faster construction than concrete, less storage space on site, larger-span column free space, and encouraged use of labour efficient design requiring higher skill workers (28). Steel tubes filled with UHPC uses a lot of the benefits brought by using steel such as faster construction. The additional benefit of this is that the composite columns provide a permanent and integral formwork which reduces time and cost of construction (28). Sufficient curing needs to take place before traditional formwork can be 
disassembled and it takes time for it to be assembled yet again for the next floor. With the steel eliminating that whole process, construction can be sped up which also reduces costs. Permanent formwork also adds the benefit of retaining the water in the concrete mix, so the curing process can continue for some time after casting, improving the strength of the hardened concrete in the long run.

UHPC infilled steel sections can change the way future infrastructure is design. It can be beneficial in both building and bridge design for two main reasons: its ability to handle high axial loads and fails at a very ductile point (24). Structural designers aim to make structure fail in a ductal fashion. This way any deflection or deformation in a beam, slab, or column can be observed slowly over time so the appropriate safety measures can be taken. 


\section{Chapter 3 - Experimental Investigation}

In this chapter, the details of the experimental investigation will be discussed. This will include any of the specimens tested, how they were built, and the methods used to test them.

\subsection{Test Specimen}

The column specimens were divided into two mixing stages; the first for UHPC and the second for HSC. Each batch contained 3 columns, two are confined with steel tube and one is unconfined. All $600 \mathrm{~mm}$ specimen were confined, while the $1000 \mathrm{~mm}$ specimen can be confined or unconfined. In total, 6 specimens were tested for this experiment; 3 UHPC samples and 3 HSC ones. The six specimens are summarized and tabulated in Table 3-1.

Table 3-1: Specimen Summary

\begin{tabular}{|l|l|c|c|}
\hline Specimen & Concrete & $\begin{array}{c}\text { Length } \\
(\mathbf{m m})\end{array}$ & $\begin{array}{c}\text { Confined } \\
(\mathbf{Y} / \mathbf{N})\end{array}$ \\
\hline Batch 1 & \multicolumn{1}{|c|}{} \\
\hline UHPC-U-1000 & UHPC & 1000 & $\mathrm{~N}$ \\
\hline UHPC-C-1000 & UHPC & 1000 & Y \\
\hline UHPC-C-600 & UHPC & 600 & Y \\
\hline Batch 2 & & & \\
\hline HSC-U-1000 & HSC & 1000 & N \\
\hline HSC-C-1000 & HSC & 1000 & Y \\
\hline HSC-C-600 & HSC & 600 & Y \\
\hline
\end{tabular}

In this experiment, there are several variables that are changed. The variables that are looked at are as follows:

D Strength of Concrete (UHPC vs. HSC)

Length (600 mm vs. $1000 \mathrm{~mm})$

Confinement (Steel tube confinement vs. Unconfined) 


\subsection{Member Fabrication}

All six columns were set up at the same time. The UHPC were casted in the first mix, followed by the HSC at a later time. Each column had formwork, reinforcement, then finally infilled with the appropriate concrete mix.

\subsubsection{Formwork}

The column formwork was fabricated in two ways; one for confined and another for the unconfined. The confined columns were simply prefabricated steel tubes infilled with concrete, which meant that the can simply act as permanent formwork without the needing removal. For the unconfined columns, 6-inch diameter concrete forming tube was cut to the specific length (600 $\mathrm{mm}$ and $1000 \mathrm{~mm}$ ). Figure 3-1 shows the formwork of a $1000 \mathrm{~mm}$ unconfined column on the left, and a $600 \mathrm{~mm}$ confined column on the right; both with the reinforcement placed prior to pouring in the concrete.

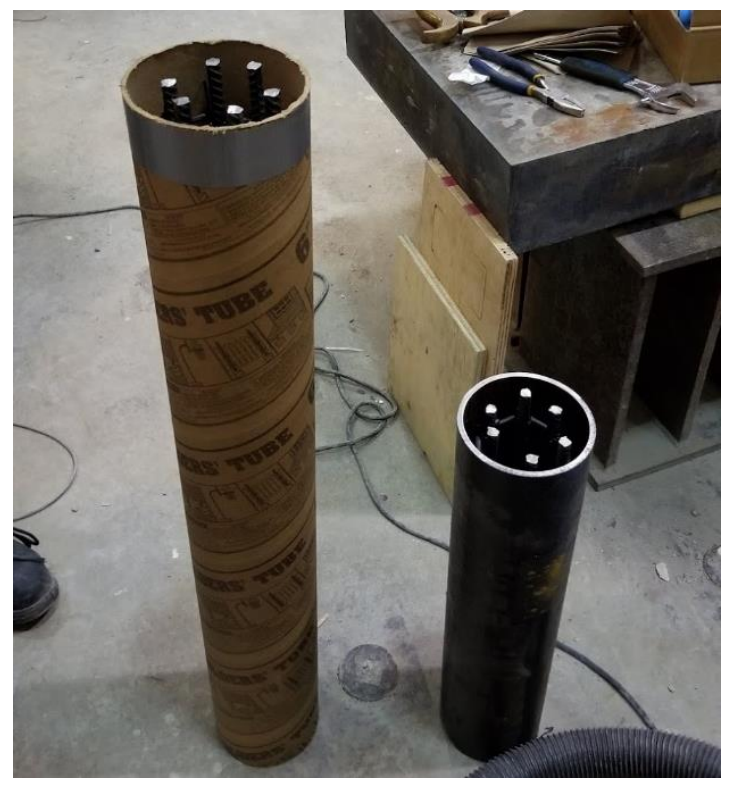

Figure 3-1: Unconfined (Left) and Confined (Right) Column Formwork 


\subsubsection{Reinforcement Set-up}

All the columns tested had the same longitudinal and transverse reinforcement set up and spacing, except for the length being $600 \mathrm{~mm}$ or $1000 \mathrm{~mm}$ for each respective specimen height. The longitudinal reinforcement was six $10 \mathrm{M}$ rebar and the transverse ones were $6 \mathrm{M}$ bars spaced 100 $\mathrm{mm}$ apart. The transverse reinforcement was bent manually into a hexagonal shape where each of the longitudinal rebar was placed. Figure 3-2 shows the process of bending each rebar and Figure 3-3Figure 3-3: Completed Shaped Transverse Reinforcement shows the completed transverse reinforcement prior to connecting it to the longitudinal reinforcement.

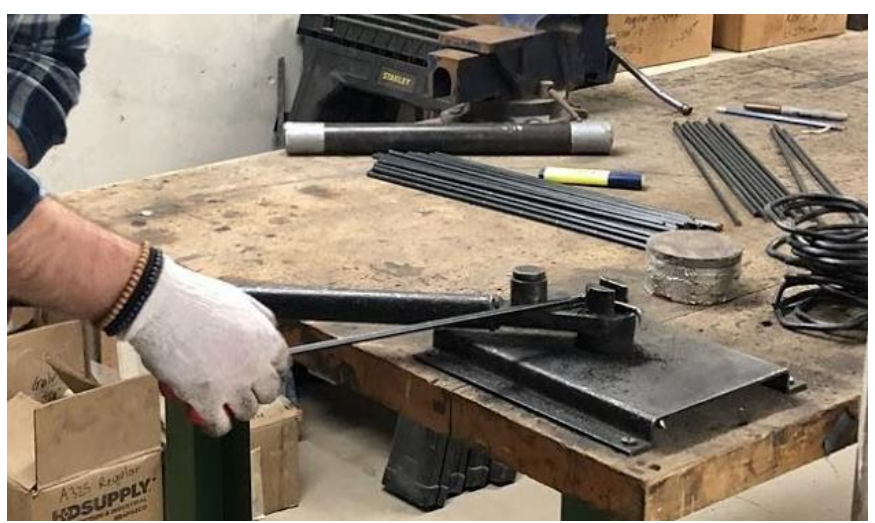

Figure 3-2: Bending the 6-M Rebar for Transverse Reinforcement

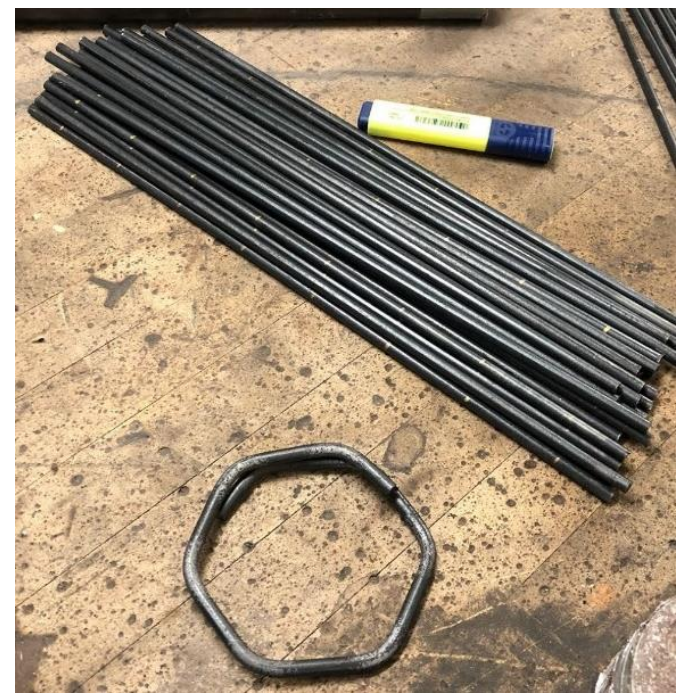

Figure 3-3: Completed Shaped Transverse Reinforcement 
Once all the transverse reinforcements were bent to shape, it was attached to the longitudinal rebars using zip ties. For all specimen, the spacing of the transverse reinforcement used was $100 \mathrm{~mm}$. Figure 3-4 shows the completed reinforcement cages for the $600 \mathrm{~mm}$ and 1000 $\mathrm{mm}$ specimen. The steel cages were placed into either the steel tube or the concrete forming tube, depending on the specimen.

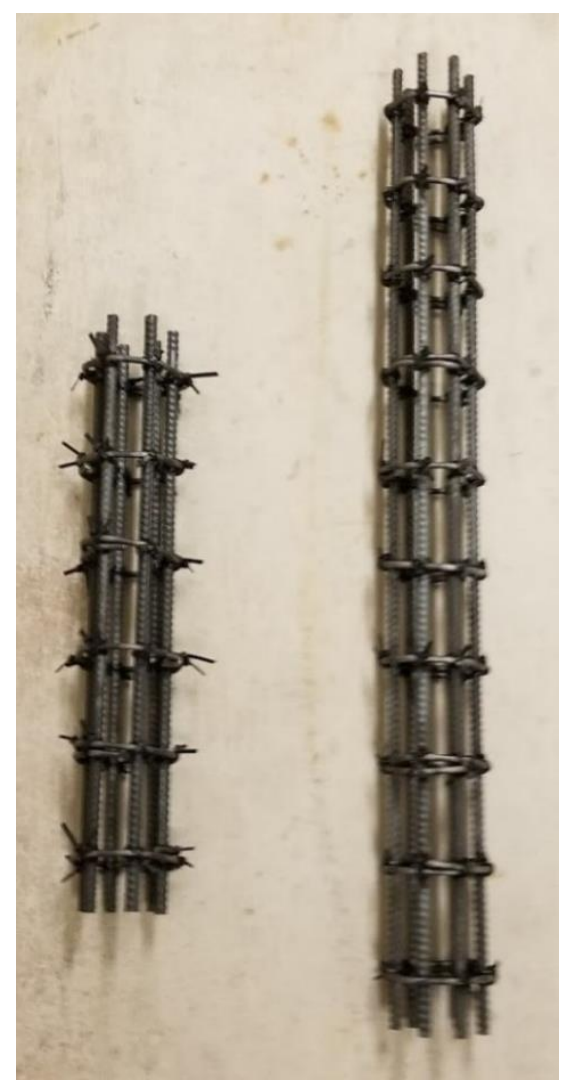

Figure 3-4: Final Steel Cage Reinforcement for 600 mm (left) and 1000 mm (right) Specimen

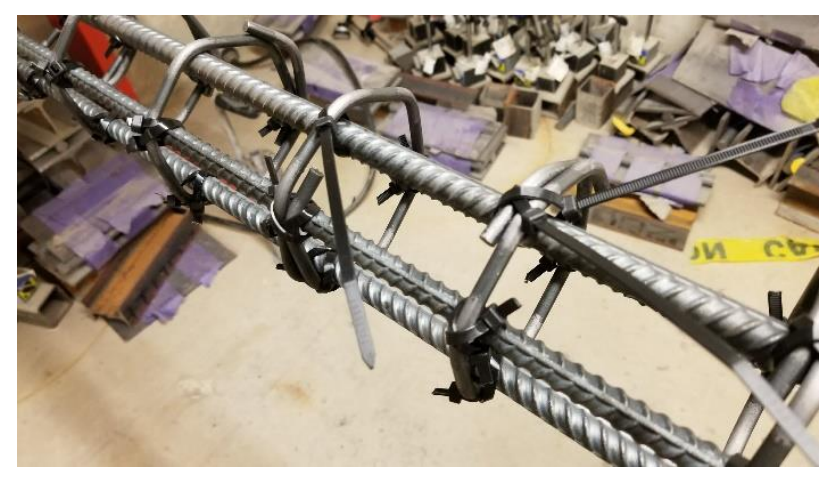

Figure 3-5: Close-up of Transverse Reinforcement Connection to Longitudinal Rebar 
Figure 3-6 shows the cross-section of the column for confined with steel tube and unconfined specimen. The transverse reinforcement had a diameter of $100 \mathrm{~mm}$. The outer diameter of the columns is $141.3 \mathrm{~mm}$. For the confined sections, the steel tube had an inner diameter of 127 $\mathrm{mm}$ and a thickness of $6.55 \mathrm{~mm}$.
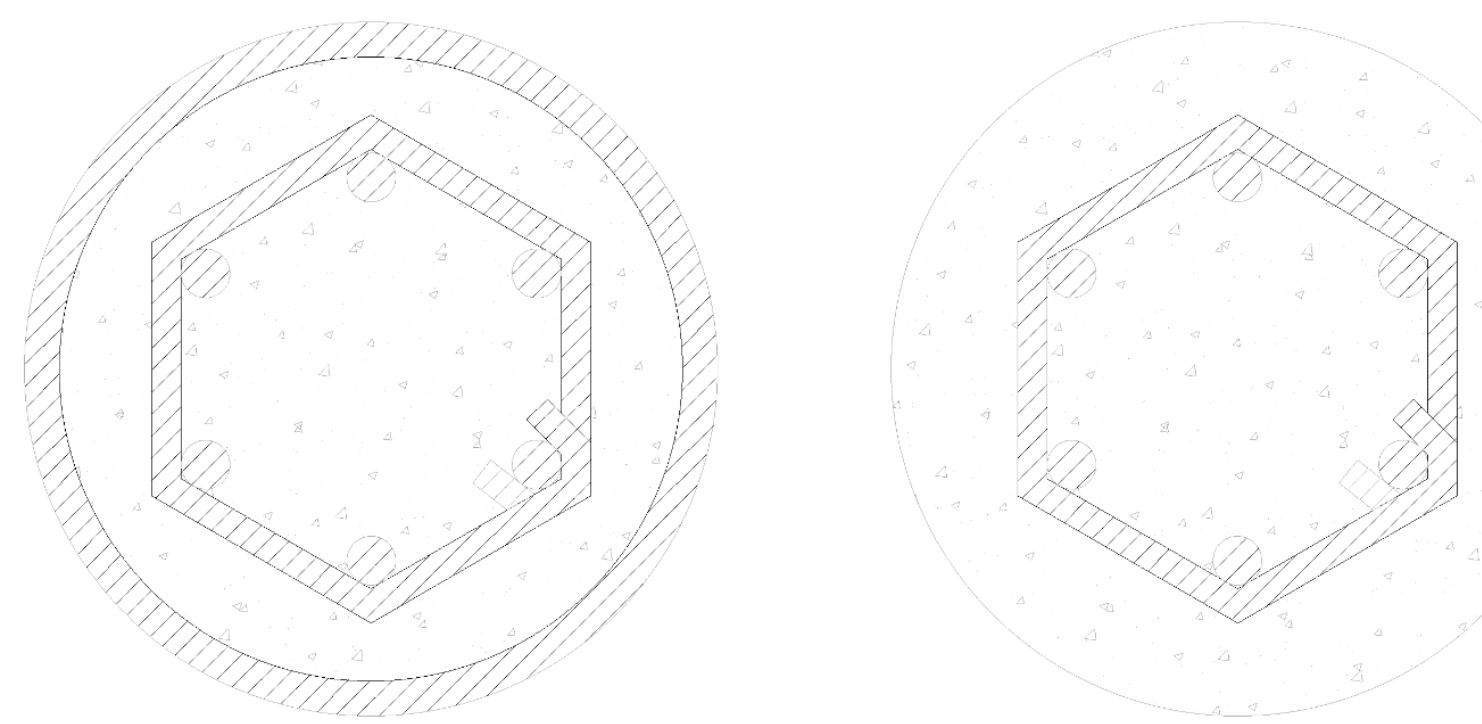

Figure 3-6: Cross-Section of Confined (left) and Unconfined (right) Column Sections

\subsubsection{Casting and Curing}

The mix procedure for this experiment was split into two parts: one for HSC and one for UHPC. Since the focus of the experiment was on UHPC, that mix was completed first. A $250 \mathrm{~L}$ capacity shear mixer was used to place all the materials in. After the materials were mixed, they were transported to the forms and the wet mix was poured. The intended design strength for HSC and UHPC were $90 \mathrm{MPa}$ and $150 \mathrm{MPa}$ respectively. The details of the mix design for both mixes are listed in Table 3-2. A cut and polished cylinder of each of the concrete mixes are shown in Figure 3-7 to illustrate the difference between HSC and UHPC after they have cured. 
Table 3-2: HSC and UHPC Mix Design Proportions

\begin{tabular}{|l|c|c|}
\hline & HSC & UHPC \\
\hline Design Strength (MPa) & 90.0 & 150.0 \\
\hline Volume (L) & 180.0 & 100.0 \\
\hline Premix Bags (kg) & - & 255.0 \\
\hline Pea Gravel (kg) & 165.0 & - \\
\hline Sand (kg) & 105.0 & - \\
\hline Cement Bags (kg) & - & - \\
\hline Fibers (kg) & - & 16.0 \\
\hline Water (kg) & 23.0 & 13.5 \\
\hline Superplasticizer (kg) & 1.0 & 3.1 \\
\hline Silica-Fumes (kg) & 8.0 & - \\
\hline
\end{tabular}

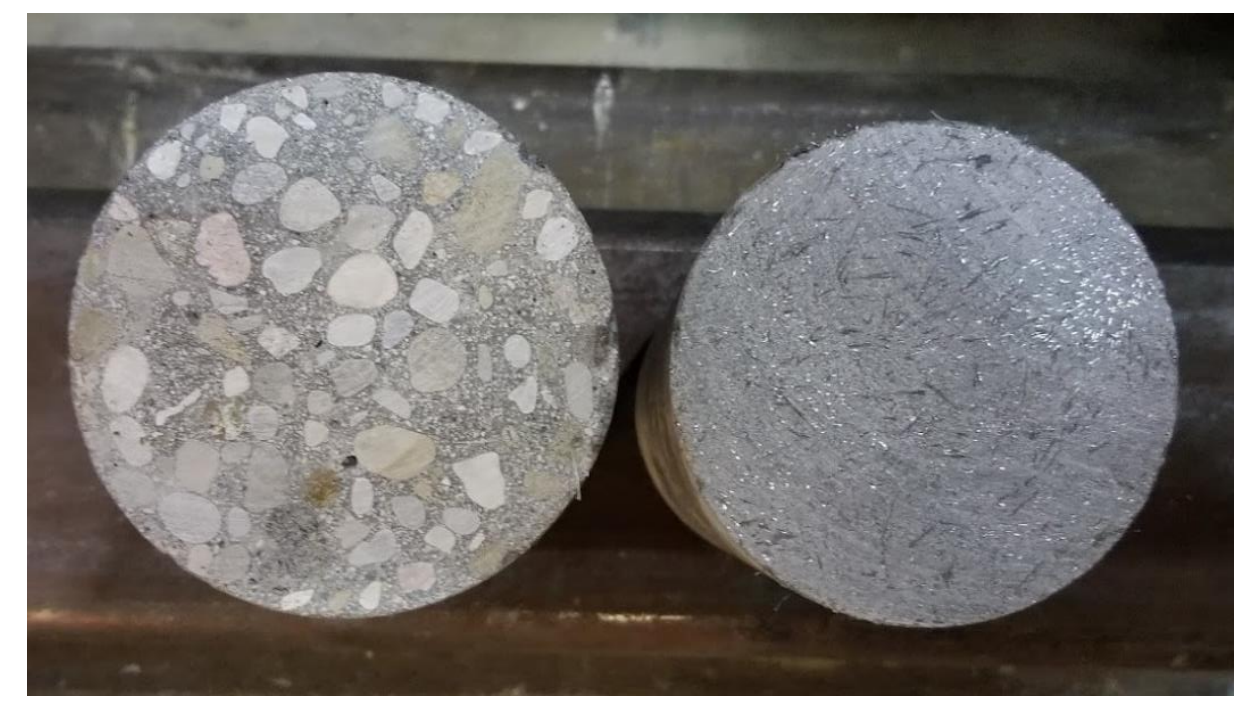

Figure 3-7: HSC (left) and UHPC (right) Samples Cut and Polished

For each mix, the concrete was poured and allowed to harden for at least 28-days before testing. The steel tubes and concrete forming tubes were placed on a flat wooden board and leveled to be plumb. The bottom or each column form was sealed with caulking to prevent any concrete from leaking during casting. To maintain hydration during curing, small amounts of water were applied to the top of each column for 7 days after casting. 


\subsection{Experimental Setup}

. All the columns, 28-days after casting, were tested in an MTS Model 815 machine. The compressive strength and the lateral deformation at mid-height of each column were recorded to be analyzed later. The columns were lifted and placed into the machine using an overhead crane due to their size and weight. The columns were painted in a white coat to highlight any cracks or deformations for ease of visibility after testing.

\subsubsection{Compressive Machine}

The MTS Model 815 has a maximum height capacity of $1000 \mathrm{~mm}$ specimen and a compression rating of $4600 \mathrm{kN}$ (29). Two sheets of plexiglass were secured on the exposed parts of the specimen during testing to ensure any debree from the column during testing remains

contained. Figure 3-8 shows the machine set up with a $1000 \mathrm{~mm}$ column and Figure 3-9 shows another specimen during testing with the added plexiglass protective layer. 


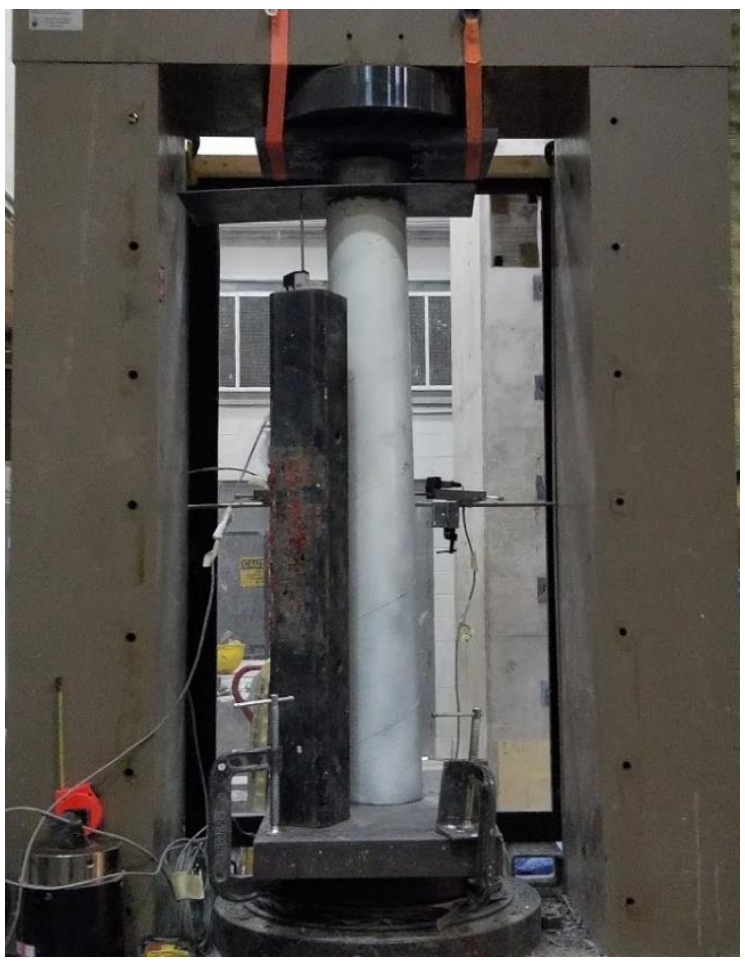

Figure 3-8: Compressive Testing Set-up

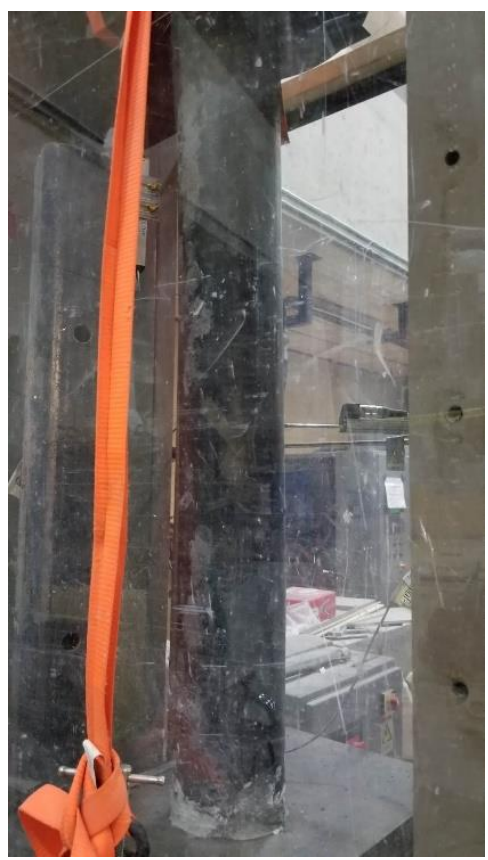

Figure 3-9: Compressive Testing Set-up with Plexiglass Protection 


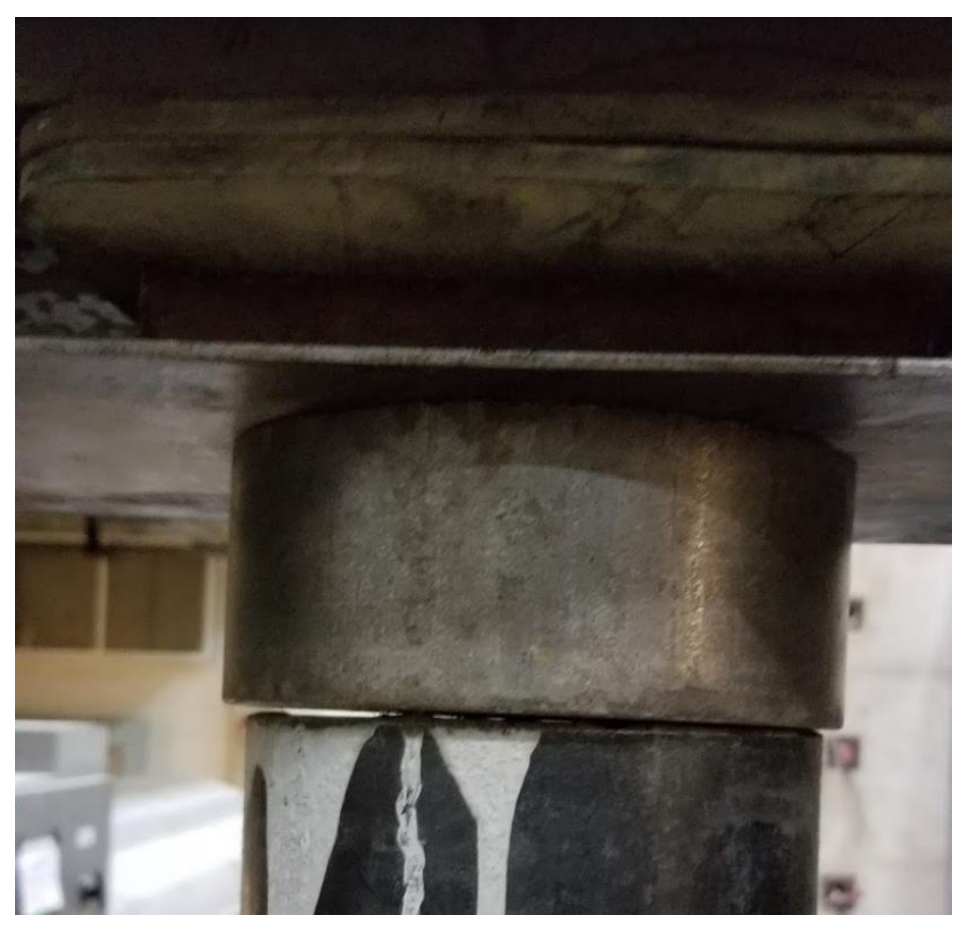

Figure 3-10: Top Portion of Loading Specimen with the Rubber Layer (top)

\subsubsection{Loading Procedure}

Since the columns were placed on a flat sheet of wood and leveled, the bottom of each column was smooth. Because of the need to repair the top of the UHPC columns, the top surface of each specimen had some slight discontinuity. Two rubber mats were added between the top plate of the press and the test specimen to even out the load applied cancelling out any discontinuity in the surface. Figure 3-10 shows the rubber bearing layer at the top with the column being tested. The steel cylinder wedge between the column and rubber was added to fill a space gap. The space gap provided room to place the specimen and remove it after completion of the test with ease.

The columns were placed in and the test commenced at a loading rate of $0.36 \mathrm{~mm} / \mathrm{min}$. This rate was maintained until post peak failure was confirmed. To ensure a smooth load transfer 
without any jumps, the test continued until $40-50 \%$ of the peak load was reached. The same procedure was followed for the entire specimens, both HSC and UHPC.

\subsubsection{Measurement Instruments}

The instrument setup took two measurements: axial load and mid-height displacement. The hydraulic press measures the load in kilonewtons $(\mathrm{kN})$ while three position transducers with return spring up to $100 \mathrm{~mm}$ were used. Two position transducers were placed horizontally at mid-height, $90^{\circ}$ apart to measure the deformation in two directions. The third one was placed vertically to measure the distance that the column was compressed. In Figure 3-11, the position transducer setup can be seen. The main measurement obtained from this is the maximum mid-height displacement in either direction. From this, information can be obtained on the behaviour of short columns for different concrete strength, confinement, or height. 


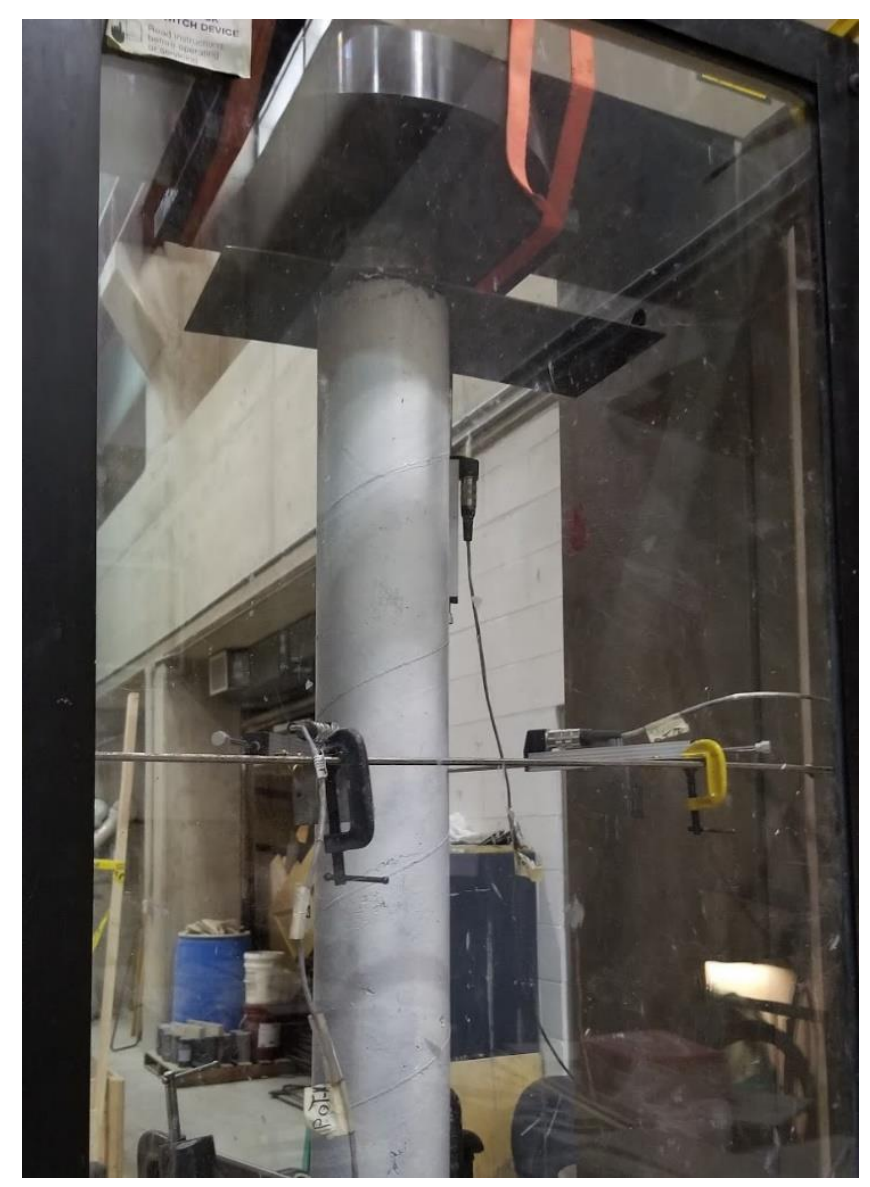

Figure 3-11: Position Transducer Placement During Compressive Testing

The position transducers collected the displacement data and the hydraulic press measured the load. The sampling rate was 5 readings/second $(5 \mathrm{~Hz})$, collecting enough data points to produce a smooth curve. All the data points were graphed in Microsoft Excel and can be found in Appendix A. Figure 3-12 shows the computer set-up that recorded the readings from the test. 


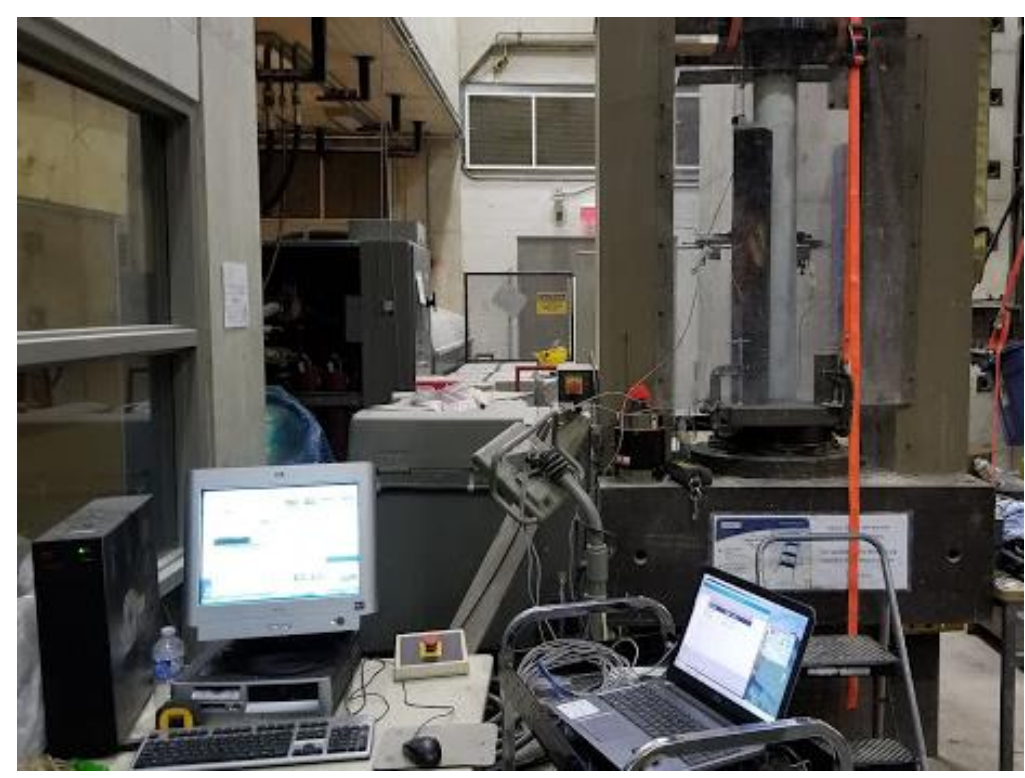

Figure 3-12: Test Set-up Recording the Readings Taken During Testing

\subsection{Test Results}

The data collected from the experiment was extracted into excel, sorted, and graphed. This section will display the main findings of the experiments and a summary of the test results obtained from the specimens. The complete data can be found in graph format in Appendix A.

\subsubsection{Numerical Data}

All six specimens, both the HSC and UHSC columns, were tested over two days. The results were compiled and summarized into Table 3-3. As to be expected, the stronger and confined concrete were able to reach higher peak loads as well as larger deflections after post-peak failure. A small UHPC cylinder was crushed to confirm the compressive strength of the mix. This produced a value of $155.68 \mathrm{kN}$, which is very close to the value of $150.00 \mathrm{kN}$ used in the analytical calculations. 
Table 3-3: Load and Displacement Data from Experimental Results

\begin{tabular}{|c|c|c|c|c|c|c|}
\hline & $\begin{array}{c}\text { HSC-C } \\
\mathbf{6 0 0}\end{array}$ & $\begin{array}{c}\text { HSC-C } \\
\mathbf{1 0 0 0}\end{array}$ & $\begin{array}{c}\text { HSC-U } \\
\mathbf{1 0 0 0}\end{array}$ & $\begin{array}{c}\text { UHPC-C } \\
\mathbf{6 0 0}\end{array}$ & $\begin{array}{c}\text { UHPC -C } \\
\mathbf{1 0 0 0}\end{array}$ & $\begin{array}{c}\text { UHPC -U } \\
\mathbf{1 0 0 0}\end{array}$ \\
\hline $\begin{array}{c}\text { Max. Force } \\
\text { (kN) }\end{array}$ & 2259.03 & 1677.86 & 274.14 & 3412.59 & 3174.61 & 1236.68 \\
\hline $\begin{array}{c}\text { Max. Deflection } \\
(\mathbf{m m})\end{array}$ & 42.69 & 49.99 & 6.27 & 27.38 & 19.85 & 9.82 \\
\hline
\end{tabular}

The columns are relatively small in diameter, and with the steel reinforcement cages there was very little space for the HSC concrete mix to flow well into the form. The HSC had relatively low workability and the gravel had very little space to flow well into the $1000 \mathrm{~mm}$ specimen. This resulted in a void approximately a third of the way down into the column for the HSC-U-1000 specimen. This void caused the steel bars to bend before they yield, providing very inaccurate results for load capacity and deformation. Since the behaviour of HSC columns were already know and this column was used as a reference, the test was not redone.

As expected, the UHPC performed much better than the HSC under concentric loading. The curve shape also differs between the two types of concretes. For the confined HSC, both the $600 \mathrm{~mm}$ and $1000 \mathrm{~mm}$ experienced the same type of gradual increase then a plateau in axial load for some time before declining again. For UHPC, there was an increase with a minor drop then a continuous increase for the axial load. Once the peak is hit, there a short but sudden drop then a gradual decrease before the test was stopped. The axial load vs. time for the $1000 \mathrm{~mm}$ and $600 \mathrm{~mm}$ columns are shown in Figure 3-13 and Figure 3-14 respectively.

For the deformation, it was seen from the test results that the confined specimens were much more ductile. This is due to the steel tube being less rigid than the concrete core resulting in the composite structure to deform more before peak load is reached. 


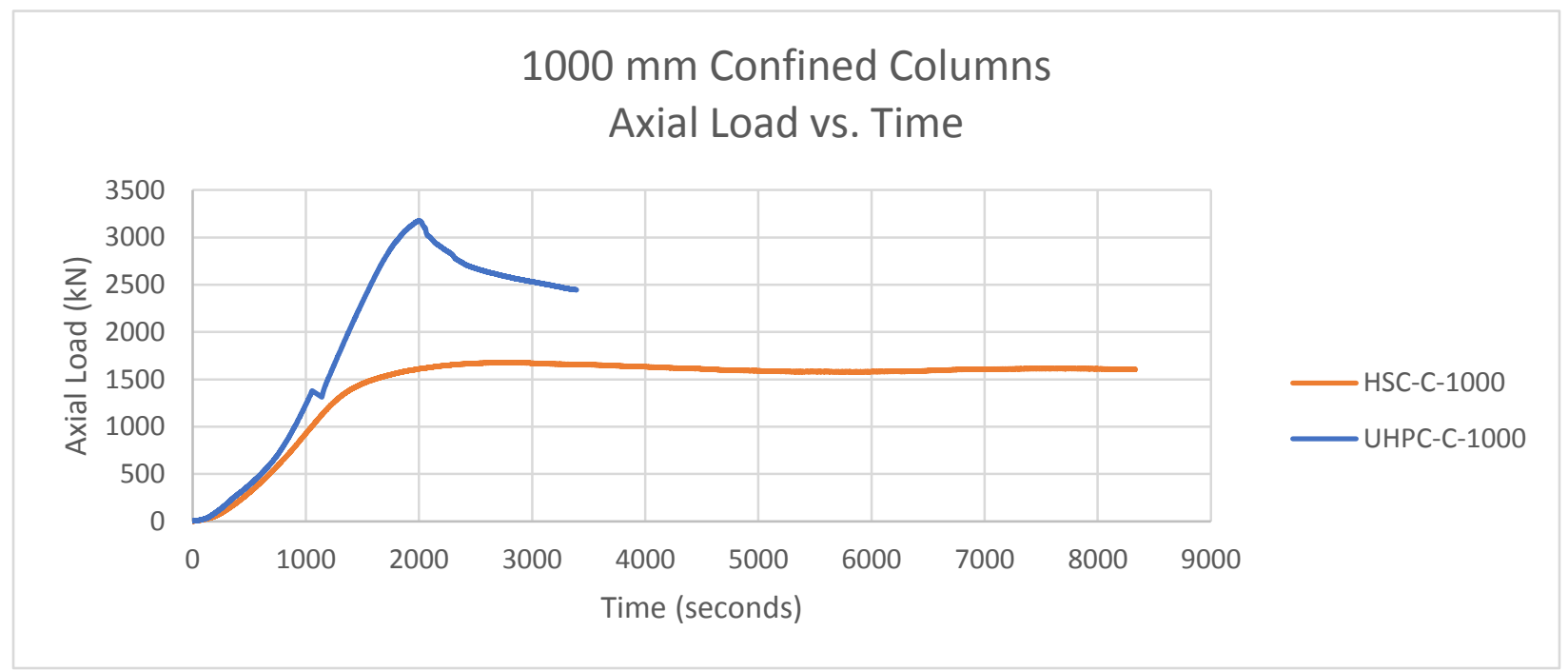

Figure 3-13: Load vs. Time for 1000 mm HSC and UHPC Confined Specimen

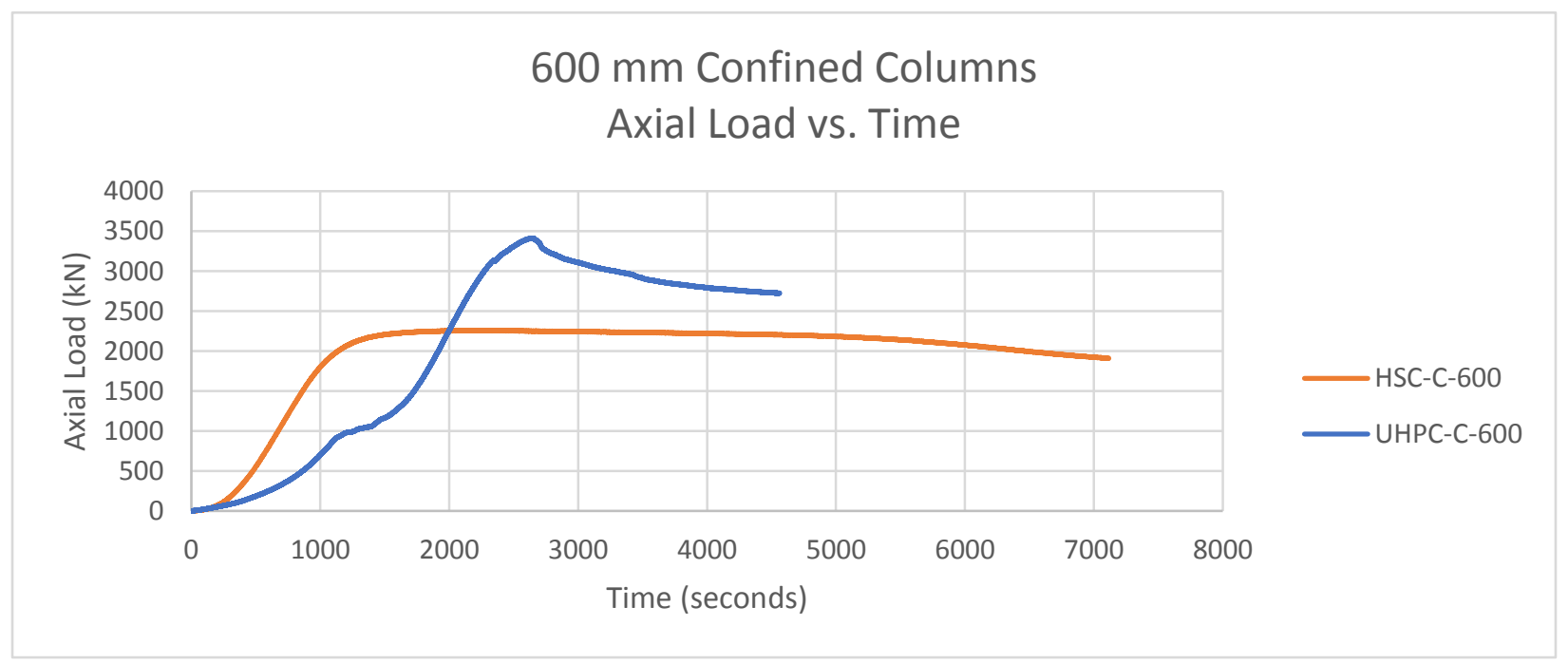

Figure 3-14: Load vs. Time for $600 \mathrm{~mm}$ HSC and UHPC Confined Specimen 


\subsubsection{Failure Modes}

Once each specimen was crushed, its deformation shape was documented to better understand how the different columns deform. The different deformation shapes of all the tested specimen can be seen in Figure 3-15. The confined UHPC has the least visible deformation compared to their HSC column counterparts. The confined HSC can be seen bent about a third of the length from the top where the loading took place. For the unconfined UHPC, there was crushing at the very top which may have resulted in data slightly lower than it should have been. For the HSC-U-1000 column, the void resulted in a small compressive load resistance.

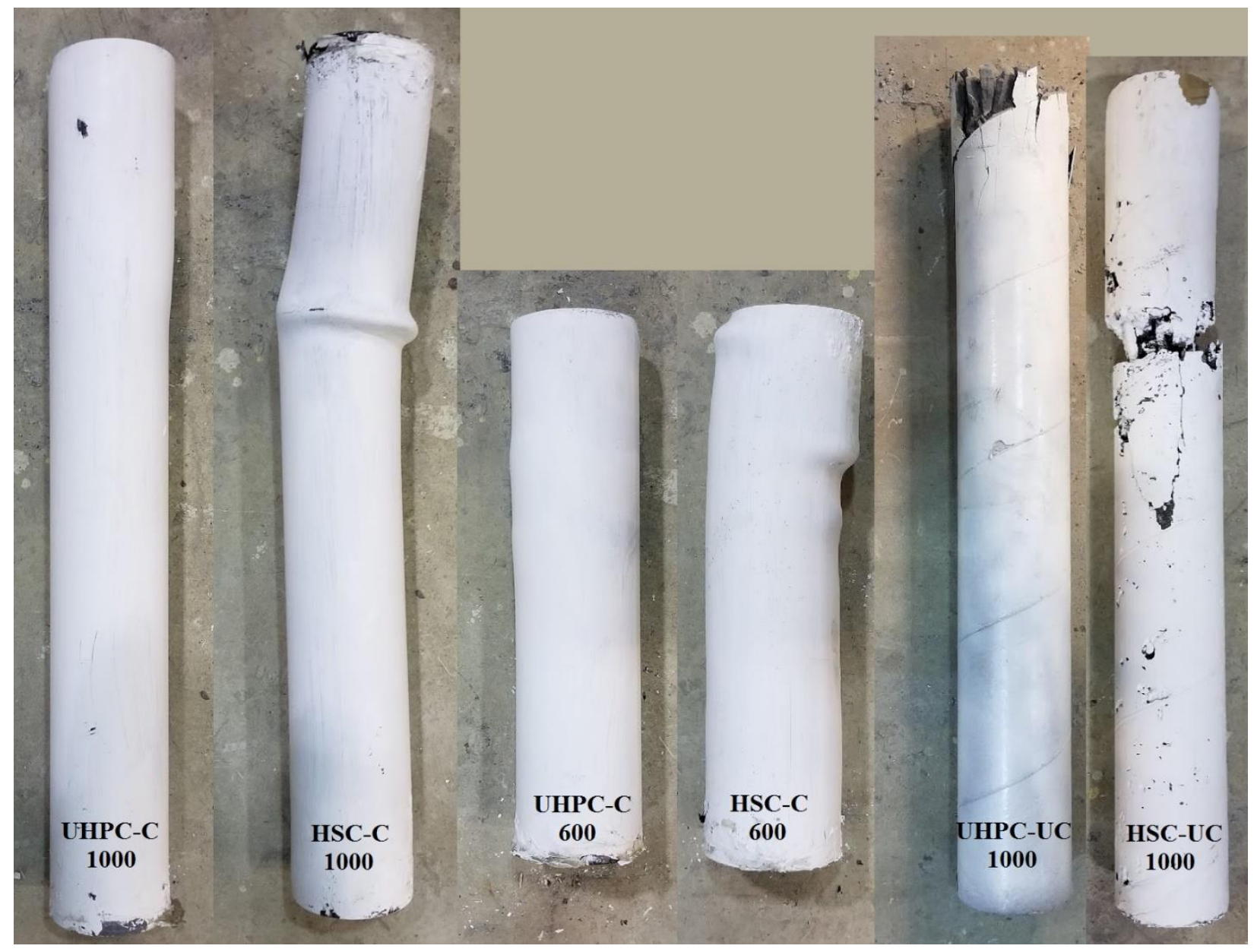

Figure 3-15: Deformation Shapes of All Six Specimen After Testing 


\section{Chapter 4 - Analytical Analysis - Column Interaction Curve}

In this chapter, the interaction curve for the designed cross-section will be developed using two design codes: Canadian code and EC4. Additionally, the compressive strength will be calculated using the ACI in addition to the other two codes and all three will be compared with the experimental results in Chapter 5. This chapter will provide the results, but the step-by-step calculations can be found in Appendix B. The calculations were primarily executed on Microsoft Excel. Each variable used in this chapter is defined in the List of Notations presented at the beginning of the report.

\subsection{Canadian Code Design}

Since the Canadian design code (CSA A23.3-14) does not have a specified method for calculating the load capacity for UHPC or confined columns, the general method for ordinary concrete was used. This method is not an accurate way to predict confined UHPC since the Canadian code is not valid for concrete of strengths at that level. For this report, the methods in the code will be used as is and compared to other codes, such as the Eurocode 4 which has more established design methods.

\subsubsection{Column Interaction Curve}

The column interaction curve for the UHPC confined cross-section was calculated using the CSA A23.3-14 the design equations. The section was divided up into compression and tension regions based on Brzev and Pao (4). To form the column curve, a few key points are found then joint together and graphed. The three main points are pure axial forces, balanced moment resistance, and pure bending/pure tension. Two additional points are found to add to the accuracy of the curve. One of these points is calculated prior to the steel yielding (before balanced moment) and another after the steel has yielded (after balanced moment). The point of pure tension was 
calculated and connected to the post steel yielding point. The value where the line intersects with the $\mathrm{x}$-axis represents the point of pure bending. This section will show the results and the interaction curve. The final column interaction curve using the Canadian design code and equations is shown in Figure 4-1.

\subsubsection{Pure Axial Load}

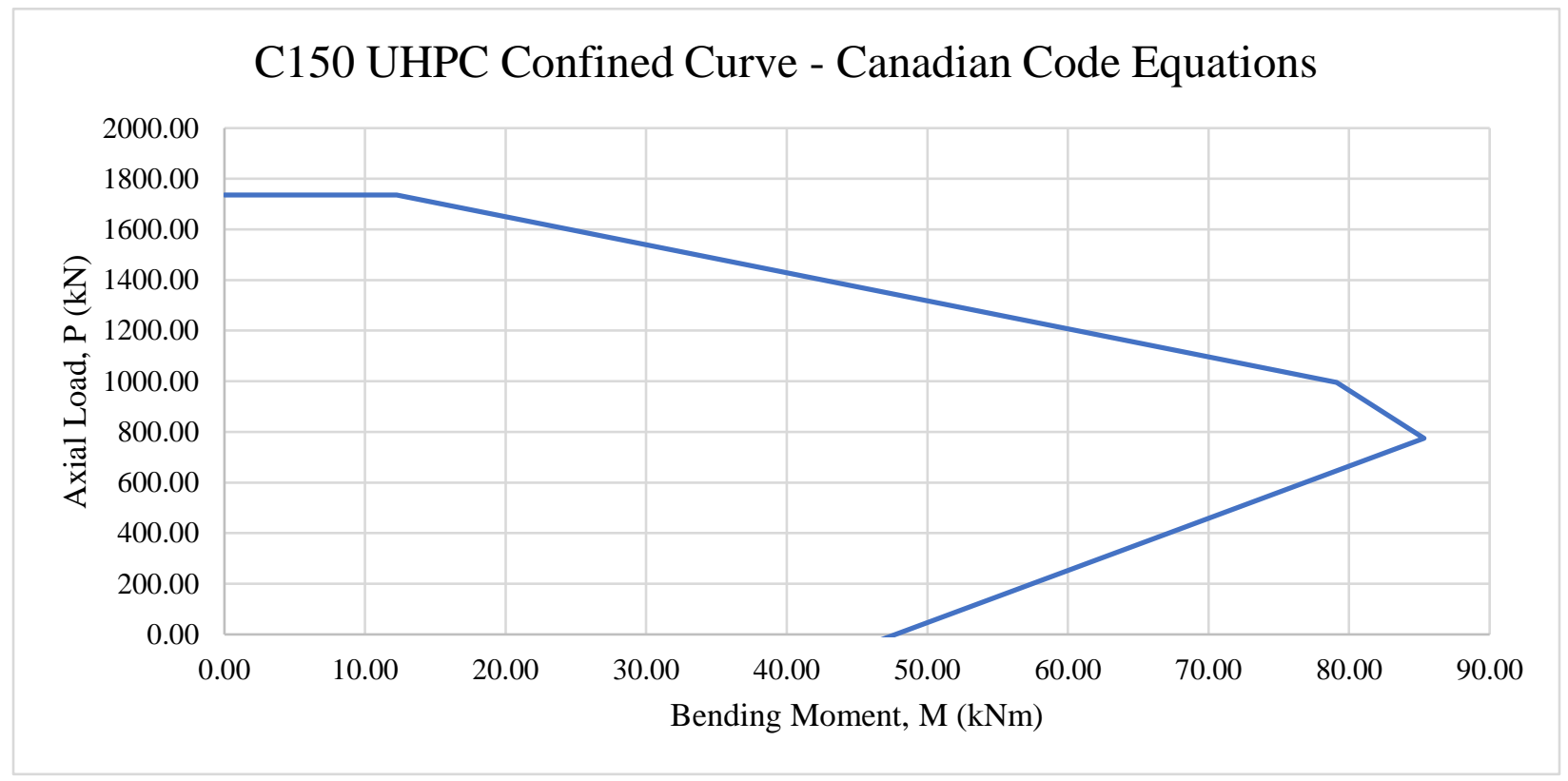

Figure 4-1: Column Interaction Diagram for UHPC Confined Cross-Section Using the Canadian Code Equations

The following equation from the Canadian design code was used to calculate the pure axial load of the column (4):

$$
P_{\text {ro }}=\alpha_{1} \emptyset_{c} f_{c}^{\prime}\left(A_{g}-A_{s t}\right)+\emptyset_{s} f_{y} A_{s}+\emptyset_{s} f_{y} A_{a}
$$

Once all the variables are plugged in, the axial load capacity is obtained as $P_{r o}=2169.81 \mathrm{kN}$. This value is then reduced by $20 \%$ to account for a safer design approach. Equation (4.2) is based on the column being circular (30).

$$
P_{\text {rmax }}=0.8 P_{\text {ro }}
$$

The maximum compressive value that is used as the first point on the interaction diagram then is $P_{\text {max }}=1735.85 \mathrm{kN}$. 
In the field, there is always a small eccentricity involved with any installation of columns. To be more conservative, a minimum eccentricity is applied. This eccentricity has the value of 5\% of the diameter of the column section. This moves the pure axial resistance of the column to have a bending moment resistance of $12.26 \mathrm{kNm}$ with an eccentricity of $7.07 \mathrm{~mm}$.

\subsubsection{Balanced Load}

The balanced load occurs at the point of the steel yielding. This is calculated by finding the depth of the neutral axis at the yield point of both the steel and the concrete, then summing the forces using around the center. The neutral axis depth, $c_{b}$, is found by using the following equation (4):

$$
\begin{gathered}
c_{b}=\frac{\varepsilon_{c}}{\varepsilon_{y}+\varepsilon_{c}} \times d_{2} \\
a=\beta_{1} c_{b}
\end{gathered}
$$

Using equation (4.3), the neutral axis depth is $70.16 \mathrm{~mm}$. The depth of the compression zone, $a$, is found by using equation (4.4) with $\beta_{1}=0.9$ as a general design practice. The value of $a$ is found to be $63.14 \mathrm{~mm}$. From this, the forces can be found and summed to find the forces. The forces were divided for each component of the cross-section and the multiplied by their respective center of gravity. The cross-section was drawn to scale on AutoCAD and the MASSPROP command was used to find the center of gravity and the area of each material on the corresponding side of the neutral axis. Only the area of the sections within the compression depth section, $a$, were used to find the stresses that are in compression. The depth value of $c_{b}$ was used to find the tension members within the compression zone. Figure 4-2 is the cross-section at the point of balance load as drawn on AutoCAD. 


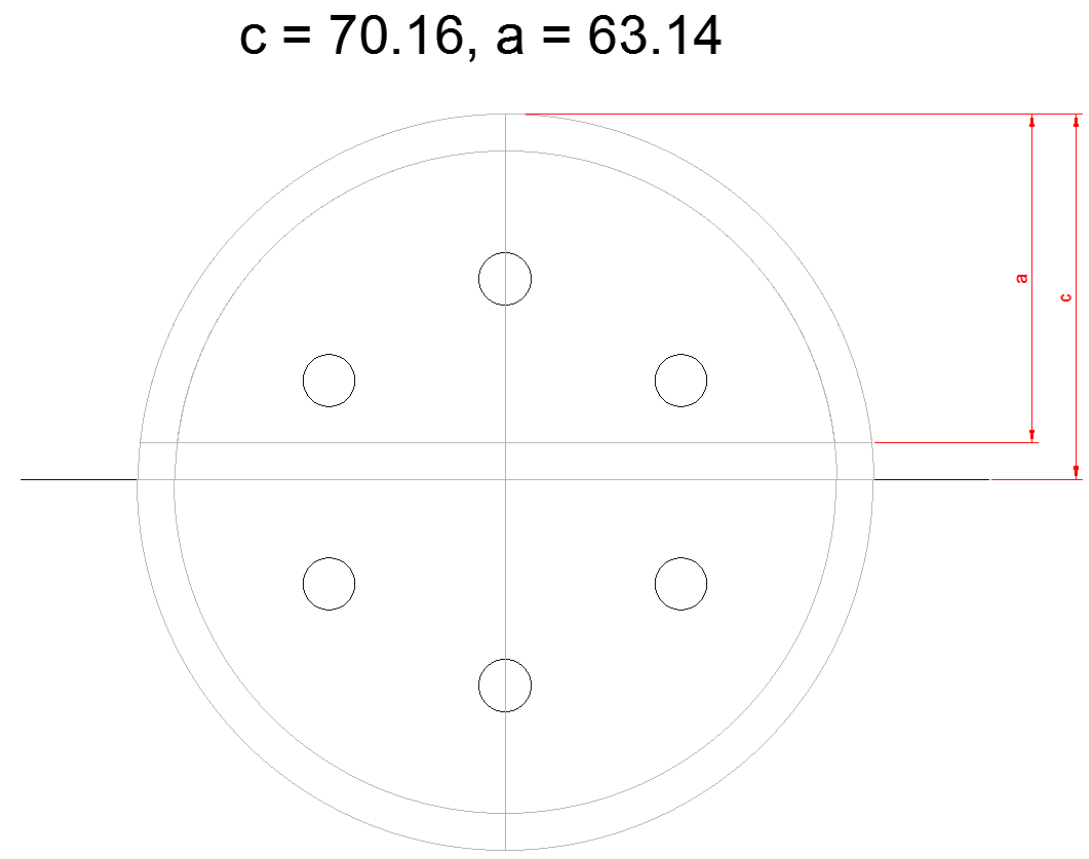

Figure 4-2: Neutral Axis and Compression Depth of Cross-Section Under Balanced Conditions

The following equations were used to acquire the forces used to find the stresses for each material (4):

Compression region:

$$
\begin{gathered}
C_{r}=C_{c}+C_{\text {sbar }}+C_{\text {stube }} \\
C_{c}=\alpha_{1} \emptyset_{c} f_{c}^{\prime}\left(A_{g}-A_{s}\right) \\
C_{\text {sbar }}=\emptyset_{s} f_{y} A_{s} \\
C_{\text {stube }}=\emptyset_{s} f_{y} A_{a}
\end{gathered}
$$

Tension in compression region:

$$
\begin{gathered}
F_{r s 1}=T_{s 1 \text { bar }}+T_{s 1 \text { tube }} \\
T_{s 1 \text { bar }}=\emptyset_{s} f_{y} A_{s 1} \\
T_{s 1 \text { tube }}=\emptyset_{s} f_{y} A_{a 1}
\end{gathered}
$$


Tension region:

$$
\begin{gathered}
F_{r s 2}=T_{s 2 b a r}+T_{s 2 t u b e} \\
T_{s 2 b a r}=\emptyset_{s} f_{y} A_{s 2} \\
T_{s 2 \text { tube }}=\emptyset_{s} f_{y} A_{a 2}
\end{gathered}
$$

Once all the known values are inputted in the equations above, the forces are summed up as positive value in compression region and negative in the tension region. This results in the axial force in balanced conditions, $P_{r b}=775.47 \mathrm{kN}$.

The next step is to find the bending moment resistance at balance, $M_{r b}$. From the AutoCAD drawing above, all the center of gravity of each corresponding force was found. The $c_{g}$ of each force was multiplied but the stress, all the stresses were summed up and divided by $P_{r b}$. This provides the eccentricity at balance, $e_{b}$, which is then multiplied by $P_{r b}$ to obtain the bending moment resistance at balance, $M_{r b}=85.33 \mathrm{kNm}$. The axial load capacity and the bending moment resistance at balance are used to plot the next point on the interaction diagram.

\subsubsection{Pre/Post Balanced Load}

Once the balanced load is found, a point before the steel has yielded and one after the fact are found to provide more details to the curve. One point was found prior to and another post yielding to help shape the curve. These two points are found by changing the yield strain, $\varepsilon_{y}$, and recalculating the neutral axis depth. To refrain from unnecessary complications, the compression zone was slightly adjusted to ensure that it is not placed in the center of any longitudinal reinforcement bars but rather right on the edge. The neutral axis depth and the compression depth were recalculated using the new yield strain values using equations (4.3) and (4.4) respectively. 
Prior steel yielding, $\varepsilon_{y}=0.001$ :

This point on the graph is calculated in the same method as the point of balance, but with a different neutral axis and compression depth found using equations (4.3) and (4.4). The new values for the neutral axis and compression depth are $c=85.15 \mathrm{~mm}$ and a $=76.64 \mathrm{~mm}$ respectively. Figure 4-3 shows the new parameters used to calculate the center of gravity for the different tension and compression regions. The compression and tension stresses were calculated using equations (4.5) through (4.14).

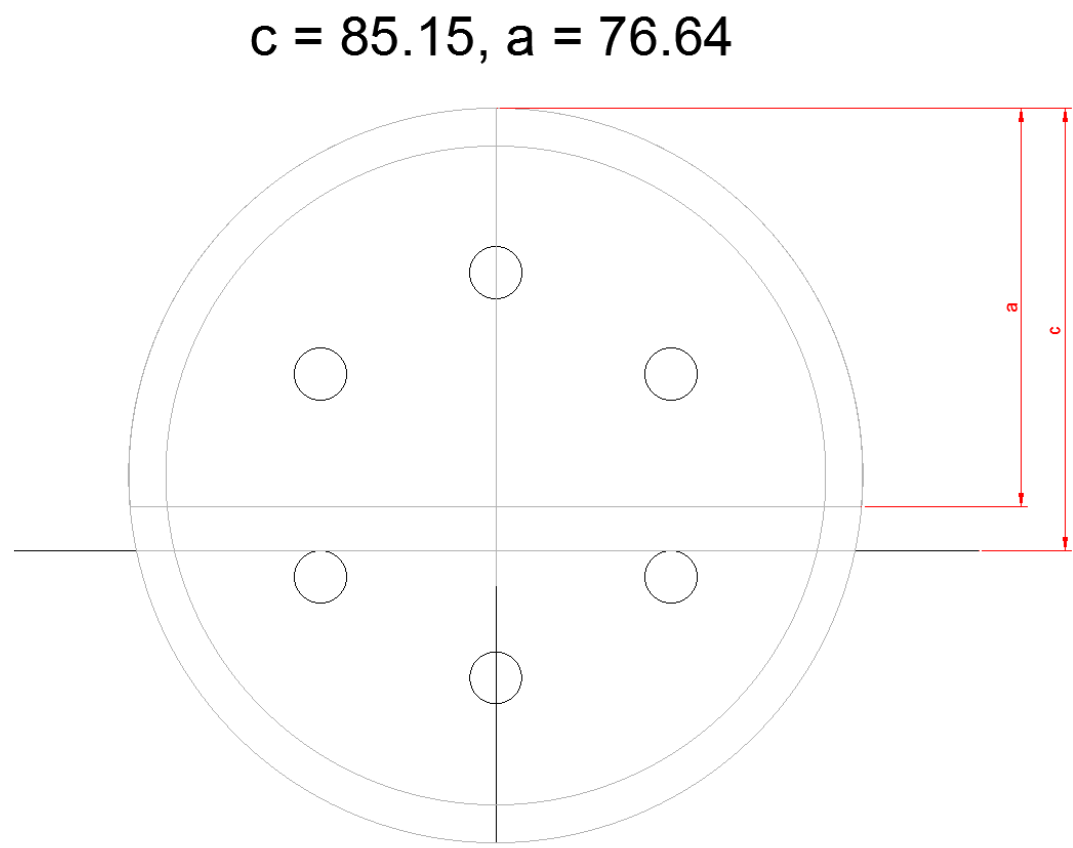

Figure 4-3:Neutral Axis and Compression Depth of Cross-Section Prior to the Steel Yielding

With the new value, a new axial load capacity and bending moment resistance are found to be $P_{r}=995.54 \mathrm{kN}$ and $M_{r}=79.11 \mathrm{kNm}$, with an eccentricity of $e=79.47 \mathrm{~mm}$. This point is then plotted along with the other points forming the column interaction diagram. 
Post steel yielding, $\varepsilon_{y}=0.004$ :

The post steel yielding point is found after the reinforcement has yielded but the column is still undertaking the force, which results in loss of bending moment resistance capacity. Using equations (4.3) and (4.4), a new neutral axis and compression depth are found to be $c=62.39 \mathrm{~mm}$ and $\mathrm{a}=56.15 \mathrm{~mm}$ respectively.

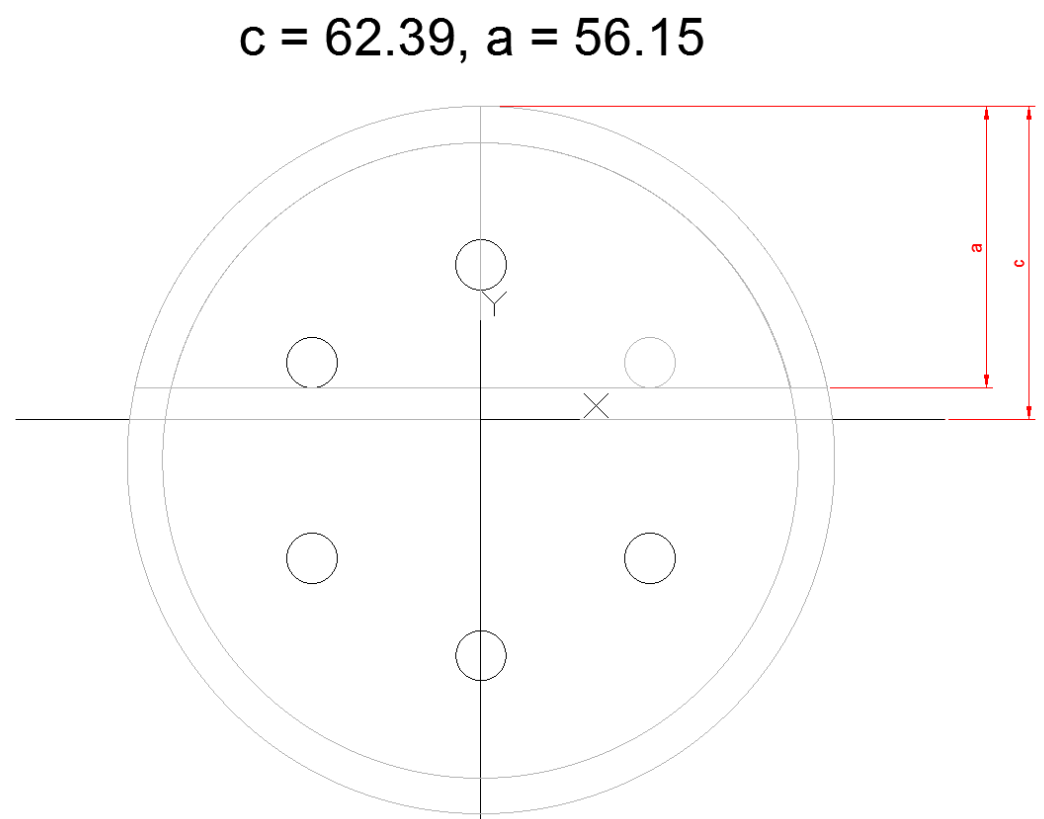

Figure 4-4:Neutral Axis and Compression Depth of Cross-Section Post Steel Yielding

The new neutral axis is shown in Figure 4-4 and the new $c_{g}$ of each force was calculated using AutoCAD. Equations (4.5) through (4.14) were used to find the corresponding compression and tension stresses for the post steel yield neutral axis. The axial load capacity and bending moment resistance were found to be $P_{r}=415.47 \mathrm{kN}$ and $M_{r}=67.96 \mathrm{kNm}$ with a respective eccentricity of $e=163.57 \mathrm{~mm}$. 


\subsubsection{Pure Tension}

The value of the column under pure tension was calculated as a simple method to find the point of pure bending ( $\mathrm{x}$-axis intercept). The following list of equations was used to find the column axial capacity under pure tension (4):

$$
\begin{gathered}
F_{r s}=T_{\text {sbar }}+T_{\text {stube }} \\
T_{\text {sbar }}=\emptyset_{s} f_{y} A_{s} \\
T_{\text {stube }}=\emptyset_{s} f_{y} A_{a}
\end{gathered}
$$

After plugging the known values in, the tension capacity of the cross section was found to be $F_{r s}=-982.83 k N$. This point is not shown in Figure 4-1 but it is connected to the post steel yielding one. the pure bending moment capacity of the column is found to be $M_{r}=47.77 \mathrm{kNm}$ by using the method of calculating pure tension.

This final point is added to the interaction diagram which completes the curve for the crosssection being studied using Canadian code design methods and equations. All the points plotted for the column interaction curve for Figure 4-1 are summarized in Table 4-1.

Table 4-1: Canadian Design Code Data Points to be Plotted for Interaction Curve

\begin{tabular}{|l|c|c|}
\hline & Pr $(\mathbf{k N})$ & $\mathbf{M r}(\mathbf{k N m})$ \\
\hline Pure Axial & 2169.81 & 0.00 \\
\hline Pure Axial (max) & 1735.85 & 0.00 \\
\hline Min. e (5\% d) & 1735.85 & 12.26 \\
\hline Pre steel yield & 995.54 & 79.11 \\
\hline Balanced & 775.47 & 85.33 \\
\hline Post steel yield & 415.47 & 67.96 \\
\hline Pure Bending & 0.00 & 47.77 \\
\hline Pure Tension & -982.83 & 0.00 \\
\hline
\end{tabular}




\subsection{EC4 Design (Simplified Method)}

The Eurocode 4 design methods are much more versed in the design of strengths as high as those of UHPC as well as steel confined concrete sections. The simplified method of forming a column interaction curve was used to later be compared to the results of the CSA A23.3-14 design equations. J. Y. Richard Liew and M.X. Xiong (31) have done a lot of research in this field and the simplified method of the EC4 used for this project was taken out of a research publication they have done. The rest of the procedure followed in this report was taken from a presentation conducted by Dr. Gerhard Hanswille from the University of Wuppertal, Germany (2) on composite column design through EC4.

\subsubsection{Column Interaction Curve}

This section will show the procedure followed and equations used to form the column interaction curve in Figure 4-5. Four main points were calculated and graphed for the final product. The details and the step-by-step calculations can be found in Appendix B.

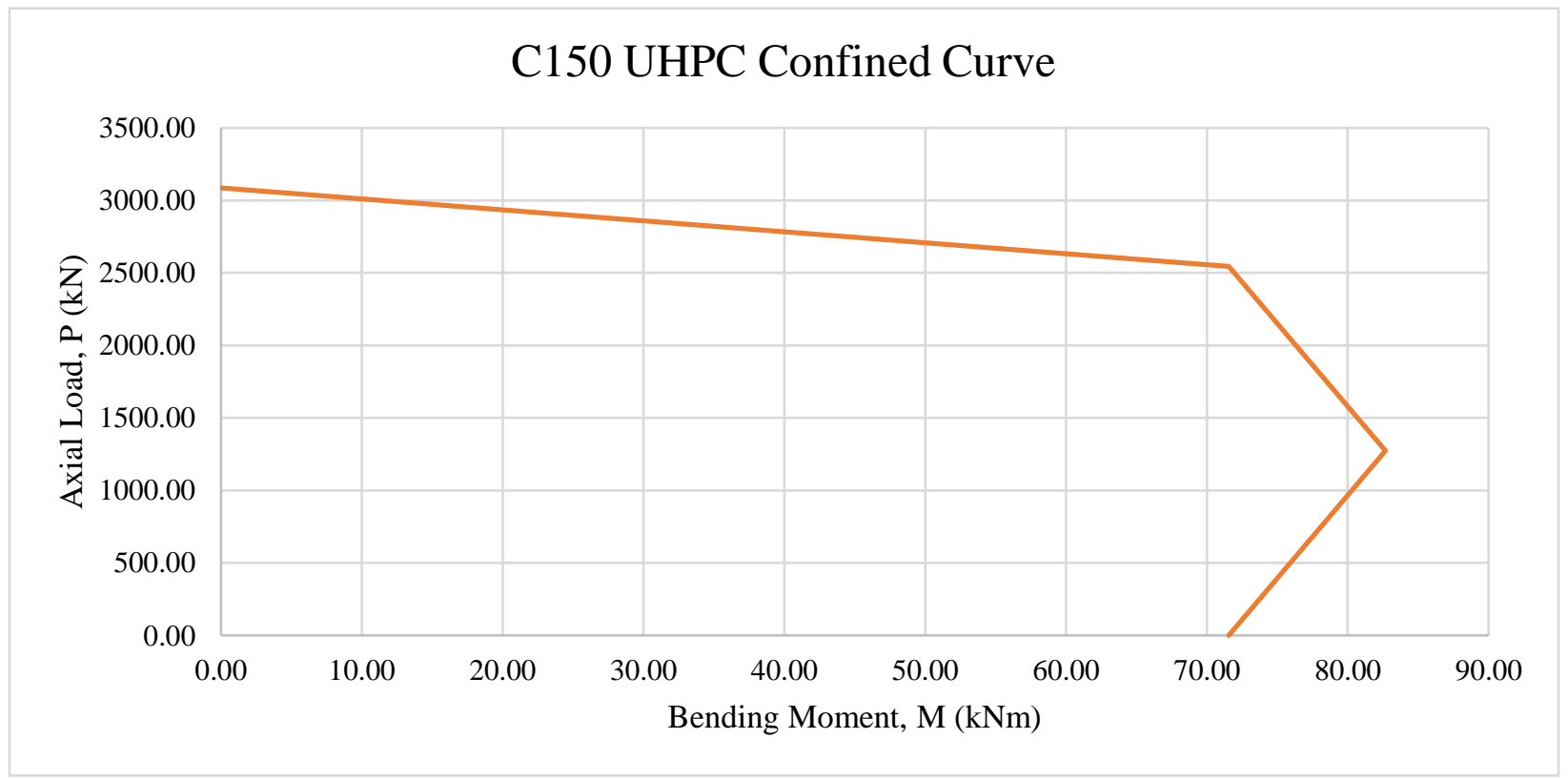

Figure 4-5: UHPC Confined Column Interaction Curve Using EC4 Simplified Method 
The four points gathered to form the column interaction diagram are A, B, C, and D and show in Figure 4-6.

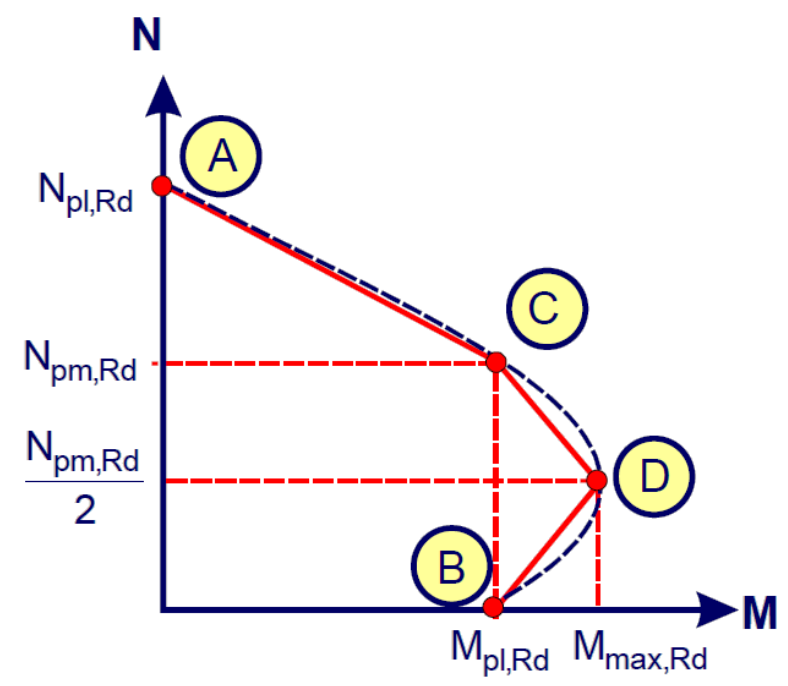

Figure 4-6: Four Points Used to Form Column Interaction Diagram - EC4 (2)

\subsubsection{Pure Axial Load (Point A)}

The pure axial load was the first point found in plotting Figure 4-6. The following equation was used to calculate the axial compression capacity that considers confinement effects (31):

$$
N_{p l, R d}=\eta_{a} A_{a} f_{y d}+A_{c} f_{c d}\left(1+\eta_{c} \frac{t_{t u b e}}{d} \frac{f_{y}}{f_{c d}}\right)+A_{s} f_{s d}
$$

With all the parameters plugged in, the values found are $N_{p l, R d}=3085.88 k N$ and $M_{p l, R d}=0 \mathrm{kNm}$. This is the first value plotted on the interaction curve. The slenderness and eccentricity factors, $\eta_{a}$ and $\eta_{c}$, were used in a simplified fashion. This assumes the column is stocky and centrically loaded, which was acceptable in this experiment since the specimen were relatively short and conducted in a controlled lab environment. The values for these factors were taken as $\eta_{a}=0.25$ and $\eta_{c}=4.9$ (2). The strength of concrete was reduced a factor of $\eta=0.8$ since its strength was greater than $90 \mathrm{MPa}$ (31). 


\subsubsection{Pure Bending (Point B)}

Finding the depth of the natural axis is the first step to calculate the pure bending load using the following equation (31):

$$
h_{n}=\frac{A_{c} f_{c d}}{2 d f_{c d}+4 t_{\text {tube }}\left(2 f_{y d}-f_{c d}\right)+4 t_{s}\left(2 f_{s d}-f_{c d}\right)}
$$

The next set of equations is used to calculate the bending moment by using plastic sections modulus of steel tube, reinforcement, and concrete. The following set of equations was used for inf these values (31):

$$
\begin{gathered}
W_{p c}=\frac{\left(d-2 t_{\text {tube }}\right)^{3}}{6} \\
W_{p c, n}=\left(d-2 t_{\text {tube }}\right) h_{n}^{2} \\
W_{p a}=\frac{d^{3}}{6}-W_{p c} \\
W_{p a, n}=d h_{n}^{2}-W_{p c, n} \\
W_{p s}=\frac{\left(D_{s}{ }^{3}-\left(D_{s}-2 t_{s}\right)^{3}\right)}{6} \\
W_{p s, n}=2 t_{s} h_{n}^{2}
\end{gathered}
$$

The values of $t_{s}$ and $D_{s}$ represent the longitudinal reinforcement bars as an equivalent tube and are calculated using the following equations (31):

$$
\begin{gathered}
t_{s}=\frac{A_{s}}{\pi(d-2 \times \text { Cover })} \\
D_{s}=d-(2 \times \text { Cover })+t_{s}
\end{gathered}
$$

Once all the values from equations (4.20) through (4.25) are obtained, they are plugged into equation (4.28) to find the pure bending moment value of $M_{p l, R d}=71.57 \mathrm{kNm}$ (31). 


$$
M_{p l, R d}=\left(W_{p a}-W_{p a, n}\right) f_{y d}+\left(W_{p s}-W_{p s, n}\right) f_{s d}+0.5\left(W_{p c}-W_{p c, n}\right) f_{c d}
$$

\subsubsection{Prior to Steel Yield (Point C)}

To find the axial capacity of the point prior to balance load, the following equation was used (31):

$$
N_{p m, R d}=A_{c} f_{c d}\left(1+\eta_{c} \frac{t}{d} \frac{f_{y}}{f_{c d}}\right)
$$

The value obtained from equation (4.29) is $N_{p m, R d}=2544.55 \mathrm{kN}$. The corresponding moment value to this point is taken as the same moment as Point B with a value of $M_{p l, R d}=$ $71.57 \mathrm{kNm}$.

\subsubsection{Balanced Load (Point D)}

The axial capacity of Point D is found by taking half the value of that found in Point $C$ (2). This provides an axial capacity of $N_{D R}=1272.27 \mathrm{kN}$. For the bending moment capacity for the point of balance, equation (4.30) was used (31). The moment at Point D is $M_{p l, R d}=82.68 \mathrm{kNm}$.

$$
M_{p l, R d}=\left(W_{p a}\right) f_{y d}+\left(W_{p s}\right) f_{s d}+0.5\left(W_{p c}\right) f_{c d}
$$


Table 4-2: EC4 Code Method Data to Plot Column Interaction Diagram

\begin{tabular}{|l|c|c|}
\hline & $\begin{array}{c}\mathbf{N}_{\mathbf{p l}, \mathbf{R d}} \\
(\mathbf{k N})\end{array}$ & $\begin{array}{c}\mathbf{M}_{\mathbf{p l}, \mathbf{R d}} \\
(\mathbf{k N m})\end{array}$ \\
\hline A - Pure Axial & 3085.88 & 0.00 \\
\hline C - Prior to Steel Yielding & 2544.55 & 71.57 \\
\hline D - Balanced & 1272.27 & 82.68 \\
\hline C - Pure Bending & 0.00 & 71.57 \\
\hline
\end{tabular}

Table 4-2 summarizes the data for Points A, B, C, and D for the axial load and the bending moment resistance capacity of the cross-section using EC4 simplified method. The data is used to plot the interaction diagram in Figure 4-5. 


\subsection{ACI Code (ACI 318-14)}

For the ACI code, only the compressive strength was calculated and compared to both the Canadian and the EC4 codes. The ACI design code is very similar to the Canadian code in the sense that neither have previsions for confined concrete or UHPC strength consideration. Simply, only the compressive strength of the cross-section was calculated using the ACI design practices to add an additional value that can be compared to the Canadian and EC4 codes, as well as the experimental data.

\subsubsection{Axial Compression Calculation}

The process for calculating the axial compression capacity of the column was taken from lecture notes at the University of Memphis. The procedure is very similar to the CSA A23.3-14 equations and therefore the results are also similar. The difference with the ACI and Canadian code design methods are that the Canadian code has different reduction values for concrete and steel. The ACI 318-14 applies one reduction factor, $\varnothing$, for both materials. Since the transvers reinforcements for the columns in this project are tied, the reduction factor is taken as $\varnothing=0.65$ (3). The equations below were used to find the capacity values of the column (3):

$$
\begin{gathered}
P_{r o}=\varnothing\left[\alpha_{1} f_{c}^{\prime}\left(A_{g}-A_{s}\right)+f_{y} A_{s}+f_{y} A_{a}\right] \\
P_{r \max }=0.8 P_{r o}
\end{gathered}
$$

Using equations (4.31) and (4.32), the maximum value of axial compressive deign capacity is $P_{\text {rmax }}=1551.66 \mathrm{kN}$. This value is to be compared to the ones obtain from CSA A23.3-14, EC4 methods, and the experimental lab data. 


\section{Chapter 5 - Discussion and Conclusion}

\subsection{Compiling the Results}

With all the experimental data and analytical calculations complete, the different methods and procedures can be compared. The pure axial capacity of the column cross-section was calculated using the following design codes: Canadian code, ACI, and EC4. The test results for every $1000 \mathrm{~mm}$ specimen was compared to the results found using the codes mentioned. A summary of all the values is listed in Table 5-1. The column interaction curves formed using the Canadian and EC4 codes, with the experimental value, are plotted in Figure 5-1 for comparison.

Table 5-1: Pure Axial Capacity Comparison for All Specimen Tested

\begin{tabular}{|l|c|c|c|c|}
\hline \multirow{2}{*}{} & \multicolumn{4}{|c|}{ Pure Axial Capacity (kN) } \\
\cline { 2 - 5 } & CSA A23.3-14 & ACI 318-14 & EC4 & Test \\
\hline HSC Unconfined & 615.01 & 604.85 & - & 274.14 \\
\hline HSC Confined & 1434.64 & 1231.63 & 2506.63 & 1677.86 \\
\hline UHPC Unconfined & 916.22 & 924.89 & - & 1236.68 \\
\hline UHPC Confined & 1735.85 & 1551.66 & 3085.88 & 3174.61 \\
\hline
\end{tabular}

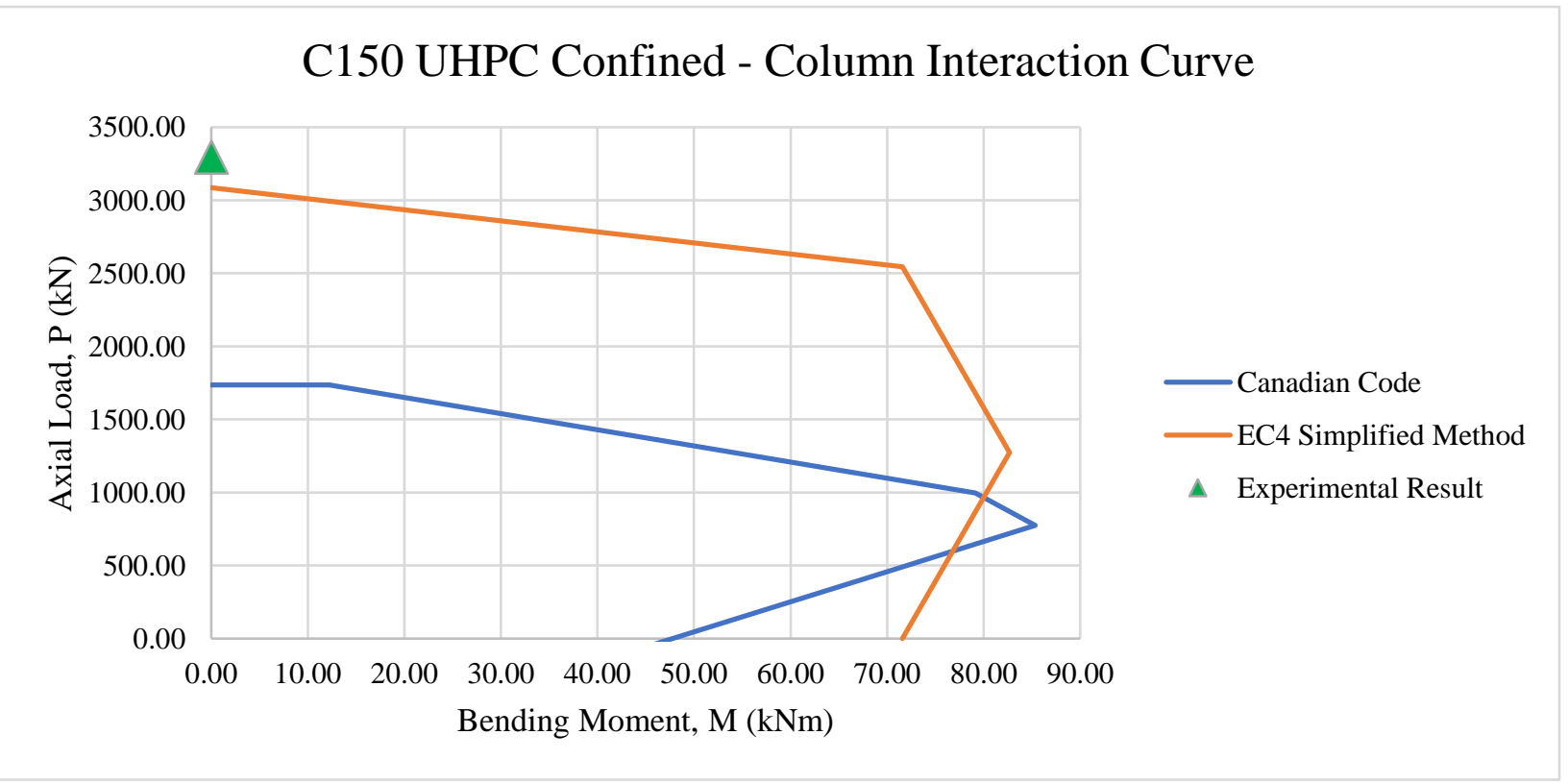

Figure 5-1: UHPC Interaction Curve - Canadian Code, EC4, and Experimental Data 


\subsection{Findings}

The findings from this research were rather consistent with many of the conclusions discussed in previous studies. The UHPC confined specimen produced the largest axial load resisting capacity. As predicted, the confined specimen for both HSC and UHPC preformed better than their unconfined respective counterparts. The steel tube added strength and ductility to the concrete member. Similar conclusions were found by Le and Fehling (10) in Germany; confined steel tubes improve the performance of UHPC columns. This additional strength resulted with the confined columns being more ductile and simultaneously achieving a higher axial load capacity. Le and Fehling (10) also found that the addition of steel fibers improved the shear resistance in the concrete and minimizing the deformation. This experiment showed similar results since the UHPC columns had deformed less than their HSC counterparts as shown in Figure 3-15 from Chapter 3.

The UHPC-U-1000 specimen experienced early cracking at loading surface, causing a slightly lower capacity than previously expected. The data gathered from the test specimen was sufficient, and therefore the results were used as is. The $600 \mathrm{~mm}$ columns were able to reach a higher compressive capacity than the $1000 \mathrm{~mm}$ columns. This difference is because of a lower slenderness ratio; more likely to fail under crushing rather than buckling.

The interaction curves in Figure 5-1 shows that the CSA A23.3-14 and EC4 equations do not produce the same curve, although it is analysing the same column. The experimental data for UHPC-C-1000 specimen was also plotted with theoretical axial load calculations. The EC4 simplified method produced a curve with a much higher axial load capacity and bending moment resistance. Additionally, the EC4 simplified method demonstrated the most accurate results compared to the test specimen. Liew et al. (1) concluded that the EC4 methods are safe to use for confined UHPC and the findings in this report concur with that. 
The main reason the Canadian code did not accurately predict the column capacity is that it is not yet validated for concrete strengths as high as $150 \mathrm{MPa}$. Furthermore, they do not consider the effects of confinement at all. This report used a concrete strain value of 0.0035 , which is the current value used for HSC while a value of 0.0030 is used for NSC. Using UHPC in design would require a higher strain value to accommodate its strength. The Canadian code design methods underestimate the strength of UHPC composite columns by nearly $50 \%$ in some cases, which could result in overdesigning sections. Revising the Canadian design code to include UHPC and CFST would bring this new material to be used in future high rise designs.

Research by Shin et al. (22) suggests a similar concrete strain value as Ductal ${ }^{\circledR}$ (6) and Yazdizadeh (7) when using UHPC compared to NSC or HSC. As shown in Figure 5-2, UHPC requires a larger initial strain value assumption than $0.35 \%$. Using a strain value of $0.40 \%$ for UHPC cross-section should yield more accurate results for compression capacity of the member. The same strain value conclusion is further verified by Ridha (11) who also suggests a $0.4 \%$ strain value for fiber reinforced UHPC.

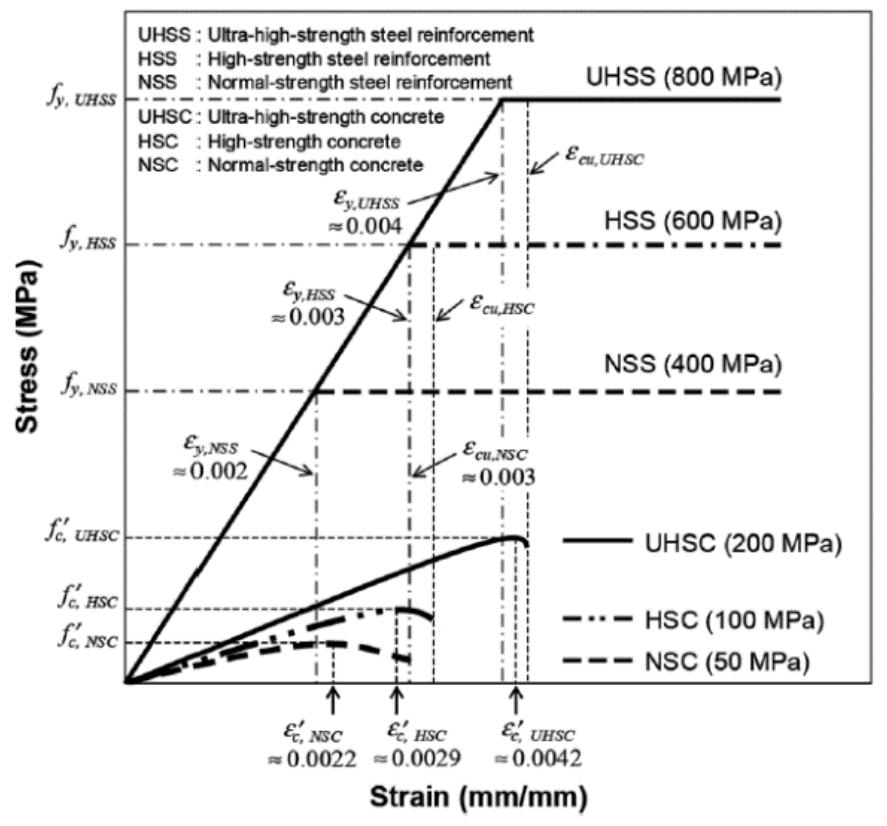

Figure 5-2: Stress-Strain Curve for Differing Concrete Strengths (22) 
Researchers at the University of Technology, Australia (11) concluded that the amount of fibers or number of lateral reinforcements was insignificant to the column's load bearing capacity. Because of this, those two parameters were constant for all the specimens.

\subsection{Conclusion and Future Research}

In conclusion, the Canadian design code cannot be used for UHPC columns, in either the confined or unconfined cases, without any modifications. Using a higher value for the concrete strain would produce more accurate load capacity values in future research. A value of $0.4 \%$ for strain should yield more accurately results in future UHPC design. Another factor that can be increased to improve the results is $\emptyset_{c}$, the resistance factor for concrete. Rather than using a value of 0.65 , it could be increased to 0.8 for cases when UHPC is used.

Future research on this topic should use a larger number of specimens. It is difficult to validate the results if only one column for each length and confined/unconfined. With more data, it would be easier to rule out any unpredictable issues during testing, such as early cracking. Lastly, adding a factor to account for confinement would also help accurately estimate the effect of CFST.

UHPC has the ability to improve structural design of high-rise buildings with efficient and economical systems such as the 'super frame'. In the foreseeable future, buildings implementing CFST columns with UHPC will be able to redefine the limit for tall buildings. 


\section{Appendix A: Experimental Results}



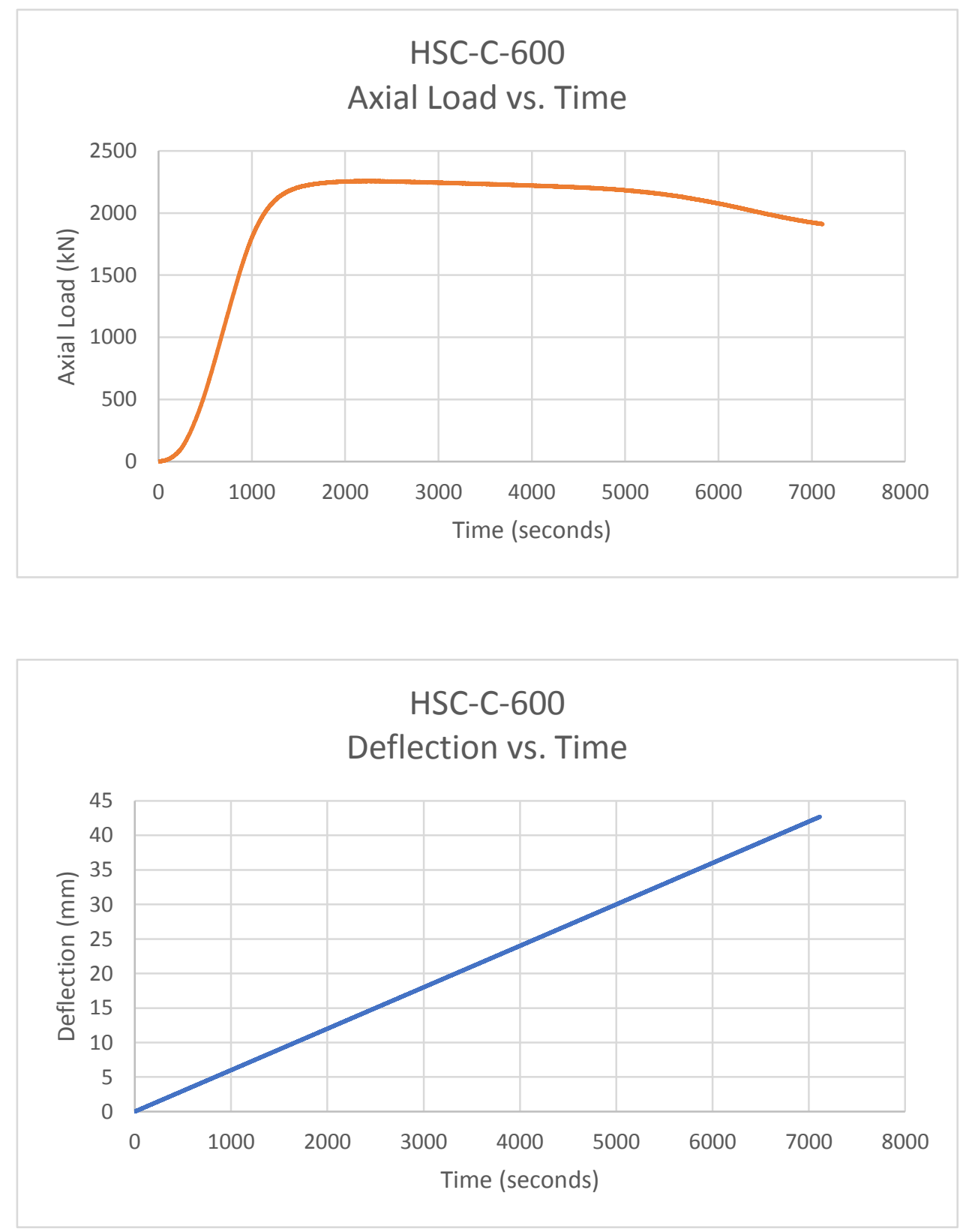

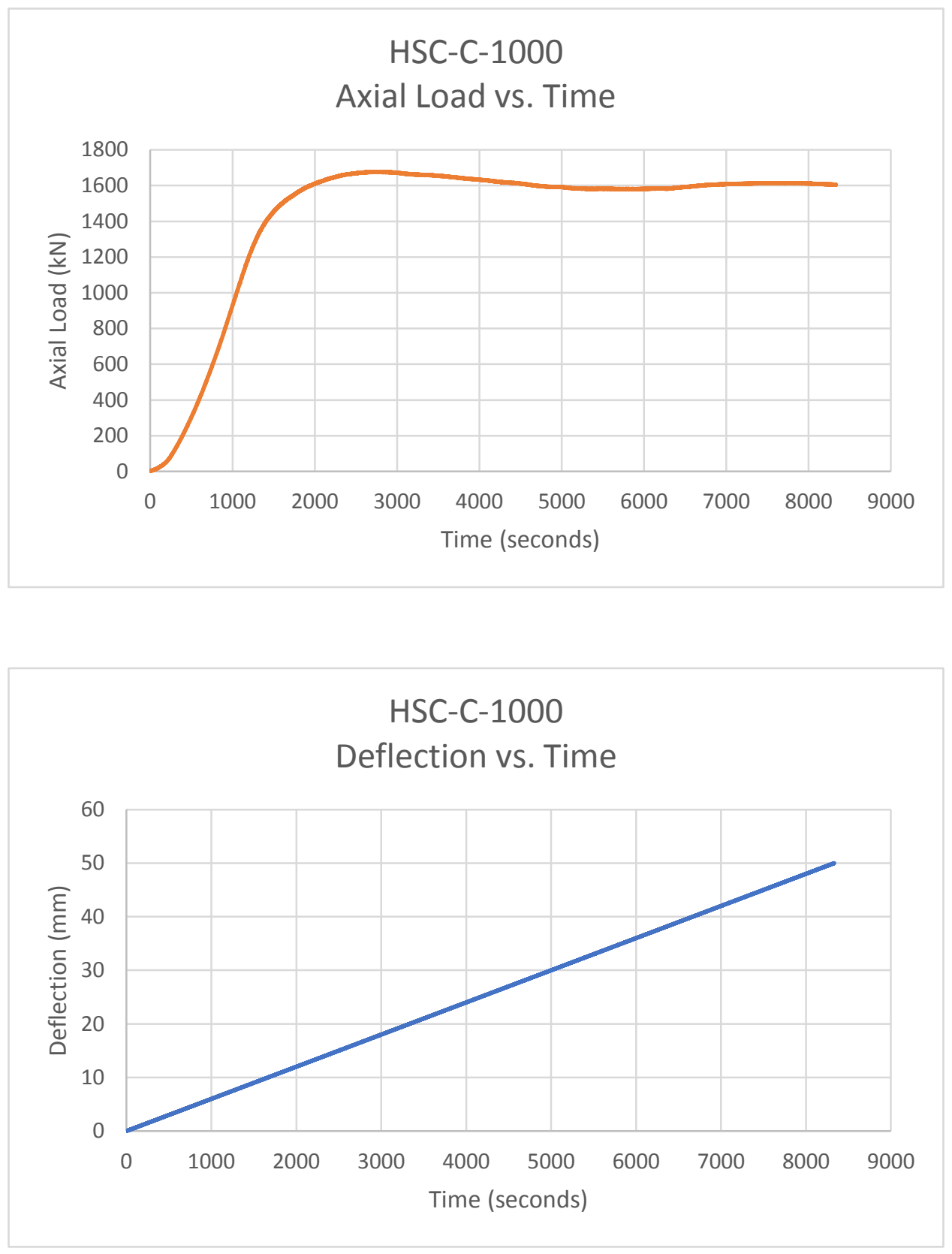

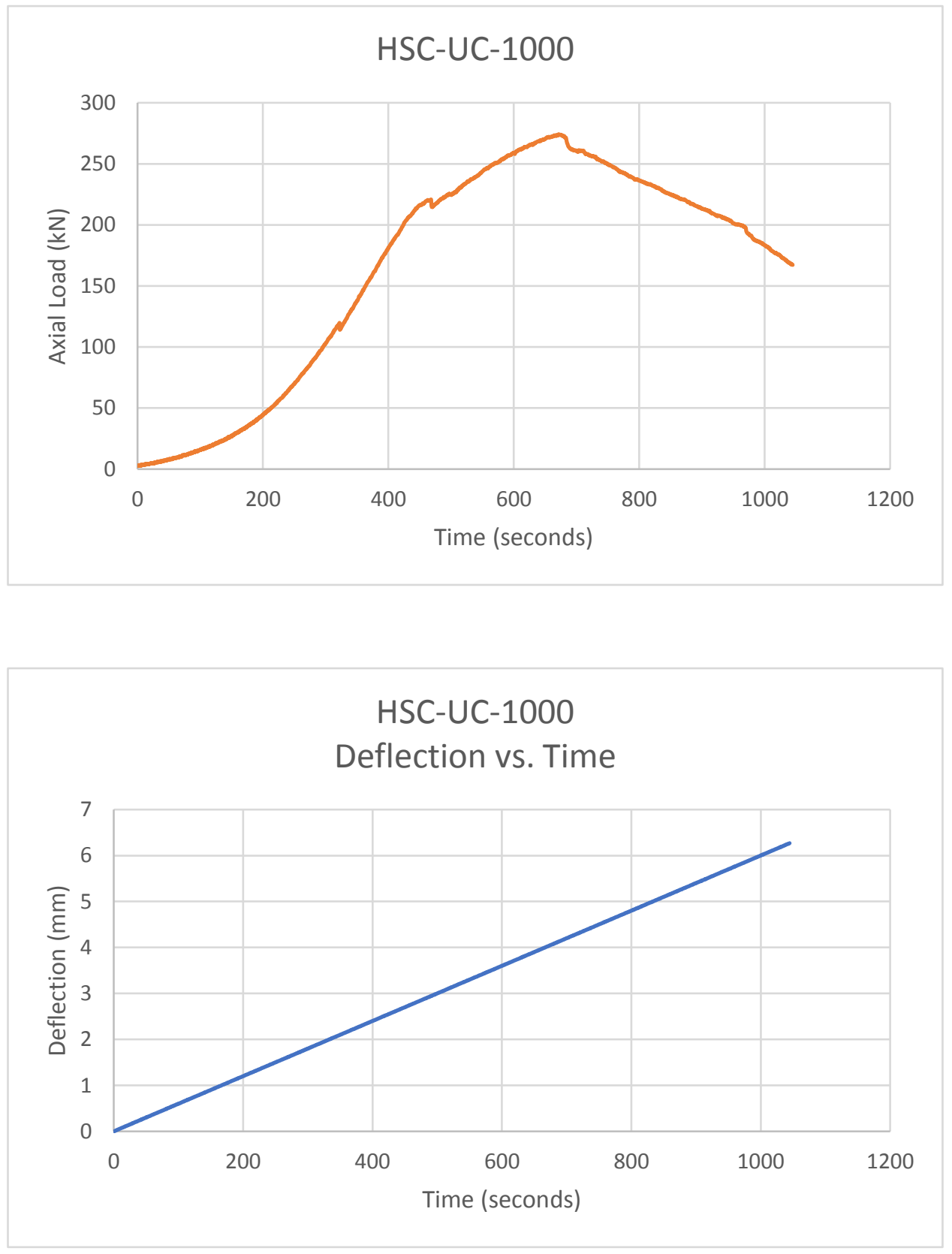

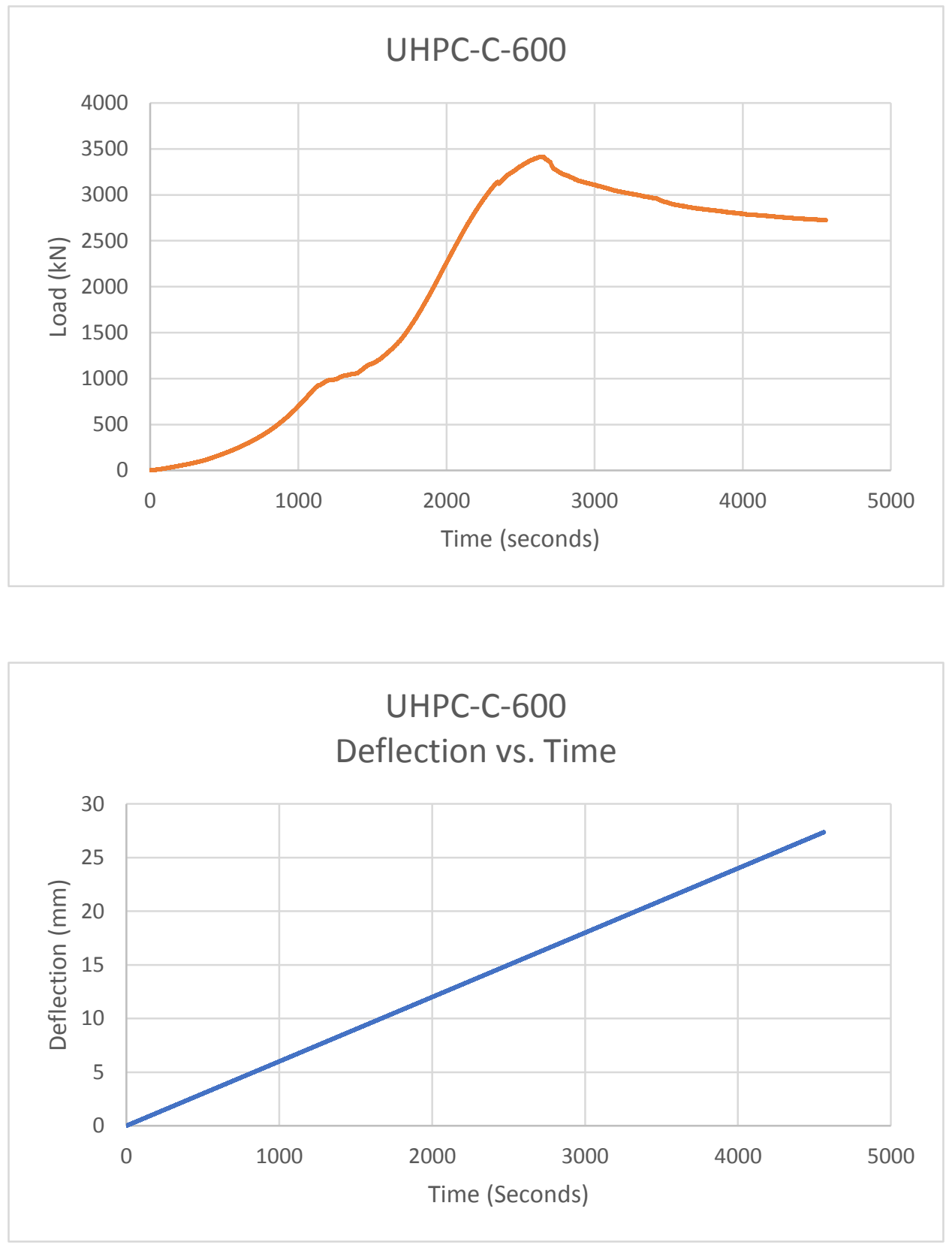

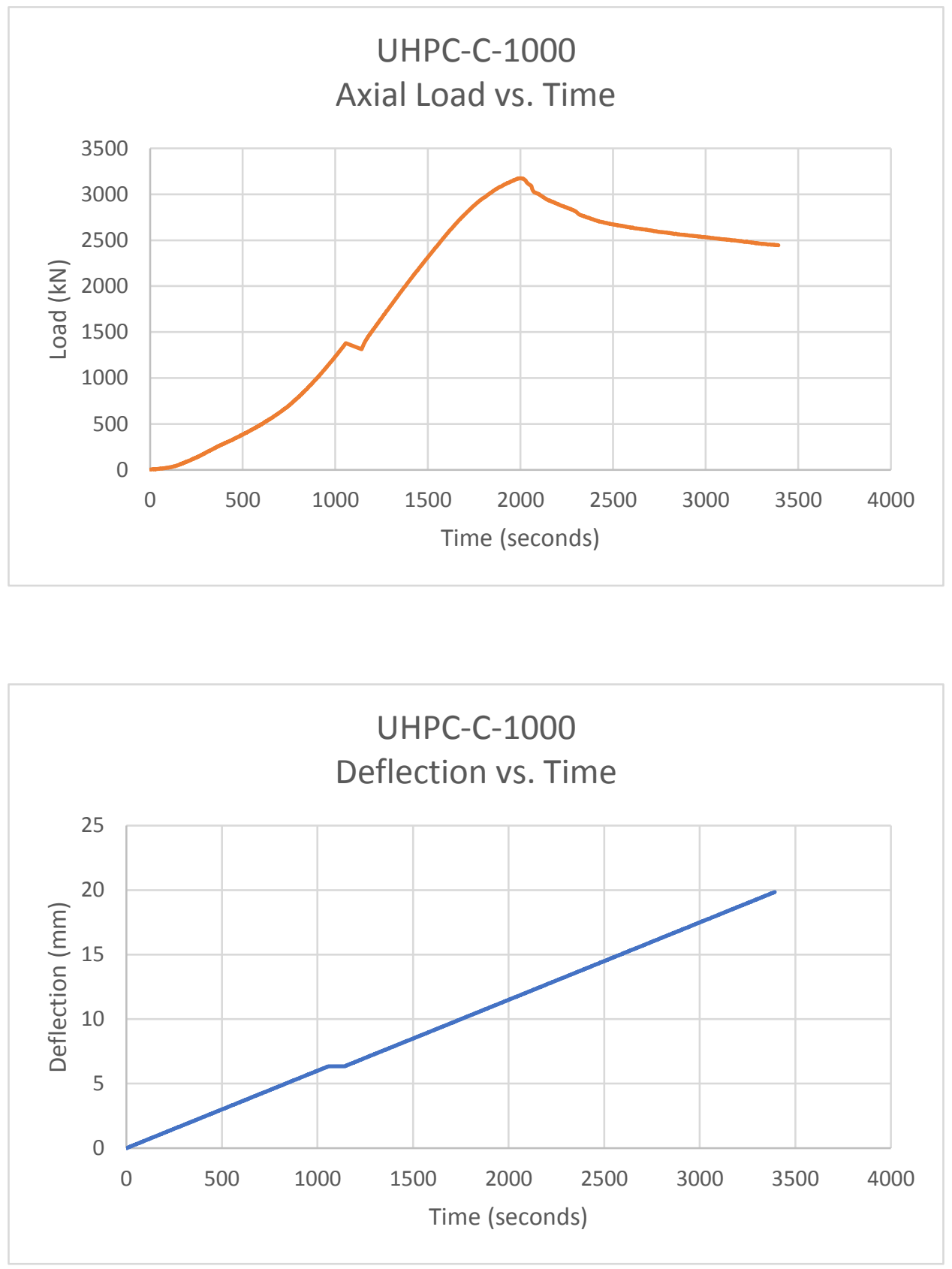

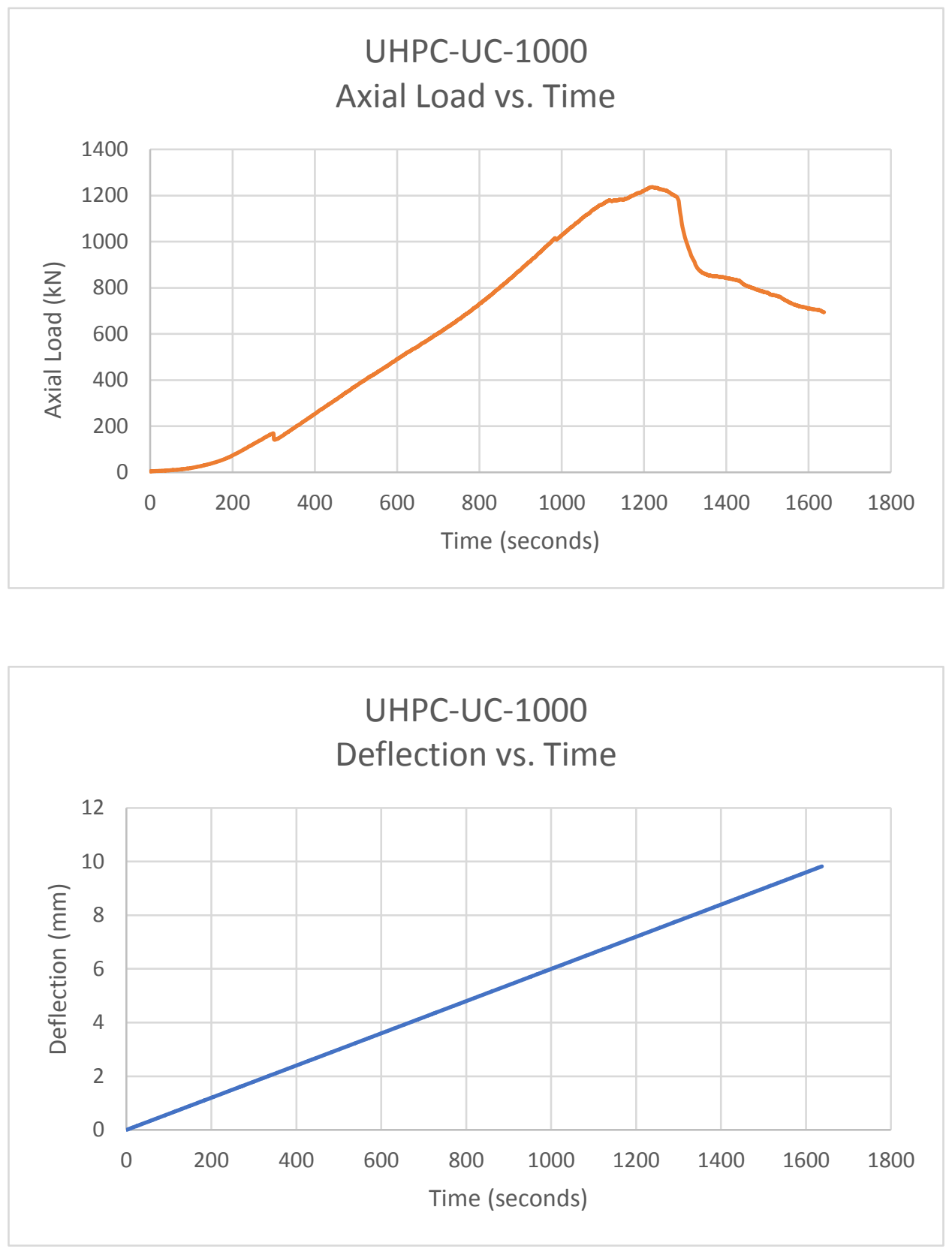
Appendix B: Calculations 


\section{Canadian Code Design:}

Pure Axial Load

$$
\begin{array}{ll}
P_{r o}=\alpha_{1} \emptyset_{c} f_{c}^{\prime}\left(A_{g}-A_{s t}\right)+\emptyset_{s} f_{y} A_{s t} & P_{r \max }=0.8 P_{r o} \\
P_{r o}=(0.8)(0.65)(150)(12667.69-600)+(0.85)(400)(600) & P_{r \max }=0.8(2169.81) \\
P_{\text {ro }}=2169.81 \mathrm{kN} & P_{\text {rmax }}=1735.85 \mathrm{kN}
\end{array}
$$

The procedure above was followed for HSC and unconfined HSC/UHPC axial load calculations.

Balanced Load

$$
\begin{aligned}
& d_{2}=d-t_{\text {tube }}-\text { cover }-d_{\text {ties }}-\frac{d_{\text {bar }}}{2} \\
& d_{2}=141.3-6.55-13.5-6-\frac{10}{2} \\
& d_{2}=110.25 \mathrm{~mm} \\
& \begin{array}{rlrl}
c_{b}=\frac{\varepsilon_{c}}{\varepsilon_{y}+\varepsilon_{c}} \times d_{2} & a & =\beta_{1} c_{b} \\
& a & =(0.9)(70.16)
\end{array} \\
& c_{b}=\frac{0.0035}{0.002+0.0035} \times 110.25 \quad a=63.14 \mathrm{~mm} \\
& c_{b}=70.16 \mathrm{~mm}
\end{aligned}
$$

Compression:

$$
\begin{array}{ll}
C_{c}=\alpha_{1} \emptyset_{c} f_{c}^{\prime}\left(A_{g}-A_{s}\right) & C_{\text {sbar }}=\emptyset_{s} f_{y} A_{s} \\
C_{c}=(0.8)(0.65)(150)(12667.69-600) & C_{\text {sbar }}=(0.65)(400)(400) \\
C_{c}=396.42 \mathrm{kN} & C_{\text {sbar }}=102.00 \mathrm{kN} \\
& \\
C_{\text {stube }}=\emptyset_{s} f_{y} A_{a} & C_{r}=C_{c}+C_{\text {sbar }}+C_{\text {stube }} \\
C_{\text {stube }}=(0.65)(400)(3013.33) & C_{r}=396.42+102+475.68 \\
C_{\text {stube }}=475.68 \mathrm{kN} & C_{r}=974.10 \mathrm{kN}
\end{array}
$$

Tension in compression region:

$$
\begin{array}{ll}
T_{\text {s1bar }}=\emptyset_{s} f_{y} A_{s 1} & T_{\text {s1tube }}=\emptyset_{s} f_{y} A_{a 1} \\
T_{\text {s1bar }}=(0.85)(400)(300) & T_{\text {s1tube }}=(0.65)(400)(1499.66) \\
T_{\text {s1bar }}=102.00 \mathrm{kN} & T_{\text {s1tube }}=509.88 \mathrm{kN} \\
& \\
F_{r s 1}=T_{s 1 \text { bar }}+T_{s 1 \text { tube }} & \\
F_{r s 1}=102+509.88 & \\
F_{r s 1}=611.88 \mathrm{kN} &
\end{array}
$$


Tension region:

$$
\begin{array}{ll}
T_{s 2 b a r}=-\emptyset_{s} f_{y} A_{s 2} & T_{\text {s2tube }}=-\emptyset_{s} f_{y} A_{a 2} \\
T_{\text {s2bar }}=-(0.85)(400)(300) & T_{\text {s2tube }}=-(0.65)(400)(1513.67) \\
T_{s 2 b a r}=-102.00 \mathrm{kN} & T_{\text {s2tube }}=-514.65 \mathrm{kN} \\
& \\
F_{r s 2}=T_{\text {s2bar }}+T_{\text {s2tube }} & \\
F_{r s 2}=(-102)+(-514.65) & \\
F_{r s 2}=-616.65 \mathrm{kN} &
\end{array}
$$

Axial and Bending Moment Resistance

$$
\begin{aligned}
& P_{r b}=0.8\left(C_{r}+F_{r s 1}+F_{r s 2}\right) \\
& P_{r b}=0.8(974.10+611.88+(-616.65)) \\
& P_{r b}=775.47 \mathrm{kN} \\
& \begin{aligned}
P_{r b} e_{b}=C_{c} c_{g}+C_{\text {sbar }} c_{g}+C_{\text {stube }} c_{g}+T_{\text {s1bar }} c_{g}+T_{\text {s1tube }} c_{g}+T_{\text {s2bar }} c_{g}+T_{\text {s2tube }} c_{g} \\
775.47 e_{b}=396.42(30.56)+102(25.5)+475.68(42.25)+102(25.5)+509.88(42.45) \\
\quad \quad+(-102)(-26.5)+(-514.65)(-43.03)
\end{aligned} \\
& e_{b}=110.04 \mathrm{~mm} \\
& M_{r b}=P_{r b} e_{b} \\
& M_{r b}=775.47(110.04)(10 E-3) \\
& M_{r b}=85.33 \mathrm{kNm}
\end{aligned}
$$

The same procedure was followed for the poitns before and after balance using the new neutral axis. The reuslts are summarized in the table on the following page.

Pure Tension

$$
\begin{array}{ll}
T_{\text {sbar }}=-\emptyset_{s} f_{y} A_{s} & T_{\text {stube }}=-\emptyset_{s} f_{y} A_{a} \\
T_{\text {s2bar }}=-(0.85)(400)(600) & T_{\text {s2tube }}=-(0.65)(400)(1513.67) \\
T_{\text {s2bar }}=-204.00 \mathrm{kN} & T_{\text {s2tube }}=-1024.53 \mathrm{kN} \\
& \\
F_{r s}=0.8\left(T_{\text {sbar }}+T_{\text {stube }}\right) & \\
F_{r s 2}=0.8((-204)+(-1024.53)) & \\
F_{r s 2}=-982.83 \mathrm{kN} &
\end{array}
$$




\begin{tabular}{|c|c|c|c|c|c|c|c|c|c|}
\hline & & & & \multicolumn{2}{|c|}{$\mathrm{Cc}$} & \multicolumn{2}{|c|}{ Cs bar } & \multicolumn{2}{|c|}{ Cs tube } \\
\hline & $\varepsilon_{\mathrm{y}}$ & $\begin{array}{c}\mathrm{c} \\
(\mathrm{mm})\end{array}$ & $\begin{array}{c}\mathrm{a} \\
(\mathrm{mm})\end{array}$ & $\begin{array}{c}\text { Force } \\
(\mathrm{kN})\end{array}$ & $\mathrm{Cg}(\mathrm{mm})$ & $\begin{array}{c}\text { Force } \\
(\mathrm{kN})\end{array}$ & $\begin{array}{c}\mathrm{Cg} \\
(\mathrm{mm})\end{array}$ & $\begin{array}{l}\text { Force } \\
(\mathrm{kN})\end{array}$ & $\begin{array}{c}\mathrm{Cg} \\
(\mathrm{mm})\end{array}$ \\
\hline Pure Axial & - & - & - & 941.28 & - & 204.00 & - & 1024.53 & - \\
\hline \multirow[t]{2}{*}{ Min. e (5\% d) } & - & - & - & 941.28 & - & 204.00 & - & 1024.53 & - \\
\hline & 0.001 & 85.15 & 76.64 & 529.89 & 38.24 & 102.00 & 40.50 & 541.43 & 54.78 \\
\hline \multirow[t]{2}{*}{ Balanced } & 0.002 & 70.16 & 63.14 & 396.42 & 30.56 & 102.00 & 25.50 & 475.68 & 45.25 \\
\hline & 0.004 & 62.39 & 56.15 & 328.26 & 26.68 & 51.00 & 17.74 & 220.60 & 40.19 \\
\hline Pure Bending & - & - & - & - & - & - & - & - & - \\
\hline \multirow[t]{3}{*}{ Pure Tension } & - & - & - & 0.00 & 0.00 & 0.00 & 0.00 & 0.00 & 0.00 \\
\hline & & & & \multicolumn{2}{|c|}{ Ts1 bar } & \multicolumn{2}{|c|}{ Ts1 tube } & & \\
\hline & $\varepsilon_{\mathrm{y}}$ & $\begin{array}{c}\mathrm{c} \\
(\mathrm{mm})\end{array}$ & $\begin{array}{c}\mathrm{a} \\
(\mathrm{mm})\end{array}$ & $\begin{array}{l}\text { Force } \\
(\mathrm{kN})\end{array}$ & $\begin{array}{c}\mathrm{Cg} \\
(\mathrm{mm})\end{array}$ & $\begin{array}{c}\text { Force } \\
(\mathrm{kN})\end{array}$ & $\begin{array}{c}\mathrm{Cg} \\
(\mathrm{mm})\end{array}$ & & \\
\hline Pure Axial & - & - & - & 0.00 & 0.00 & 0.00 & 0.00 & & \\
\hline \multirow[t]{2}{*}{ Min. e (5\% d) } & - & - & - & 0.00 & 0.00 & 0.00 & 0.00 & & \\
\hline & 0.001 & 85.15 & 76.64 & 51.00 & 40.50 & 291.66 & 51.15 & & \\
\hline \multirow[t]{2}{*}{ Balanced } & 0.002 & 70.16 & 63.14 & 102.00 & 25.50 & 509.88 & 42.45 & & \\
\hline & 0.004 & 62.39 & 56.15 & 102.00 & 17.74 & 472.01 & 37.78 & & \\
\hline Pure Bending & - & - & - & - & - & - & - & & \\
\hline \multirow[t]{3}{*}{ Pure Tension } & - & - & - & 0.00 & 0.00 & 0.00 & 0.00 & & \\
\hline & & & & \multicolumn{2}{|c|}{ Ts2 bar } & \multicolumn{2}{|c|}{ Ts2 tube } & & \\
\hline & $\varepsilon_{\mathrm{y}}$ & $\begin{array}{c}\mathrm{c} \\
(\mathrm{mm})\end{array}$ & $\begin{array}{c}\mathrm{a} \\
(\mathrm{mm})\end{array}$ & $\begin{array}{l}\text { Force } \\
(\mathrm{kN})\end{array}$ & $\begin{array}{c}\mathrm{Cg} \\
(\mathrm{mm})\end{array}$ & $\begin{array}{c}\text { Force } \\
(\mathrm{kN})\end{array}$ & $\begin{array}{c}\mathrm{Cg} \\
(\mathrm{mm})\end{array}$ & & \\
\hline Pure Axial & - & - & - & 0.00 & 0.00 & 0.00 & 0.00 & & \\
\hline \multirow[t]{2}{*}{ Min. e (5\% d) } & - & - & - & 0.00 & 0.00 & 0.00 & 0.00 & & \\
\hline & 0.001 & 85.15 & 76.64 & -51.00 & -11.50 & -220.55 & -33.96 & & \\
\hline \multirow[t]{2}{*}{ Balanced } & 0.002 & 70.16 & 63.14 & -102.00 & -26.50 & -514.65 & -43.03 & & \\
\hline & 0.004 & 62.39 & 56.15 & -102.00 & -34.26 & -552.53 & -47.59 & & \\
\hline Pure Bending & - & - & - & - & - & - & - & & \\
\hline \multirow[t]{2}{*}{ Pure Tension } & - & - & - & -204.00 & - & -1024.53 & - & & \\
\hline & $\varepsilon_{\mathrm{y}}$ & $\begin{array}{c}\mathrm{c} \\
(\mathrm{mm})\end{array}$ & $\begin{array}{c}\mathrm{a} \\
(\mathrm{mm})\end{array}$ & $\begin{array}{c}\operatorname{Pr} \\
(\mathbf{k N})\end{array}$ & $\underset{(\mathrm{kNmm})}{\operatorname{Pr} \times \mathrm{e}}$ & $\begin{array}{c}\mathrm{e} \\
(\mathbf{m m})\end{array}$ & $\underset{(\mathbf{k N m})}{\mathrm{Mr}}$ & & \\
\hline Pure Axial & & & & 1735.85 & - & 0.00 & 0.00 & & \\
\hline \multirow[t]{2}{*}{ Min. e (5\% d) } & - & - & - & 1735.85 & - & 7.07 & 12.26 & & \\
\hline & 0.001 & 85.15 & 76.64 & 995.54 & 79113.97 & 79.47 & 79.11 & & \\
\hline \multirow[t]{2}{*}{ Balanced } & 0.002 & 70.16 & 63.14 & 775.47 & 85333.85 & 110.04 & 85.33 & & \\
\hline & 0.004 & 62.39 & 56.15 & 415.47 & 67959.79 & 163.57 & 67.96 & & \\
\hline Pure Bending & - & - & - & 0.00 & 0.00 & 0.00 & 47.77 & & \\
\hline Pure Tension & - & - & - & -982.83 & - & 0.00 & 0.00 & & \\
\hline
\end{tabular}




\section{EC4 Design - Simplified Method}

Pure Axial Load (Point A)

$$
\begin{aligned}
& N_{p l, R d}=\eta_{a} A_{a} f_{y d}+A_{c} f_{c d}\left(1+\eta_{c} \frac{t_{\text {tube }}}{d} \frac{f_{y}}{f_{c}^{\prime}}\right)+A_{s} f_{s d} \\
& N_{p l, R d}=(0.25)(3013.33)(400)+(12667.69)(150)\left(1+4.9 \frac{6.55}{141.3} \frac{400}{0.8 * 150}\right)+(600)(400) \\
& N_{p l, R d}=3085.88 \mathrm{kN}
\end{aligned}
$$

Pure Bending (Point B)

$$
\begin{aligned}
& t_{s}=\frac{A_{s}}{\pi(d-2 \times \text { Cover })} \\
& D_{s}=d-(2 \times \text { Cover })+t_{s} \\
& t_{s}=\frac{600}{\pi(141.3-2(13.5))} \\
& D_{s}=141.3-(2(13.5))+1.67 \\
& t_{s}=1.67 \mathrm{~mm} \\
& D_{s}=115.3 \\
& h_{n}=\frac{A_{c} f_{c d}}{2 d f_{c d}+4 t_{t u b e}\left(2 f_{y d}-f_{c d}\right)+4 t_{s}\left(2 f_{s d}-f_{c d}\right)} \\
& h_{n}=\frac{(12667.69)(150)}{2(141.2)(150)+4(6.55)(2(400)-150)+4(1.67(2(400)-150)} \\
& h_{n}=26.19 \mathrm{~mm} \\
& W_{p c}=\frac{\left(d-2 t_{\text {tube }}\right)^{3}}{6} \quad W_{p c, n}=\left(d-2 t_{t u b e}\right) h_{n}^{2} \\
& W_{p c}=\frac{(141.3-2(6.55))^{3}}{6} \quad W_{p c, n}=(141.3-2(6.55))(26.19)^{2} \\
& W_{p c}=351.57 \mathrm{~cm}^{3} \quad W_{p c, n}=87.96 \mathrm{~cm}^{3} \\
& W_{p a}=\frac{d^{3}}{6}-W_{p c} \quad W_{p a, n}=d h_{n}^{2}-W_{p c, n} \\
& W_{p a}=\frac{141.3^{3}}{6}-351.57 E 3 \quad W_{p a, n}=(141.3)(26.19)^{2}-87.96 E 3 \\
& W_{p a}=119.03 \mathrm{~cm}^{3} \quad W_{p a, n}=8.99 \mathrm{~cm}^{3} \\
& W_{p s}=\frac{\left(D_{s}^{3}-\left(D_{s}-2 t_{s}\right)^{3}\right)}{6} \quad W_{p s, n}=2 t_{s} h_{n}^{2} \\
& W_{p s}=\frac{\left(115.3^{3}-(115.3-2(1.67))^{3}\right)}{6} \quad W_{p s, n}=2(1.67)(26.19)^{2}
\end{aligned}
$$




$$
\begin{aligned}
& W_{p s}=21.83 \mathrm{~cm}^{3} \quad W_{p s, n}=2.29 \mathrm{~cm}^{3} \\
& M_{p l, R d}=\left(W_{p a}-W_{p a, n}\right) f_{y d}+\left(W_{p s}-W_{p s, n}\right) f_{s d}+0.5\left(W_{p c}-W_{p c, n}\right) f_{c d} \\
& M_{p l, R d}=(119.03-8.99)(400)+(21.83-2.29)(400)+0.5(351.57-87.96)(150) \\
& M_{p l, R d}=71.75 \mathrm{kNm}
\end{aligned}
$$

Prior to Steel Yeilding (Point C)

$$
\begin{aligned}
& N_{p m, R d}=A_{c} f_{c d}\left(1+\eta_{c} \frac{t}{d} \frac{f_{y}}{f_{c d}}\right) \\
& N_{p m, R d}=(12667.69)(150)\left(1+4.9 \frac{6.55}{141.3} \frac{400}{0.8 * 150}\right) \\
& N_{p m, R d}=2544.55 k N
\end{aligned}
$$

Balanced Load (Point D)

$$
\begin{aligned}
& M_{p l, R d}=\left(W_{p a}\right) f_{y d}+\left(W_{p s}\right) f_{s d}+0.5\left(W_{p c}\right) f_{c d} \\
& M_{p l, R d}=(119.03)(400)+(21.83)(400)+0.5(351.57)(150) \\
& M_{p l, R d}=82.68 k N m
\end{aligned}
$$

The procedure above was followed for HSC axial load calculations. 


\section{ACI Code}

Axial Compression Calcualtion

$$
\begin{aligned}
& P_{\text {ro }}=\varnothing\left[\alpha_{1} f_{c}^{\prime}\left(A_{g}-A_{s}\right)+f_{y} A_{s}+f_{y} A_{a}\right] \\
& P_{r o}=0.65[(0.8)(150)(12667.69-600)+(400)(600)+(400)(3013.33)] \\
& P_{\text {ro }}=1939.58 \mathrm{kN} \\
& P_{\text {rmax }}=0.8 P_{\text {ro }} \\
& P_{\text {rmax }}=0.8(1939.58) \\
& P_{r \max }=1551.66 \mathrm{kN}
\end{aligned}
$$

The procedure above was followed for HSC and unconfined HSC/UHPC axial load calculations. 


\section{References}

1. Liew JYR, Xiong M, Xiong D. Design of Concrete Filled Tubular Beam-column with High Strength Steel and Concrete. ELSEVIER: Structures. 2016;: p. 213-226.

2. Hanswille DG. Eurocode 4 Composite Columns. Brussels, Germany:; 2008.

3. Pezeshk S. Axially Loaded Memebers. Memphis; 2014.

4. Brzev S, Pao J. Reinforced Concrete Desing: A Practical Approach. 2nd ed. Toronto: Prentice Hall; 2013.

5. Wille K, Naaman AE, Parra-Montesinos GJ. Ultra-High Performance Concrete with Compressive Strenght Exceeding $150 \mathrm{MPa}$ (22ksi): A Simpler Way. ACI Materials Journal. 2011 January;: p. 46-54.

6. LafargeHolcim. http://www.ductal.com. [Online].; 2018 [cited 2018 August. Available from: http://www.ductal.com.

7. Yazdizadeh Z. Use of fiber brag gating sensors in civil engineering applications. MASc Thesis. Toronto: Ryerson University, Civil Engineering; 2014.

8. Wahba K, Marzouk H, Dawood N. Fracture Energy properties of Ultra High Performance Fibre Reinforced Concrete. M.A.Sc Thesis. Toronto: Ryerson University, Faculty of Engineering, Architecture and Science; 2012.

9. USDoT. Material Property Characterization of Ultra-High Performance Concrete. McLean, VA:; 2006.

10. Le HA, Fehling E. Test on Circular Steel Tube Confined UHPC and UHPFRC Columns Under A. In Int. Symposium on Ultra-High Performance Fiber-Reinforced Concrete; 2017; Montpellier, France. p. 499-508.

11. Ridha MM. Axial-Flexural Interaction of Square FRP Tube Columns In-Filled with UltraHigh Performance Concrete. iMedPub Journals. 2017; 3: p. 1-12.

12. Metha PK, Burrows RW. Structures in the 21st Century. Concrete International. 2001;: p. 5763. 
13. Liew JYR, Xiong DX. Ultra-High Strength Concrete Filled Composite Columns for MultiStorey Building Construction. Advances in Structural Engineering. 2012; 15(9): p. 14871503.

14. Aoude H, Hosinieh MM, Cook WD, Mitchell D. Behaviour of Rectangular Columns Constructed with SCC and Steel Fibers. Journal of Structural Engineering. 2015; 141(8).

15. Marzouk H, Chen ZW. Fracture Energy and Tension Properties of High-Strenght Concrete. Journal of Materials in Civil Engineering. 1995 May; 7(2): p. 108-116.

16. Wahba K, Marzouk H. The Use of FBG Sensor to Determine the Fracture Energy Properties of UHPFC. Toronto: Ryerson University, Faculty of Engineering, Architecture and Science.

17. Othman H, Marzouk H. Analysis of Super Frame Structure Design for High-Rise Building. Toronto: Ryerson University, Department of Civil Engineering; 2018.

18. Yazdizadeh Z, Marzouk H, Hadianfard MA. Monitoring of concrete shrinkage and creep using Fiber Bragg Grating sensors. ELSEVIER: Construction and Building Materials. 2017 January;(137): p. 505-512.

19. Vojvodic G, Hadl P, Tung ND, Tue NV. Circular UHPC-NSC Composite Columns Under Concentric Loading. In Int. Symposium on Ultra-High Performance Fiber-Reinforced Concrete; 2017; Montpellier, France. p. 491-497.

20. Liew R, Xiong MX, Xiong DX. Design of High Strength Concrete Filled Tubular Columns for Tall Buildings. International Journal of High-Rise Buildings. 2014; 3(3): p. 215-221.

21. Saatcioglu M, Razvi SR. High-Strenght Concrete Columns with Square Sections Under Concentric Compression. Journal of Structural Engineering. 1998;: p. 1438-1447.

22. Shin HO, Yoon YS, Cook WD, Mitchell D. Axial Load Response of Ultra-High-Strength Concrete Columns and High-Strength Reinforcement. ACI Structural Journal. 2016;: p. 325336.

23. Liew JYR, Xiong M, Wang YB. Design of High Strength Concrete Filled Tubular Columns. ce/papers. $2017 ;:$ p. 1869-1878.

24. Tue NV, Kuchler M, Schenck G, Jurgen R. Application of UHPC filled Tubed in Buildings and Bridges. In International Symposium on High Performance Concrete; 2004; Kassel, Germany: Kassel University Press. p. 807-817. 
25. Zohrevand P, Mirmiran A. Behavior of Ultrahigh-Performance Concrete Confined by FiberReinforced Polymers. Journal of Materials in Civil Engineering ASCE. 2011;: p. 1727-1734. 26. Razvi S, Saatchioglu M. Confinement Model for High-Strenght Concrete. Journal of Structural Engineering. 1999;: p. 281-289.

27. Guler S, Aydogan M, Copur A. Axial Capacity and Ductility of Circular UHPC-Filled Steel Tube Columns. Magazine of Concrete Research. 2013;: p. 898-905.

28. Liew JYR. Buildable Design of Multi-storey and Large-span Steel Structures. Steel Structures. 2004;: p. 53-70.

29. MTS Systems Corporation. MTS Model 815 and 816 Rock Mechanics Test Systems. Eden Prairie:; 2014.

30. Chaallal O, Lachemi M. Reinforced Concrete Structures, Desing according to CSA A23.3-04 Quebec: Pressess de l'Universite du Quebec; 2010.

31. Liew JYR, Xiong MX. Design for Concrete Filled Tubular Memebers with High Strength Materials to Eurocode 4. Singapore:; 2015. 